\title{
CONTRIBUTION OF NATURAL TERRESTRIAL SOURCES TO THE TOTAL RADIATION DOSE TO MAN
}

\author{
A THESIS \\ Presented to \\ The Faculty of the Division of Graduate \\ Studies and Research \\ by \\ John Alden Auxier
}

\author{
In Partial Fulfillment \\ of the Requirements for the Degree \\ Doctor of Philosophy \\ in the \\ School of Nuclear Engineering
}

Georgia Institute of Technology

December, 1972 
CONTRIBUTION OF NATURAL TERRESTRIAL SOURCES TO THE TOTAL RADIATION DOSE TO MAN

Approved:

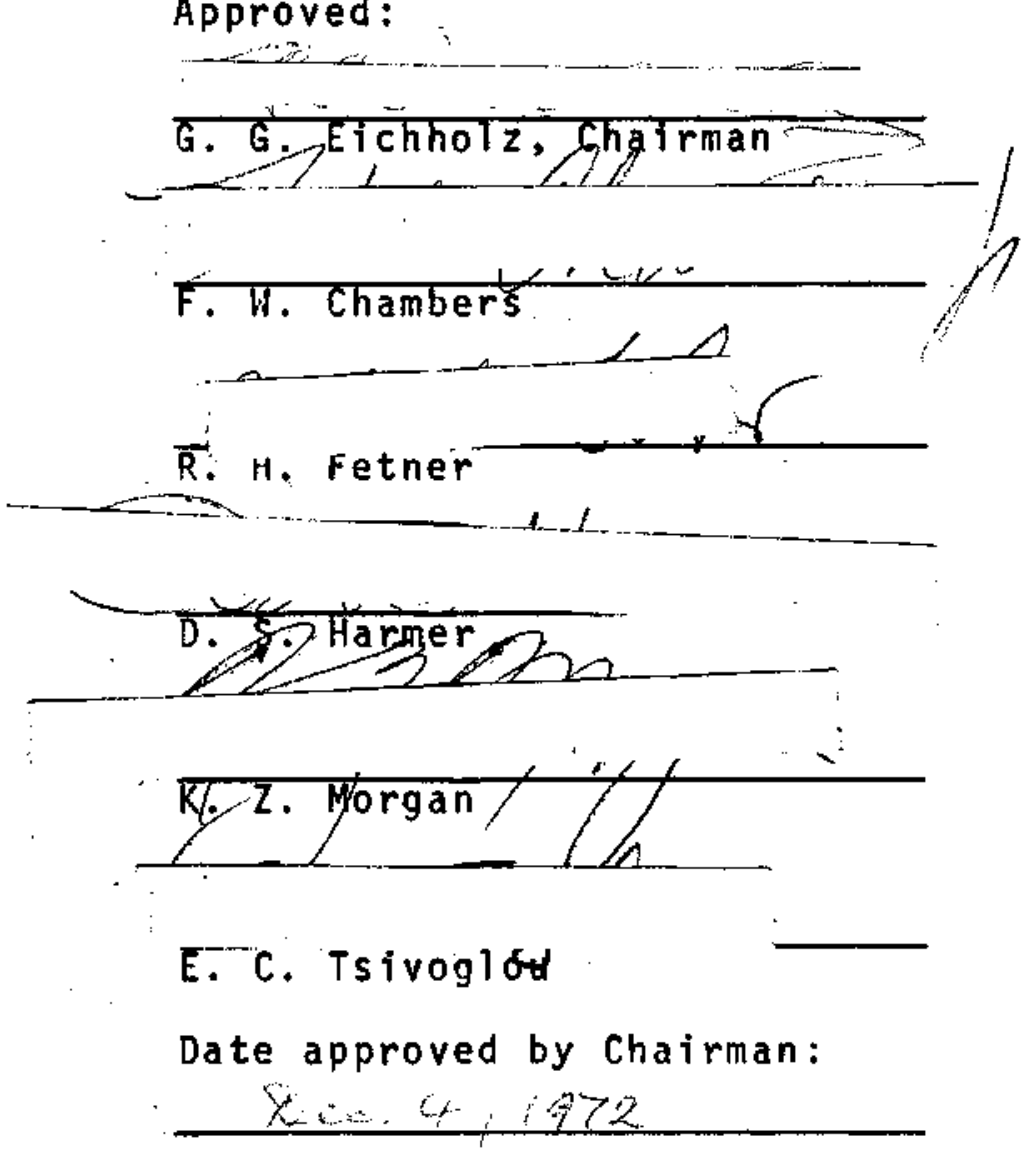


In presentîng the dissertation as a partial fulfillment of the requirements for an advanced degree from the Georgia Institute of Technology, I agree that the Library of the Institute shall make it available for inspection and circulation in accordance with its regulations governing materials of this type. I agree that permission to copy from, or to publish from, this dissertation may be granted by the professor under whose direction it. was written, or, in his absence, by the Dean of the Graduate Division when such copying or publication is solely for scholarly purposes and does not involve potential financial gain. It is understood that any copying from; or publication of, this dissertation which involves potential financial gain will not be allowed without written permission.

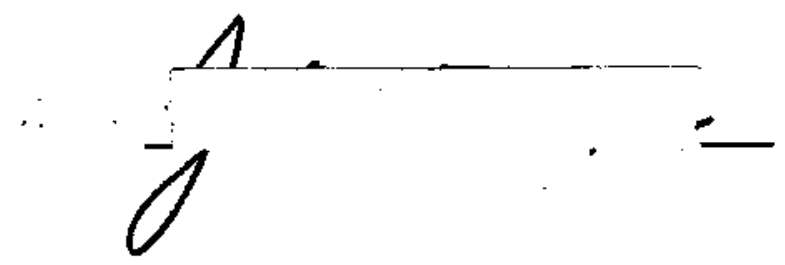

$7 / 25 / 68$ 
ACKNOWLEDGMENTS

I wish to express my sincere gratitude to my thesis advisor, Professor Geoffrey Eichholz, for his extensive guidance, interest, and patfent understanding. I ari sure that I was a special stress in view of my accumulated experience and the habits concomitantiy developed.

A1so, I am deeply grateful for the guidance given by the other members of my Reading Committee, Professors F. 1. Chambers, R. II. Fetner, D. S. Harmer, K. Z. Morgan, and E. c. Tsivoglou. There is no way to express my full gratitude to friend; his greatest influence on this research and all that made it possible extend far back before this specific study was conceived, back over 20 years. His support, plus that of J. L. Liverman, then Associate Director for Bionedical and Environmental Sciences, F. L. Culler, Deputy Dfrector, and A. M. Weinberg, Director, of the Oak Ridge National Laboratory, permitted me the opportunity to pursue a Doctoral Degree.

Many of the staff of the Health Physics Division of the Dak Ridqe llational Laboratory contributed extensively to this work, including D. J. Christian, B. R. Fish, U. F. Fox, T. D. Jones, G. D. Kerr, P. T. Perdue, H. H. Shinpaugh, and 3. Il. Thorngate. A special acknowledgment of appreciation goes to T. D. Jones, G. D. Kerr, W. H. 
Shfnpaugh, and J. H. Thorngate for the long hours beyond the call of duty in which they helped with the final generation of this report. J. W. Poston gave invaluable advice over the entire period of the work toward this degree.

Gratitude is expressed to J. P. Hickey for his excellent work in preparing the publication drawings.

There is always a special acknowledgment of the typist who must struggle to get the manuscript into the perfect and precise form required. However, in this case there was added a special problem, that of putting the manuscript into a computer so that editing and reproduction could be expedited. Thus, I am doubly indebted to Becky Bush for her courage, skill, dedication, and very long hours in learning the programming procedures and the thesis preparation guide during the short interval available to her for putting handwritten material into a finished manuscript.

Gwen Dagley helped with the typing of equations and did extra work during the manuscript preparation for which I am appreciative. Natalie Tarr helped with organizing and typing the bibliographies for which I am grateful.

My gratitude cannot be adequately expressed for the patience and devotion of my secretary, Jeanne Carver, during the several months that a full-tine administrative job had to be conducted during thesis research and preparation; her 
defense of my office is alone worthy of commendation.

The graduate work at the Georgia Institute of Technology and the research at the oak Ridge ilational Laboratory were supported by the Laboratory which is operated for the U. S. Atomic Eneray Commission by the Union Carbide iluclear Company. My gratitude for this support and my appreciation for being a part of this Laboratory is inexpressible.

Also, I wish to thank the Division of Graduate Studies and Research of the Georgia Institute of Technology for permission to use the special pagination in order to comply with the reproduction criteria of the oak Ridge National Laboratory and the special computer controlled typewriter which made practical the right margin justification. 
TABLE OF CONTENTS

Page

ACKNOWLEOGMENTS ................... . . $1 . .11$

LIST OF TABLES . . . . . . . . . . . . . . . . viii

LIST OF ILLUSTRATIONS . . . . . . . . . . . . $x$

SUMMARY ....................... xi

Chapter

I. INTRODUCTION ............... I

Genera?

Description of the Natural Radiation Environment The Uranium and Thorium Decay Series

other Naturally Occurring Radionuclides

Whole Body Exposure to Man From the Natural

Radiation Environment

Dose to the Respiratory System Due to Radon and Radon Daughters

objectives

II. GAMMA RADIATION FROM THE GROUND . . . . . .

Introduction

Theory

Spectrometer system

other Equipment

Field Experiments

Procedures

Calibration

Experimental Data

Discussion of Results

III. EMANATION OF RADON FROM CONCRETE ........ 72

Theory

Tsivoglou Method

Spectrometry Method

Method of Error Analys is

Instrumentation

Results and Analys is 
vi1

TABLE OF CONTENTS (Continued)

Page

IV. DISCUSSIONS AND CONCLUSIONS ......... 127 Appendixes

I. DISTRIBUTIONS OF DOSE FROM NATURAL SOURCES

IN "NORMAL" AREAS ............ 136

11. GENETICALLY SIGNIFICANT DOSE . . . . . . . 139

111. THE MAXIMUM PERMISSIBLE CONCENTRATION VS. THE WORKING LEVEL .............. 141

IV. GAMMA SPECTRAL DATA FROM THE FIELD . . . . 145 BIBLIOGRAPHY (cited) . . . . . . . . . . 160 BIBLIOGRAPHY (Uncited) . . . . . . . . . . 167 VITA.................... 176 


\section{LIST OF TABLES}

Table

1. Most Important Radiation Properties of the Isotopes of the Uranium Series ........... 9

2. Most Important Radiation Properties of the Isotopes of the Thorium Series ............ 12

3. Average Concentration of Uranium and Thorium in

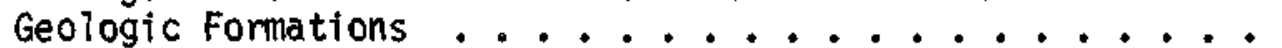

4. Geographical Areas Having Soil Concentrations of Uranium and/or Thorium to Produce the Additional Dose Increments

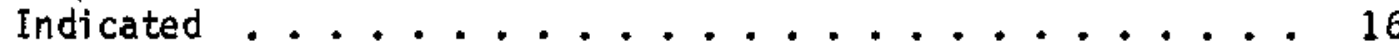

5. Field Measurement Sites and Survey Instrument Readings .... 47

6. Ratio $R$ of Counts in Photopeak to Gamma Rays Emitted Per Cubic Centimeter of Soil ........... 58

7. Identified Gamma Ray Lines at EGCR Site ..........60

8. Identified Gamma Ray Lines at Cesium Field Site .......66 61

9. Identified Ganma Ray Lines at Storage Area Site ....... 62

10. Identified Gamma Ray Lines at Whitley City, Ky., Site .... 64

11. Identified Garma Ray Lines at At7antic Beach, Fla., Site ... 66

12. Identified Gamma Ray Lines at Bartow, Fla., Site [Second Run (Playground)] ...............68

13. Identified Gamma Ray Lines at Stone Mountain, Ga., Site ... 70

14. Gamma Ray Emission from Bare Concrete Blocks ......... 119

15. The Effects of Epoxy Paint on the Escape of Radon from a Stuccoed Concrete Block ............. 123

16. Gamma Ray Emission from a Stuccoed Concrete Block Before and After Application of Epoxy Paint .......... 1 1 . $1<4$

17. Dose Rates Due to External and Internal Irradiation from Natural Sources in "Norma1" Areas 


\section{LIST OF TABLES (Continued)}

Table

Page

18. Cosmic Ray Intensities and Dose Rates ......... 138

19. Comparative Values of WL and the MPC as Given by ICRP and NCRP for an Atmosphere of $10^{-7} \mu / \mathrm{Ci} / \mathrm{CC}\left(10^{-11} \mathrm{Ci} / 1\right)$ of $222 R_{n} \ldots \ldots \ldots$ 
Figure

1. The Uranium Decay Series........... 7

2. The Thorlum Decay Series........... 8

3. Decay Schemes of ${ }^{40} \mathrm{~K},{ }^{87} \mathrm{Rb},{ }^{14} \mathrm{C}$, and ${ }^{3} \mathrm{H} . \ldots 18$

4. Diagram Showing Geometrical Parameters Used in Computing Gamma Ray Fluences from the Ground. .

5. Lithium Drifted Germanium Detector: Form and Dimensions...............

6. Block Diagram of Ge(Li) Spectrometer System and Diagram of Input Circuitry...........

7. View of Field Spectrometry and Air Sampling Equipment as Used Typicaliy ......... 44

8. View of Interfor of Van Laboratory....... 45

9. Air Sampling Apparatus used in Field and Close-up of the Cascade Impactor . . . . . . . . .

10. Exploded View of Alpha Counter Showing Position of the Surface Barrier Diode Detector .....

11. The Assembled Alpha Counter ........ 96

12. The Alpha Counter Response Curves for a Nominal 239 Pu Source counted in Air, in Helium, and in vacuum . . . . . . . . . . . . . .

13. Examples of Response Curve and Relative Count Rates for RaA and $R a C^{\prime}$ as a Function of Time After Termination of Air Sampling . . . . .

14. Diagram of Segment of Radon Daughter Decay Curve and Relations used in Determining Average Count Rates as a Function of Time ......... 


\section{LIST OF ILLUSTRATIONS (Continued)}

Figure

Page

15. Computed Geometry Factor for Alpha Counter as Function of Source Sample for Radium with Two Experimental Points Determined with Americium-241 and Thorjum-230.....................

16. Diagram of Afrtight Enclosure Used for Radon

Emanation Studies with Concrete Block and Ge(Li)

Detector in Place . . . . . . . . . . . .

17. Diagram of Typical Concrete Block Used in Radon Emanation studies Showing Copper Tubing and Thermocouple Placement . . . . . . . . . .

18. Typical Electron Micrograph for State 4 of Cascade Impactor (Magnification 1000x) .... 112

19. Concentration of Radon Daughters in Emanation Enclosure as a Function of Temperature for High and Low Moisture Content of Concrete Block. . . 114

20. Concentration of Radon Daughters in Emanation Enclosure as a Function of llumidity . . . . . . 117 


\section{SUMMARY}

The central objective of this research was the analysis and synthesis of data available concerning human exposures to the natural terrestrial radiation environment and the solution of some key problems which appeared to be hampering the understanding of it. A better knowledge of the natural radiation environment appears to be necessary to a realistic interpretation of the effects of low levels (for example, current occupational guide levels) of radiation exposure of man.

Specific objectives included a determination of the important parameters affecting radon emanation from concrete, the measurement and correlation of the gamma ray spectra from radionuclides for typical concentrations in soil. a determination of the possibility and practicability of using high resolution spectrometers to measure low levels of radioactive contamination due to human activities, and an evaluation of major sources of external and internal human exposure due to the natural radiation environment.

All of the important objectives were accomplished and some unexpected benefits were obtained. A 50 cubic centimeter Ge(Li) detector provides a satisfactory bas is for evaluating low levels of radioactive contamination in the range zero to five militrads/year of gamma rays; however, a larger detector used with specially designed peripheral 
equipment would be more desfrable. It was demonstrated that the most important parameter in controlling the emanation of radon from concrete is the free moisture content of the concrete. Within the normai range of home temperatures, the temperature of the concrete is not a sensitive parameter and thus has negligible effect on the emanation. Radon concentrations in dwellings constructed of uranium bearing materials are often in the range 1-5 plcocuries/liter of air. These concentrations result in the irradiation of the basal cells of the bronchial epithelium near the first five hifurcations by the alpha emittinc daughters of radon that often exceeds, sometimes by a large factor, the average whole body absorbed dose due to the gamma rays from the natural radiation environment. Further, the doses to these basal cells over a 50-year span may approach the levels at which the incidence of lung cancer in uranium miners is increased by a factor of two over the normal incidence in men of the same age. 
CHAPTER I

INTRODUCTION

General

Although the radiations associated with medical diagnostic techniques, radiotheraphy and the nuclear power industry contribute increasing fractions of the total radiation exposure of man, the most important source is still the naturally occurring radiation environment. The absorbed dose levels range from a few tens of millirads/year to a few rads/year depending on several factors, the most important of which is the concentration of potassium. uranium, and/or thorium in the rock and soll of the environs (UISCEAR 1958, 1962, and 1966). Other factors that influence exposure levels include geomanetic latitude, altitude relative to sea level, general topological terrain and geological features, climate, and composition of buildings in which an individual lives or works. An analysis of the contribution of the various components of the natural radiation environment which contribute both to internal and external exposure is given in Appendix I (UiISCEAR 1966). The variation of the cosmic ray dose with altitude above sea-level and geomagnetic latitude is also shown in Appendix 1 .

The United Nations Scientific Committee on the Effects of Atomic Radiation (UNSCEAR) estimated that the 
world average genetically signiflcant dose (GSD) to man is 125 miltirems/year (UNSCEAR 1962). A discussion of GoD is given in Appendix II. The somatic effects of radiations at world average levels of exposure or even at the dose leveis of the anomalously high areas have not been observed and/or reported in the literature. Although much is known about the effects of relatively high acute doses of radiation to man, e.g., 100-400 rads, little is known about the effects of low chronic exposures such as those from the natura? radiation environment. so little is known, in fact, that there is divided scientific optrion as to whether there exists a threshold dose below which radiation is not harmful (threshold hypothesis) or whether effects can be lineariy extrapoiated from observed effects at high levels to low dose levels (linear hypothesis) regardless of dose rate, or even whether some other model is required. However, since there is some justification and considerable precedence for applying the linear hypothesis (UNSCEAR 1958, 1962, and 1966), it seems prudent to assune that there are some somatic as well as genetic effects from radiation doses from the natural radiation environment.

It was because there were many apparent problems relating to human exposures to the natural radiation environment that this area of research was chosen. Implicit in statements of concern over low levels of exposure is the linear hypothesis of biological effects and the "man-rad" 
concept. The term "man-rad" refers to the sum of the whole body doses without regard to the distribution of doses within the populations. Thus, whether $x$ number of people get a dose of $y$ rads each or 10 x people get one-tenth of $y$ rads each, the effect on the population, somatic or genetic, is the same. This reasoning does not apply if $y$ to a given individual becomes large enough that the probability of an observed effect in that individual is no longer small, 1.e.. the logic applies only to individual doses of a few tens of rads at the highest.

Although some progress has been made, there are still many important unanswered questions concerning our knowledge of the effects of man's exposure to the natural radiation environment. Because this radiation is from "natural" sources, there has been, in the author's opinion, an apparent disregard of many of the problems associated with it. Because some of the radiations are so penetrating. (e.g., the high energy component of the cosinic radiation) and so all-pervasive (e.g., the beta and gama emitter, potassium-40 is present in all potassium, including that in the skeleton of man), this disregard might appear to be justifiable. However, evaluations of the various source contributions are needed in order to provide recommendations for control of those exposures for which some degree of control might be possible. A preliminary step in this direction was made in 1972 in the United Kingdom. 
The British National Radiological Protection Board issued a statement on June 14,1972 , in response to proposals from the building industry to use by-product gypsum in building materials which included the following:

Sources of the raw material giving rise to concentrations of radium in the finished product significantiy in excess of 25 picocuries per gram should be avoided so that the average over the whole country shall not exceed 25 picocuries per gram.

The term "by-product" refers to gypsum resulting from the neutralization of excess sulfuric acid in sulphonation processes; for example see Thorpe and Whiteley (1946). Although the recommendation does not, in fact, limit the general use of a material averaging more than 25 picocuries of radium per gram of material, it does show an increased awareness of the desirability of some controls. Implicit in the concept of controls concerning the radiation exposure of man from the naturally occurring radionuclides are the philosophical questions relating to man's choice of his type of domicile and its geographical location. For example, should the public be made aware of any possible danger to itself and its progeny through increased radiation exposure due to choice of home construction materials and location? Among the important technical questions related to this philosophical one is that dealing with quantizing these effects, namely the prediction of probable exposure by extrapolation of known radiation effects at high dose levels to the relatively low levels of the natural radiation 
environment. Assuming a linear extrapolation model (UIISCEAR 1958, 1962, and 1966), it can be shown that there may be non-negligible genetic and somatic risks to those living in houses in which the gamma radiation exposure is significantly higher than the world average. These risks may be amplified if the lungs are also exposed to high concentrations of alpha-emitting particles.

Description of the Natural Radiation Environment

The natural radiation environment may be considered to consist of emission from terrestrial radionuclides and cosmic radiations. For this study, all radionuclides in the natural environment were considered to be terrestrial, even those produced by nuclear reactions from cosmic ray bombardment of terrestrial atoms. Because more information is available on the geographical and altitudinal variations of the direct cosific ray component of the natural radiation environment than is available on the terrestrial component, only the latter has received detailed consideration in this study. Of the terrestrial sources, the most important are radionuclides of the uranium and thorium series, and the potassium isotope of atomic mass 40 . These radionuclides respectively contribute to human exposure by penetrating radiations, chiefly gamma rays, from sources in the environment, through "external exposure," and from radionuclides inside the human body, frequently 
located in vital body tissues, giving rise to "internal exposure."

The Urantum and Thorium Decay Series

As shown by the tables in Appendix I, more than 50 percent of man's exposure from natural terrestrial sources is due to the uranium and thorium series (parent isotopes are uranium-238 and thorium-232, respectively) (Eisenbud 1963, UNSCEAR 1966). These series are shown schematically and respectively in Figures 1 and 2. Similarly, the properties of the individual isotopes in each series are listed in Tables 1 and 2 (E1senbud 1963, Ditiman 1969, and Lederer et al. 1967). A third series, the actinium series, derived from uranium-235, contributes a negligible part of man's exposure and is not considered here (Eisenbud $1963)$.

Characteristics of the isotopes in the uranium and thorfum series of most consequence to human exposure inciude:

1. Penetrating $x$ and gamma rays from many of the isotopes contribute significantly to the exposure of man if the decay occurs inside the human body or in the near environs.

2. More than 90 per cent of the energy radiated by the decaying isotopes is carried by alpha particles, but because alpha particles in the energy range of interest here (< $10 \mathrm{MeV}$ ) do not penetrate the skin, this energy does not 


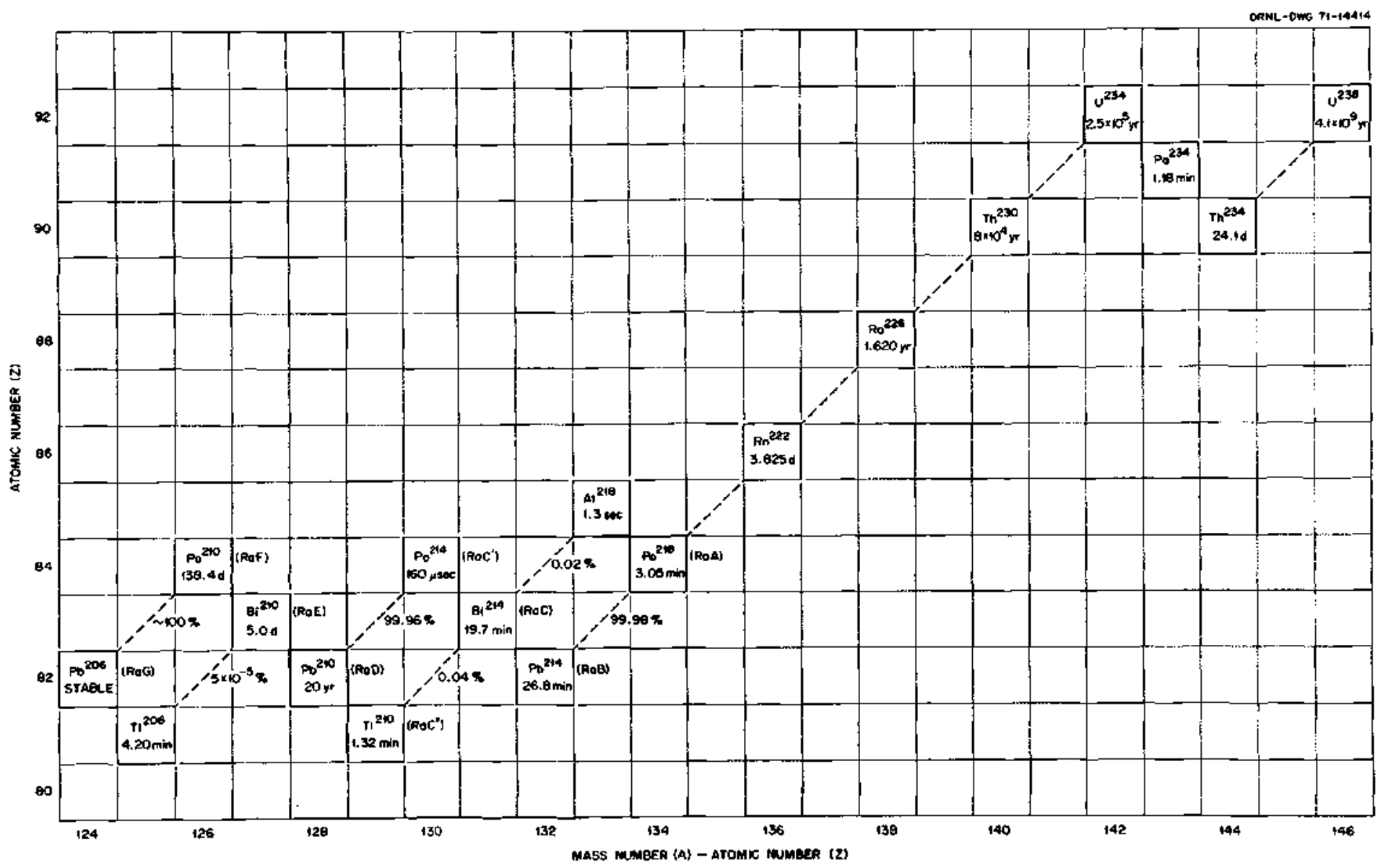

Figure 1. The Uranium Decay Series. 


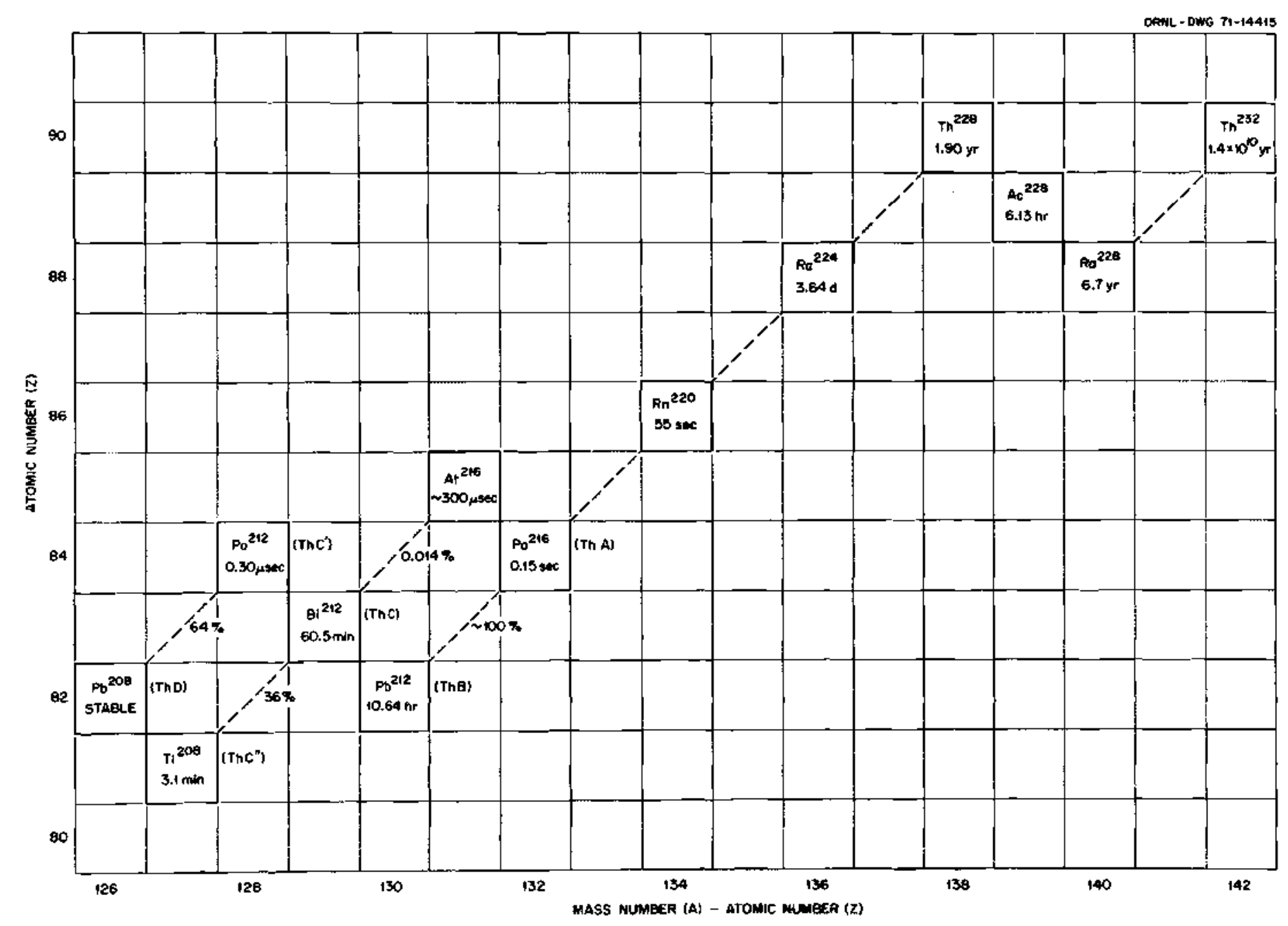

Figure 2. The Thorium Decay Series. 
Table 1. Most Important Radiation Properties of the Is otopes of the Uranium Series

\begin{tabular}{|c|c|c|}
\hline Is ot ope & Radiation & Energy in MeV and \% Yield \\
\hline${ }^{238} \mathrm{U}\left(4.5 \times 10^{9} \mathrm{yr}\right)$ & $\alpha$ & $4.20(75 \%)$ and $4.15(25 \%)$ \\
\hline${ }^{234} \mathrm{Th}(24.1 \mathrm{~d})$ & $B^{-}$ & $0.19(100 \%)$ \\
\hline \multirow[t]{5}{*}{${ }^{234} \mathrm{~Pa}(1.75 \mathrm{~min})$} & $B^{-}(>99 \%)$ & $2.32(80 \%), 1.50(13 \%)$ \\
\hline & $\gamma$ & $0.1(50 \%), 0.126(26 \%)$ \\
\hline & & $0.22(14 \%), 0.36(13 \%)$ \\
\hline & & $0.56(15 \%), 0.70(24 \%)$ \\
\hline & & $0.90(70 \%), 1.08(12 \%)$ \\
\hline${ }^{234} \mathrm{U}\left(2.5 \times 10^{5} \mathrm{yr}\right)$ & $\alpha$ & $4.763(100 \%)$ \\
\hline${ }^{230} \mathrm{Th}\left(8.0 \times 10^{4} \mathrm{yr}\right)$ & $a$ & $4.682(75 \%), 4.613(25 \%)$ \\
\hline${ }^{226} \mathrm{Ra}(1,620 \mathrm{yr})$ & $\alpha$ & $4.777(94.3 \%), 4.589(5.7 \%)$ \\
\hline${ }^{222} \operatorname{Rn}(3.85 d)$ & $\alpha$ & $5.486(100 \%)$ \\
\hline${ }^{218} \mathrm{Po}(3.05 \mathrm{~min})$ & $\alpha \quad(>99 \%)$ & $6.0(100 \%)$ \\
\hline \multirow[t]{2}{*}{${ }^{214} \mathrm{~Pb}(26.8 \mathrm{~min})$} & $\beta^{-}$ & $0.72(100 \%)$ \\
\hline & $Y$ & $\begin{array}{l}0.295(19 \%), 0.352(36 \%) \\
+ \text { weaker }\end{array}$ \\
\hline${ }^{218}$ At $(1.3 \mathrm{sec})$ & $\beta^{-}$ & $\begin{array}{l}6.7(99 \%) \\
\text { weak }\end{array}$ \\
\hline
\end{tabular}

(Cont'd.) 
Tabie 1. (Cont'd.)

\begin{tabular}{|c|c|c|}
\hline Isotope & Radiation & Energy in MeV and \% Yield \\
\hline${ }^{214} \mathrm{Bi}(19.7 \mathrm{~min})$ & $\begin{array}{l}\beta^{-}(>99 \%) \\
\alpha \quad(0.04 \%) \\
\gamma^{\prime} s\end{array}$ & $\begin{array}{l}3.17(23 \%), 1.65(77 \%) \\
5.52,5.47,5.33 \text { (a17 weak) } \\
0.609(47 \%), 0.769(5 \%), \\
0.935(3 \%), 1.12(17 \%), \\
1.238(6 \%), 1.378(5 \%), \\
1.40(4 \%), 1.509(2 \%) \\
1.728(3 \%), 1.764(17 \%), \\
1.848(2 \%), 2.117(1 \%), \\
2.205(5 \%), 2.445(2 \%)\end{array}$ \\
\hline${ }^{214} \mathrm{Po}_{0}(160$ (usec) & $\alpha$ & $\begin{array}{l}7.683(\sim 100 \%)+\text { long } \\
\text { range alphas }\end{array}$ \\
\hline${ }^{210} \mathrm{~T}(1.32 \mathrm{~min})$ & $\begin{array}{l}B^{-} \\
\gamma\end{array}$ & $\begin{array}{l}1.9(100 \%) \\
0.296(80 \%), 0.795(100 \%), \\
1.08(19 \%), 1.21(17 \%), \\
1.31(21 \%), 2.01(7 \%), \\
2.09(5 \%), 2.36(8 \%), \\
2.43(9 \%)\end{array}$ \\
\hline $210 \mathrm{~Pb}(22 \mathrm{yr})$ & $B^{-}$ & low energies \\
\hline${ }^{210} \mathrm{Bi}(5.01 \mathrm{~d})$ & $\begin{array}{l}\beta^{-}(>99 \%) \\
\alpha\left(5 \times 10^{-5} \%\right)\end{array}$ & $\begin{array}{l}1.17(100 \%) \\
\sim 5 \mathrm{MeV}(100 \%) \\
\text { (Cont'd.) }\end{array}$ \\
\hline
\end{tabular}


Tab Te 1. (Cont'd.)

\begin{tabular}{lll}
\hline \multicolumn{1}{c}{ Isotope } & Radiation & Energy in MeV and \% Yield \\
\hline $2100_{\mathrm{Po}}(138.4 \mathrm{~d})$ & $\alpha$ & $5.3(\sim 100 \%)$ \\
& $4.5\left(\sim 10^{-3} \%\right)$ \\
$206 \mathrm{T1}(4.2 \mathrm{~min})$ & $B^{-}$ & $1.51(100 \%)$ \\
$206_{\mathrm{Pb} \text { Stable }}$ &
\end{tabular}


Table 2. Most Important Radiation Properties of the Isotopes of the Thorium Series

\begin{tabular}{|c|c|c|}
\hline Is otope & Radiation & Energy in MeV and \% Yield \\
\hline${ }^{232} \mathrm{Th}\left(1.4 \times 10^{10} \mathrm{yr}\right)$ & $\alpha$ & $4.01(76 \%, 3.95(24 \%)$ \\
\hline${ }^{228} \mathrm{Ra}(6.7 \mathrm{yr})$ & $B^{-}$ & $0.05(100 \%)$ \\
\hline${ }^{228}$ AC $(6.13 \mathrm{hr})$ & $\beta^{-}$ & $2.11(100 \%)$ \\
\hline $228_{\text {Th }}(1.91 \mathrm{yr})$ & $\alpha$ & $5.43(71 \%), 5.34(29 \%)$ \\
\hline${ }^{224} \mathrm{Ra}(3.64 \mathrm{~d})$ & $\alpha$ & $5.68(94 \%), 5.45(6 \%)$ \\
\hline${ }^{220} \mathrm{Rn}(55 \mathrm{sec})$ & $\alpha$ & $6.29(100 \%)$ \\
\hline \multirow[t]{2}{*}{${ }^{216} \mathrm{Po}(0.15 \mathrm{sec})$} & $\alpha(99+\%)$ & $6.78(100 \%)$ \\
\hline & $B(<0.01 \%)$ & --- \\
\hline${ }^{216}$ At $(300 \mu \mathrm{sec})$ & $\alpha$ & $7.80(97 \%)$ \\
\hline${ }^{212} \mathrm{~Pb}(10.64 \mathrm{hr})$ & $B^{-}$ & $0.58(100 \%)$ \\
\hline \multirow[t]{4}{*}{${ }^{212} \mathrm{Bi}(60.5 \mathrm{~min})$} & $\beta^{-}(64 \%)$ & $2.25(100 \%)$ \\
\hline & $\alpha \quad(36 \%)$ & $6.09(10 \%), 6.05(26 \%)$ \\
\hline & y & $0.727(7 \%), 0.785(1.1 \%)$, \\
\hline & & $1.62(1-8 \%)$ \\
\hline${ }^{212}$ Po $(0.3 \mu \mathrm{sec})$ & $\alpha$ & $8.87(100 \%)$ \\
\hline & & also long range alphas \\
\hline \multirow[t]{2}{*}{${ }^{208} \mathrm{~T} 1$ (3.1 min) } & $B^{-}$ & $1.80(100 \%)$ \\
\hline & $\gamma$ & $\begin{array}{l}0.51(23 \%), 0.583(86 \%) \\
0.860(12 \%), 2.614(100 \%)\end{array}$ \\
\hline${ }^{208} \mathrm{~Pb}$ Stable & & \\
\hline
\end{tabular}


contribute to the dose to man except when the decay occurs inside the human body.

3. The isotopes radon-222 and 220 are noble gases with respective half-lives of 3.8 days and 55 seconds. Half-lives of this magnitude permit the noble gases to escape. in many cases, from the rocks, soil or building materials in which they are produced. Once freed in the air the gases are subject to inhalation directly. or progeny of the noble gases can sorb onto dust particles which may be inhaled subsequently.

4. The daughters of radon-222 and radon-220 decay according to widely varying decay constants. When the activity of each of the daughter isotopes is equal approximately to that of a longer lived "parent isotope," a state of radioactive equilibrium is said to exist, i.e., after several half lives of the daughter, if the half life of the parent is much greater than that of the daughter, the activity of the daughter approaches the activity of the parent. This condition is only possible when none of the isotopes are removed from (or added to) the environs under examination or when the addition and removal occur in equal amounts. This phenomenon of radioactive equilibrium is of enormous importance in assessing the dose to man (UNSCEAR 1958, Evans 1969, Parker 1969, and Jacobi 1964), and is discussed in detail in Chapter III. 
Concentrations of uranium and thorfum in the earth's crust vary widely. Table 3 lists some average concentrations in different geologic formations, and Table 4 lists some of the geographical areas having concentrations sufficiently high to produce a significant increase in radiation exposure over the world average (UNSCEAR 1958, 1962, and 1966, Rankama 1954, Spiers, McHugh, and Appleby 1964, Johnson 1952, Johnson and Weir 1962, Marsden 1959 and 1960, Roser and Cullen 1962 and 1966, Cullen 1967, and Roser et al. 1965). The average total doses,internal plus external, from natural sources for various areas and the increment of dose over the world average are shown. Other Naturally Occurring Radionuclides

of all sources of radiation dose to man, the most important single isotope in terms of absorbed dose is potassium-40 (UNSCEAR 1958). Potassium-40 has a half-life of approximately 1.3 billion years and decays by beta emission to calcium-40 (89 percent) or electron capture to argon-40 (11 percent); the electron capture process results in the emission of an argon $X$ ray and a 1.46 MeV gamma ray. Potassium-40 is present in all potassium to an abundance of 0.01 percent and disintegrates at a rate of approximately 1900 disintegrations/mirute/gram of natural potassium. Muscle tissue of a 70-kilogram human usually contains about 130 grams of natural potassium. This 130 grams of natural potassium yieids 0.1 microcuries of potassium-40 ard a 
Table 3. Average Concentration of Uranium and Thorium in Geologic Formations

\begin{tabular}{|c|c|c|c|c|}
\hline Type of Formation & Wt. $\mathrm{J} / \mathrm{g}$ & Rock & Wt. Th/g & g Rock \\
\hline Earth's Crust & 1.0 & $\mu g$ & 4.0 & $\mu g$ \\
\hline Igneous: High Silica & 4.0 & $\mu g$ & 14.0 & $\mu g$ \\
\hline Intermediate Silica & 2.0 & $\mu g$ & 8.0 & $\mu \mathrm{g}$ \\
\hline Low Silica & 1.0 & $\mu g$ & 4.0 & $\mu \mathrm{g}$ \\
\hline Sands tone & 1.2 & $\mu g$ & 6.0 & $\mu g$ \\
\hline Shale & 1.2 & $\mu g$ & 10.0 & $\mu g$ \\
\hline Limes tone & 1.3 & $\mu g$ & 1.3 & $\mu g$ \\
\hline Granite & 4.0 & $\mu g$ & 9.0 & $\mu g$ \\
\hline $\begin{array}{l}\text { Phosphate* (Bone Valley } \\
\text { Formation, Florida) }\end{array}$ & 100.0 & $\mu g$ & 10.0 & $\mu \mathfrak{g}$ \\
\hline
\end{tabular}

*Samples from one area, Bartow, Florida, but survey instruments show general uniformity. 
Table 4. Geographical Areas Having Soil Concentrations of Uranium and/or Thorium to Produce the Dose Increments Indicated (dose values in $\mathrm{mrad} / \mathrm{yr}$ )*

\begin{tabular}{|c|c|c|c|c|c|c|}
\hline \multirow[b]{2}{*}{ World } & \multicolumn{2}{|c|}{$\begin{array}{l}\text { Dose Rate, } \\
\text { Range }\end{array}$} & \multicolumn{2}{|c|}{$\begin{array}{l}\text { Dose Rate, } \\
\text { Average }\end{array}$} & \multicolumn{2}{|c|}{$\begin{array}{l}\text { Increment } \\
\text { over World Average }\end{array}$} \\
\hline & $100-$ & 12,000 & 2 & 125 & & --- \\
\hline \multicolumn{7}{|l|}{ Monazite Sands: } \\
\hline Egypt & $200-$ & 475 & 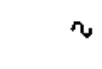 & 200 & $\imath$ & 75 \\
\hline Kerala, India & $<1,000-$ & $>8,000$ & & 1,500 & & 1,375 \\
\hline Rio de Janeíro, Brazil & $550-$ & 1,250 & $\sim$ & 600 & 2 & 475 \\
\hline Minas Gerais, Brazil & $1,700=$ & 12,000 & & 2,000 & & 1,875 \\
\hline Ceylon Granite Areas & $3,000-$ & 7,000 & & 3,000 & & 2,875 \\
\hline Nive Island & $1,000-$ & 2,000 & $\sim$ & 1,000 & $\sim$ & 875 \\
\hline West Central Florida (White Phosphate) & $150-$ & 250 & $\sim$ & 200 & 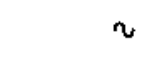 & 75 \\
\hline New England and Georgia Granite Areas & $150-$ & 250 & 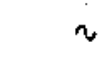 & 200 & w & 75 \\
\hline $\begin{array}{l}\text { Bartow, Florida, Areas with Excavated } \\
\text { Phosphate }\end{array}$ & $200-$ & $1,500 * *$ & Not & Applicab le & Not & Applicable \\
\hline $\begin{array}{l}\text { Many Localized "Hot Spots" Throughout } \\
\text { the United States }\end{array}$ & $1,000-$ & 10,000 & & --- & & -- \\
\hline
\end{tabular}

* Values reported by UNSCEAR in mrem have been translated to mrad, assuming that the RBE for each radiation is 1.0 and that those in mrem can be taken as mrad within the accuracy intended.

** Roadways, parking lots, and areas filled in with phosphate aggregate only; there is no method available at present to estimate average dose to the population. 
resulting absorbed dose to soft tissues and the gonads of approximately $20 \mathrm{millirads/year;} \mathrm{it} \mathrm{also} \mathrm{produces} \mathrm{a} \mathrm{dose} \mathrm{of}$ about $15 \mathrm{millirads} / y e a r$ to the bone marrow (UNSCEAR 1958 and Mayneord 1964). The decay scheme is shown in Figure 3(a) (Spiers, McHugh, and Appleby 1964 and Martin and BTichertToft 1970).

After potassium-40 and the isotopes of the uranium and thorium series, the next most important contributor to human exposure of pureiy terrestrial origin is rubidium-87 but the dose due to it can generally be neglected. The absorbed dose in the gonads from rubidium- 87 in the body is approximately 0.3 miliirads/year, which is typical of the whole body average; i.e., there is no notable local concentration of the approximately 20 nanocuries total activity in any single organ (UNSCEAR 1958, Spiers, Mcitigh, and Appleby 1964). The half-life of rubidium-87 is 47 bilition years and the decay scheme is shown in figure $3(b)$ (Rankama 1954).

Carbon-14, produced by cosmic ray neutron capture in nitrogen-14 followed by proton emission (Libby 1946), contributes approximately 1.6 millirads/year to the bone marrow dose and $0.7 \mathrm{millirads} /$ year to the gonadal dose from a whole-body activity of approximately 30 nanocuries (UNSCEAR 1958 and Mayneord 1964). Carbon is a constituent of all biological tissues and the ratio of the maximum to minimum dose in the human body from carbon-14 is 
ORNL-DWG 72-13018

a)

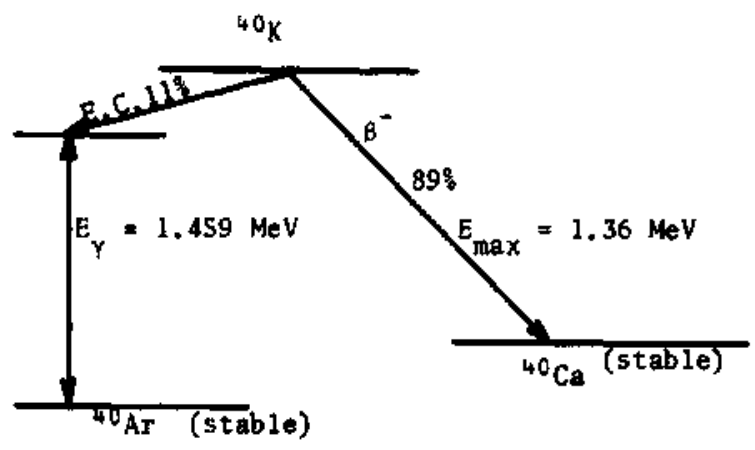

b)

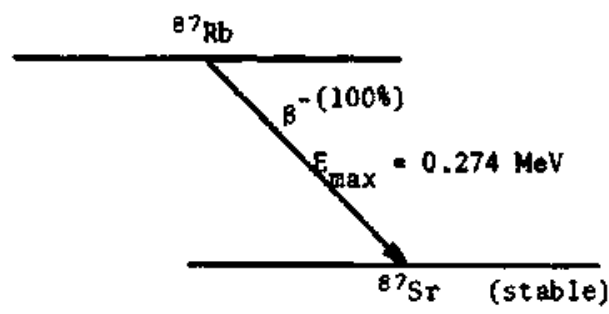

c)

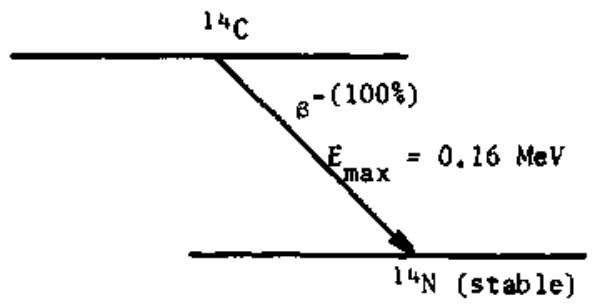

d)

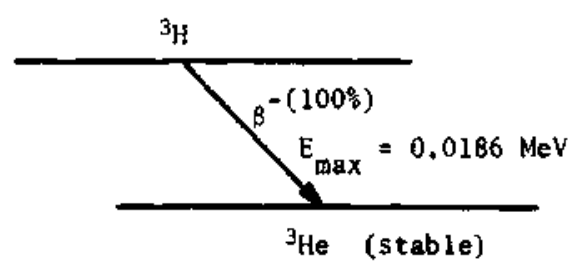

Figure 3. Decay Schemes of ${ }^{40} \mathrm{~K},{ }^{87} \mathrm{Rb},{ }^{14} \mathrm{C}$, and ${ }^{3} \mathrm{H}$. 
approximately three. As a soft beta emitter, carbon-14 contributes only to internal dose; the maximum beta ray energy is $0.16 \mathrm{MeV}$, and the mean beta energy is approximateiy $0.06 \mathrm{MeV}$ (Libby 1955). The half-life is approximately 5730 years (Atomic Energy Commission 1970) and the decay scheme for carbon-14 is shown in figure $3(\mathrm{c})$.

Tritium is also produced by cosmic ray neutrons, primarily by irradiation of sea water (Libby 1946). The half-life of tritium is 12.3 years, the maximum energy of its beta ray is $0.018 \mathrm{MeV}$, and the average beta ray energy is $0.006 \mathrm{MeV}$ (Libby 1955). The quantity of tritium in the body varies over a wide range, but the total amount is small and the dose therefrom is negligible, $\ll 1$ millirad/year (UNSCEAR 1958). The chief external sources of exposure of man from the natural radiation environment are then, in order of importance: the gamma rays from the radionuclides of the uranium and thorium series in soil, rock and building materials; the various particles, including neutrons, due to cosmic rays; and gamma rays from potassium-40 in soil and rock. Likewise, the most important sources of internal exposure are the beta rays of potassium-40; the alpha, beta and gamma rays of the uranium series; and the gamma rays of potassium-40, all contained in body tissues, respectively. These internal and external exposures are so general in the body that they can be assumed to be whole body exposures within the accuracy intended. However, there is one organ 
of the body, the lung, which is exposed additionally when radon and its daughters are contained in the respirable air. More specifically, the basal cells of the brorichial epithelium receive the highest doses and are of major interest in this research.

General reviews of many aspects of the dose to the United States population due to the natural radiation environment have been made recently by 0akley (1971) and by a Special Studies Group of the Environmental Protection Agency (1972). The latter report includes "man-made" sources such as diagnostic $x$-ray machines.

\section{Whole Body Exposure to Man From the Natural}

Radiation Environment

Gamma radiation incident from outside the body yields a relatively uniform dose distribution in man-sized tissue samples. Jones et al. (1972) have presented depth dose curves as a function of photon energy for unilateral irradiation, with the midline dose to man varying from about 25 percent of the incident surface dose at $50 \mathrm{keV}$ to more than 90 percent at $10 \mathrm{MeV}$. For isotropic irradiation the midline dose is in all cases more nearly equal to the dose at the surface. Consequently, for the purposes of this study, the external gamma radiation dose can be assumed to be a uniform whole body exposure. The gamma rays from radionuclides distributed in the body yield, in general, an even more uniform distribution, and thus the total gamma 
component can be taken as uniform.

External beta radiation is primarily of interest, in general, insofar as the skin and the eyes are concerned. The clothing and skin shield the blood forming organs from most of the beta rays which escape the soil or building materials, Also, recommended guidelines for beta irradiation of the skin and eyes are so much higher than the highest natural background levels (for example, NCRP 1971) that littie attention has been given to external beta rays; this appears to be reasonable at present. The more penetrating bremsstrahlung produced by the beta rays is included in the photon continuum; that fraction which is too low in energy to be detected by the usual detectors used in these studies can contribute only to exposure of the skin and lens of the eye and is considered as part of the external beta exposure.

Internal beta and alpha-ray emftters irradiate primarity the tissues of the organ in which they are incorporated and the dose distribution can be highly nonuniform. The daughters of radon-222 are heavy metals, and thus have lung, bone, kidney, and liver as their common target organs (ICRP 1959). The lung is a critical organ in all cases, but the radon which decays while carried in the blood and lymph produces short-lived heavy metals which also decay before they can be deposited in tissues wherein their residence will be long. Hence, they irradiate tissues in 
all areas of the body while they are in the blood or lymph and thus the whore body is the target organ. Each radon daughter thus contributes a relatively small dose to any single organ before the decay reaches lead-210. Because lead-210 has a long half-life it can become fixed in the body, particularly in bone, where the remainder of the decay energy is deposited. Consequentiy, there are two parts of the inhaled radon and radon daughter exposure; first is the dose to the lung, the critical organ, and second is the dose due to lead-210 and its daughters, bismuth-210 and polonium210. It should be noted that there is another source of internal exposure, the uranium and thorium and their daughters in the chain before it reaches radon (222 and 220 respectively) and which find their way into the body by way of the food chain and drinking water. This source of exposure has received much attention, especially the role of radium-226, and will not be reviewed here because it is numerically much less than the dose to the lung tissues.

\section{Dose to the Respiratory System Due to Radon} and Radon Daughters

During the past two decades there have been numerous studies of the dose to lungs and bronchi due to radon-222 and its daughters. However, only within the last few years has significant agreement on dose ranges been obtained by several researchers. For this study, a review and analysis of the more recent work of others were made but no 
experimental research in the area was attempted. The emphasis on exposure of the respiratory system has been and is due to the well-known increased incidence of lung cancer in uranium miners (see for example, PHS 1961, Archer 1962, 1964a, 1964b, Wagoner 1964, 1965, and Lundin 1969). Although this analysis is intended for more general exposures, there appears to be no need for significant differences in the calculation of dose in this general case from that for uranium mines; the varying dust loads, humidity, disequilibrium, etc, are encountered generally. In addition to the work cited, there is an extensive literature listed in the non-cited bibliography. The work cited was chosen on the basis of this author's judgment as the most pertinent and the choices may have been somewhat subjective.

One of the early contributors to the understanding of respiratory system exposure due to radon and its daughters was Bale (1951, 1955, and 1956) who recognized the importance of the attachment of radon daughters to dust particies. The radon daughters, whether formed in free air or in the lung cavity, have a high probability of attachment to particulates which are abundant in all air. Inspired radon gas, which is soluble in water, blood, and most other body fluids especialiy fatty tissue, may be either expired or sorbed into body fluids. Once in body fluids, especially the circulatory system, it is free to circulate throughout 
the body or to rediffuse into the lung and be expired. However, the daughters, which are heavy metals, whether attached to aerosols or free fons or atoms may be deposited in the tracheobronchial tree. Bale (1955) calculated that for equilibrium of radon and its daughters, 95 percent of the dose to the tracheobronchial epithelium was due to the daughters. As discussed earlier, there are betas and gammas emitted by the daughters, but the major part of the energy absorbed in the basal cells of the tracheobronchial epithelium is from alpha particles. The relative biological effectiveness (RBE) of alphas compared to gamma rays is not accurately known for any radiation effect in man, including lung carcinogenesis, but it is generally assumed to be in the range of 5-20, thus increasing the effectiveness of the dose due to alpha rays.

Standard anatomy texts show the details of the human respiratory system, see for example sobotta (1939). However, experimental workers with models have used various simplifications and an excellent recent study (Martin and Jacobi 1972) has demonstrated some of the important physical phenomena using a plastic model of the upper bronchial tree. With the aid of this model and radioactively tagged aerosols they have shown that the important sites for deposition of aerosols are at and near the first few bifurcations of the bronchi. This deposition is that which would be expected due to impaction of particles for both inspiration 
and expiration. However, the inhomogeneous deposition includes additional particulates in Jocations near the impaction areas, indicating that diffusion in nonlaminar flow regions is also important. Even so, the authors were not convinced that these two phenomena alone could explain the concentrations of activity in the bifurcation areas of the upper bronchial tree.

Another important facet of respiratory exposure was expiored by Chamberlain and Dyson (1956) and by Shapiro (1954 and 1956). A primary point of concern in those studies was the ratio of unattached ions or atoms of the radon daughters, mostly radium-A, to the total ions or atoms, generaliy referred to as the unattached fraction. Though the various measurements and estimates of the unattached fraction varied from near 1 percent to as much as 50 percent, a mean value of 10 percent was generally assumed. This unattached fraction is estimated to produce about 90 percent of the dose to the basal cells of the bronchial epithelium because of the easier absorption of the unattached atoms or ions to the bronchi and, to a minor extent, the absence of self-absorption by a particulate (ICRP 1959).

Although numerous researchers have investigated the problems of the alpha ray dose to the bronchi, generally by basing a set of calculations on a chosen deposition model, the recent work of Jacobi (1972), Martin and Jacobi (1972), and Harley (1971)permits not only an evaluation of the range 
of uncertainties in the bronchial dose due to radon but also a narrowing of the limits of uncertainty for a given set of exposure parameters. Harley evaluated many of the physical parameters, including stopping power, and computed the dose to the largest part of the respiratory tree (the trachea with 1.8 centimeters diameter) and the smallest bronchials (0.6 millimeters diameter). Because the differences were small, she did not compute the values for the intermediate diameters. She used experimentally determined values for the attached fraction (attached to particulates) and particle size distribution and assumed a 15-micrometer thick mucous layer lining the bronchial tree. She used a particle size diameter of 0.3 micrometers which is larger than generally used but showed that self-absorption in it is negligible; hence, her data can be applied with some confidence to smaller particles. An important conclusion drawn by Harley is that the dose to the bronchial tree where lung cancers are observed in uranium miners is lower for a given radon concentration than assumed by ICRP (1959), though the difference is strongly dependent on the lung model used. In Harley's analysis of Weibel's model (Weibel 1963), she has computed a dose to the basal cells (22-micron depth) which is nearly an order of magnitude lower than similar calculations based on a model by Altshuler (Altshuler, Nelson, and Kuschner 1964). Modifying Harley's conciusions by a different distribution of 
deposited activity, for example using the results of Martin and Jacobi for 0.3 micrometer particles, it is reasonable to conclude that the dose to the regions of bifurcation is much higher than the average and is in the range of 10-20 rads/year for exposure to 100 picocuries/liter of radon in equilibrium with its daughters for 2000 hours/year. If it is assumed for the present that the working level unit (WL), used in monitoring for radon in uranium mines and discussed in Appendix III, is numerically equal to 100 picocuries/liter, then the dose to the bifurcation regions of the bronchi is of the order of 10-20 rads per 12 working level months (WLM). Ludin et al. (1971) report that exposure to 120-359 WLA causes an increase in respiratory cancer deaths of about a factor of four over control populations. It appears prudent to assume the "doubling dose" to be about 100 WLM or 85-170 rads to the bronchi. The latent period for lung cancer depends on the exposure, but generally decreases with increasing dose. Also, no data are avallable on the relative sensitivity of women or children to the induction of this form of carcinoma, but from other human studies it might be expected that children would be more sensitive. For convenience, use is made of a "low exposure" latent period of 10 years and it may be assumed that a two-fold increased risk of death due to this cause before age 60 would represent too large a "cost" to an individual for living in a masonry house as compared to a 
wooden building (a highly suspect assumption). Then we may ask, what concentration of radon would yield a dose for exposure from birth to age 50 without doubling the respiratory cancer risk? There are 600 months for exposure and, averaged over the 50 years, something more than eight hours per day and less than 24 hours per day spent in the home; at present there is no way of arriving at a satisfactory average, especially for any specific type of home. For convenience, assume 15 hours per day over a period of 600 months which is equal, compared to the miner's eight-hour shifts for five days per week, to 1575 exposure months. In order to linit exposure to 100 WLM, the maximum WL would be $100 \mathrm{WLM} / 1575 \mathrm{M}$ or $0.06 \mathrm{WL}$. Assuming equilibrium of radon and its daughter, this is about 6 picocuries/liter of radon in air. From the study discussed in Chapter III, it is possible to find homes that are typical of those in some areas of the world where these concentrations would be exceeded. However, considering the effect of even minimal ventilation, it is expected that the dose due to inhalation (bronchial) is seldom as high as the equilibrium level (see Chapter III). At present it is not possible to ascertain the additivity of other doses to this (bronchial), e.g., the 200-400 millirads/yr of penetrating whole body exposure due to gamma rays from the masonry structural materials, the dose due to diagnostic $x$ rays, etc. Consequently, prudence would make desirable an average radon level of less than 6 
picocuries, perhaps 1 picocurie/liter for residences, especially in view of the childhood exposure. This 1 picocurielliter corresponds to a dose to age 50 years of 5 10 rads or a dose rate of 100-2nn millirads/year to the basal cells of the bronchiai epithelium.

Objectives

The general objectives of this research were: (1) to evaluate the range of dose levels to which mar is exposed to the natural radiation environment and the relative importance of the various sources contributing to the total; (2) to contribute to the basic knowledge of the natural radiatior environment; and (3) to explore the feasibility of reducing some of the higher than average levels of man's exposure to the natural radiation environment.

More specific objectives were to:

1. Obtain and interpret the gamma ray spectra of the isotopes contributing to the natural radiation environment in various geographical and mineralogical areas, e.s., the phosphate areas of Florida and granite areas of Georgia.

2. Make similar studies at sites of known contamination by man, e.g., in the oak Ridge area, and determine the factors limiting the levels that can be analyzed for control of environinental releases from nuclear centers.

3. Determine the radon emanation from the surface of structural materials per unit area and per unit çuantity of 
uranium (or radium) in the material to ascertain what parameters most strongly influence the emanation, and to explore practical methods of minimizing such emanation, espectally from concrete.

4. Measure the size of dust particles in the air into which radon gas is being emanated and determine whether isotopic equilibrium of radon progeny on the particles is obtained.

5. Evaluate the total doses to humans from the natural terrestrial radiation sources, especially in certain "high-dose environments" such as concrete structures buitt from materials containing relatively high concentrations of uranium and trorium. Emphasis was placed on those groups of persons exposed to levels of radiation from the natural environment that exceed the presumed world average of $95-125$ $\mathrm{mrad} /$ year (UNSCEAR 1958) by a factor of two or greater. Some of the input data were drawn from the work of others, e.g., the internal dose from potassium-40 in the body. 


\section{CHAPTER II}

\section{GAMMA RADIATION FROM THE GROUND}

\section{Introduction}

Some of the photons emitted by radionuclides distributed in the soil and rock near the air-ground interface escape without energy loss. The probability of escape depends on many parameters including the distribution of the radionuclide with depth, the eneray of the photon, and the composition and density of the soil. In principle, sufficient knowledge of the spectrum would permit calculation of absorbed dose in man, an inventory of the gamma emitting radionuclides on or near the surface of the ground, corrections for the energy dependence of response of various radiation detectors, etc. It was most apparent that knowledge of the spectrum due to the natural radiation sources is a prerequisite for identifying levels of contaminants from man-made sources which are low compared to the natural levels, e.g., 1-5 mrad/year. Sufficient data were available from previous studies, e.g., see seviral papers in Adams and Lowder(1964), to demonstrate that many of the various photopeaks due to gamma rays from the uranium and thorium series and potassium-40 were identifiable. However, insufficient information on the spectrum was 
available for characterizing the gamma ray environment for fulfilling the objectives of this study.

In order to describe the radiation environment above the ground, several related experiments and calculations were necessary. The first step was the calculation of fruence for uncollided photons; the second was the calibration of a gamma spectrometry system; the third was the measurement of fluence as a function of photon energy (spectrometry); the fourth was the determination of the radionuclide content of the soil (by radiochomists and analytical chemists); the fifth was the measurement of the total dose rate above the ground; and the sixth was the establishment of empirical relationships between radionuclide content of the ground and the dose rate above the ground.

\section{Theory}

Experimentally, the quantity most readily determined by the spectrometer is the number of counts in the "photopeak" which is obtained when the total energy of the photon is absorbed in the detector. In order to relate the counts recorded in the total energy peak to the density of emitting atoms in the soil, a number of factors must be taken into account. The primary factors are the efficiency of the detector as a function of energy, the absorption of gamma rays by the soil and air between the emitter and the detector, and the solid angle at the detector subtended by 
the source. Proper consideration of the effective center of the detector as a function of energy permits the assumption of a point detector (Notea 1971). Measurements of the effective center as a function of energy showed that the divergence from a point detector geometry was insignificant for the minimum source detector geometry that could be obtained in this experiment. Due to the design of the detector and its associated dewar, the perpendicular distance to the ground from the center of the detector when it was in use was 66.3 centimeters and the largest correction factor for a point detector geometry was only 0.6 percent of this distance. Moreover, small angular variations in the detector response were also unimportant due to the greater distances associated with large angles. Referring to Figure 4 to define geometrical terms, the counts recorded by the spectrometer in the total energy peak equivalent to a gamma ray energy $E_{Y}$ is given for a specified volume of emitter

$$
d n_{e}\left(E_{\gamma}\right)=\cdot \varepsilon\left(E_{\gamma}\right) \exp \left[-\sec \theta\left(\mu_{e} t+\mu_{a} D\right)\right] n\left(t, E_{\gamma}\right) d v
$$




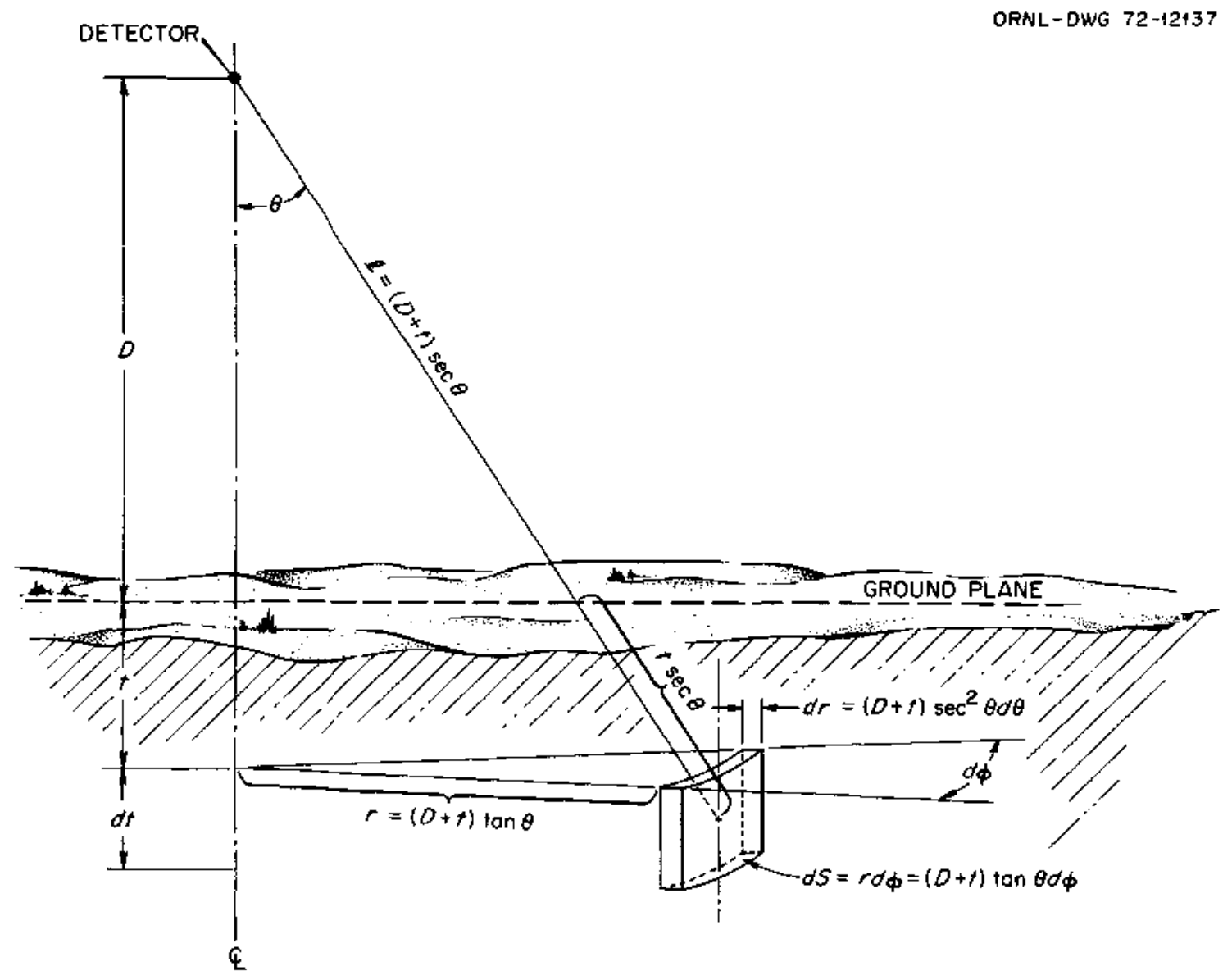

Fig. 4. Diagram Showing Geometrical Parameters used in Computing Gamma Ray Fluences from the Ground. 
where $E\left(E_{\gamma}\right)$ is the efficiency of the detector in counts/gamma ray. In this formulation the efficiency includes the effect of source to detector distance, a standard procedure in gamma-ray spectrometry. Photon attenuation in air and soil is given by the exponential term. The concentration of emitters as a function of $E_{\gamma}$ and depth in the soil, $t$, is $n\left(t, E_{\gamma}\right)$.

The volume element is $r d r d d$ or, since it is possible to write $r$ as $(D+t) \sec ^{2} \theta,(D+t)^{2} \sec ^{2} \theta \tan$ $\theta d \phi d t d \theta$. Because $\varepsilon d^{2}=k\left(E_{\gamma}\right)$ with $d=$ distance and $k=a$ constant for a given energy, the variation of efficiency with distance can be written as $\varepsilon=k(E) / d^{2}$. Using all of these values gives

$$
\begin{aligned}
& d n_{e}\left(E_{\gamma}\right)=\frac{n\left(t, E_{\gamma}\right) k\left(E_{\gamma}\right) \exp \left[-\sec \theta\left(\mu_{e} t+\mu_{a} D\right)\right]}{(D+t)^{2} \sec ^{2} \theta} . \\
& {\left[(D+t)^{2} \sec ^{2} \theta \tan \theta d \theta d t d \phi\right]} \\
& =n\left(t, E_{\gamma}\right) k\left(E_{\gamma}\right) \exp \left[-\sec \theta\left(\mu_{e} t+\mu_{a} D\right)\right] \tan \theta d \theta d t d \phi .
\end{aligned}
$$


The linear attenuation coefficients of soil, He and air $\mu_{a}$ are also energy dependent, but for a given energy this equation can be integrated

$n_{e}\left(E_{\gamma}\right)=\int_{-\phi}^{\phi} \int_{0}^{\infty} \int_{0}^{\pi / 2} n\left(t, E_{\gamma}\right) k\left(E_{\gamma}\right) \exp \left[-\sec \theta\left(\mu_{e} t+\mu_{a} D\right)\right] \cdot$

$\tan \theta d \theta d t d \phi$.

Indefinite 's are shown to allow for considerations of that part of the solid angle shielded from the detector by the dewar. Now

$n_{e}\left(E_{\gamma}\right)=2 \phi k\left(E_{\gamma}\right) \int_{0}^{\infty} n\left(t, E_{\gamma}\right) d t \int_{0}^{\pi / 2} \exp \left[-\sec \theta\left(\mu_{e} t+\mu_{a} D\right)\right] \tan \theta d \theta$

Let

$$
y=\left(\mu_{e} t+\mu_{a} D\right) \sec \theta
$$

then

$$
\begin{aligned}
d y & =\left(\mu_{e} t+\mu_{a} D\right) \sec \theta \tan \theta d \theta \\
& =y \tan \theta d \theta
\end{aligned}
$$

so

$$
n_{e}\left(E_{\gamma}\right)=2 k\left(E_{\gamma}\right) \phi \int_{0}^{\infty} n\left(t, E_{\gamma}\right) d t \int_{\mu_{e}}^{\infty} t+\mu_{a} D \frac{e^{-y}}{y} d y,
$$

or

$$
n_{e}\left(E_{\gamma}\right)=2 k\left(E_{\gamma}\right) \phi \int_{0}^{\infty} n\left(t, E_{\gamma}\right) d t\left[E_{1}\left(\mu_{e} t+\mu_{a} D\right)\right] d t
$$


which can be solved in general for any form of $n$ by $a$ numerical integration. A different approach is possible if $n$ equais a constant. Then

$$
\begin{aligned}
& n_{e}\left(E_{\gamma}\right)=2 \phi n k\left(E_{\gamma}\right) \int_{0}^{\pi / 2} e^{-\mu a^{D} \sec \theta} \tan \theta d \theta \int_{0}^{\infty} e^{-\mu} e^{t \sec \theta} d t \\
& =2 \phi n k\left(E_{\gamma}\right) \int_{0}^{\pi / 2} e^{-\mu a^{D} \sec \theta} \tan \theta d \theta\left[\frac{e^{-e^{t} \sec \theta}}{-\mu_{e} \sec \theta}\right]_{0}^{\infty} \\
& =2 \phi n k\left(E_{\gamma}\right) \int_{0}^{\pi / 2} \frac{e^{-\mu_{a} D \sec \theta} \tan \theta d \theta}{\mu_{e} \sec \theta} \text {. }
\end{aligned}
$$

To integrate (12), let $y=\sec \theta$, then dy $-\sec \theta \tan \theta d \theta$, $\theta=0$ implies $y=1, \theta=\pi / 2$ implies $y=\infty$.

$$
n_{e}\left(E_{\gamma}\right)=\frac{2 \phi n k\left(E_{\gamma}\right)}{\mu_{e}} \int_{1}^{\infty} \frac{e^{-\mu_{a} D y}}{y^{2}} d y
$$

Thus, for a uniform distribution

$$
n_{e}\left(E_{\gamma}\right)=\frac{2 \phi n k\left(E_{\gamma}\right)}{\mu_{e}} E_{2}\left(\mu_{a} D\right) .
$$


This approximation was used to reduce the data that were collected during a number of measurements. Distributions decreasing exponentially or linearly with depth might be better approximations but a uniform distribution was chosen as consistent with the quality of the data obtained. Other approaches to this problem are also possible (Anspaugh 1972). Most approaches require more information about the detector than was available at the time these data were obtained.

For these calculations the air density was taken to be 1.15 milligrams per cubic centimeter (corresponding to 23 degrees centigrade temperature and 730 millimeters $\mathrm{Hg}$ pressure) and the density of the soil was assumed to be 2.25 grams per cubic centimeter, which is arbitrarily based on the density of silicon. To allow for attenuation by the dewar and its contents, a solid angle was obtained by integrating over the polar angle from zero to $\pi / 2$ radians, and the azimuthal angle from 0 to 5.2 radians.

From the reported results of other workers, e.g., several papers in Adams and Lowder (1964), it was clear that with the relatively poor resolution of $\mathrm{NaI}$ detectors (about 15 percent) compared to Ge(Li) (always much less than one percent in the energy range of interest) that the ratio of photopeak height to compton continuum was two or a littie greater for the 6-8 more prominent peaks of the natural gamma-ray environment. With the better resolution of the 
Ge (Li) detector, the ratio was expected to be higher, at least as great as 10 , but it was also clear that it would depend on the experimental conditions, especially the ratio of uncollided to scattered photons in the environment. Because this ratio could not be calculated in practical cases due to cost (it would have to be done for each different experimenta? site), it was not attempted though the large computers and complex codes for such a calculation were avajlable. Instead, the approach outlined above and simple codes were used in a semi-empirical evaluation.

\section{Spectrometer System}

The primary measurements of the natural radiation environment were based on gamma-ray spectrometry. The most important reason for using gamma-ray spectrometry rather than dosimetry is that the contribution of a specific radionuclide can generally be determined. An accurate measurement of the fiuence of photons originating from the various naturally occurring nuclides was needed to compare with calculations, to provide a bas is for relating fluence and radionuclide concentrations in the soil, and to test for disequilibrium in the uranium and thorium decay chains. Because there is still some worldwide contamination of the land surface and near subsurface produced by nuclear weapons, added importance must be placed on the accurate identification of the various radionuclides contributing to the total gamma-ray exposure. 
Until recentiy, field spectrometry was accomplished by using scintillation spectrometers, usually NaI (see for example, Lowder et al. (1964), Wollenberg and Smith (1964), Adams and Fryer (1964), and Beck et al. (1964). However, due to the limited resolution of photon energy with this system (usually 10-15 percent of the photopeak energy) many energies contributed to the response in a given photopeak region. The extent of this response made calibration for the many peaks of the uranium and thortum series difficult and the accurate identification of many nuclides impossible by this technique.

The development of a spectrometry system based upon germanium diode detectors has eliminated many of the problems associated with scintillation spectrometers. Lithium drifted germanium detectors, $G e(L i)$, are remarkable for their high resolution of photon energy. This resolution is typically 2-3 keV for $1 \mathrm{MeV}$ photons (full-width,halfmaximum), but ranges from less than $100 \mathrm{eV}$ in the 1-5 keV region to approximately $4 \mathrm{keV}$ for photons of $3 \mathrm{MeV}$ (Krugten and Van Nooijen 1971 and Hamilton and Manthuruthil 1972). Although Ge(Li) detectors have a lower sensitivity in terms of "counts per photon" than do NaI scintillators, their higher resolution permits statistically significant spectral data to be obtained in approximately the same amount of time. Such detectors and their associated equipment are commercially available from several sources. A sketch of 
the detector, having an active volume of 50 cubic centimeters, used in this study is given in Figure 5. The inner cylinder represents the "undrifted" region, i.e., the volume in which no lithium is incorporated and is therefore a "dead" or non-sensitive volume. The diagram of the spectrometry system is shown in figure 6 and photographs of the field apparatus are shown in Figures 7 and $8 . \quad A 11$ of the field equipment was mounted or transported in a one and one-half-ton van truck. The van was air conditioned and equipped with a gasoline-powered generator for providing electrical power at remote sites. The multichannel analyzer (MCA), used early in the study had only 512 channels, and this necessitated as many as 10 measurements at a single location in order to obtain the gamma-ray spectrum to the accuracy required. Later in the study measurements were made using a 4096 channel analyzer. Because all components of the spectrometry system are commercially available from several sources, no further details will be given here.

\section{other Equipment}

Although the spectrometer system was the major item of field equipment, other equipment used either in the fleld or for analyses of samples from the field is included here for convenience of grouping though some items are related more directiy to the radon studies reported in Chapter III. Significant components are: (1) sensitive scintillation detector of the portable or survey type, (2) a scanning 
ORNL-DWG 72-12496

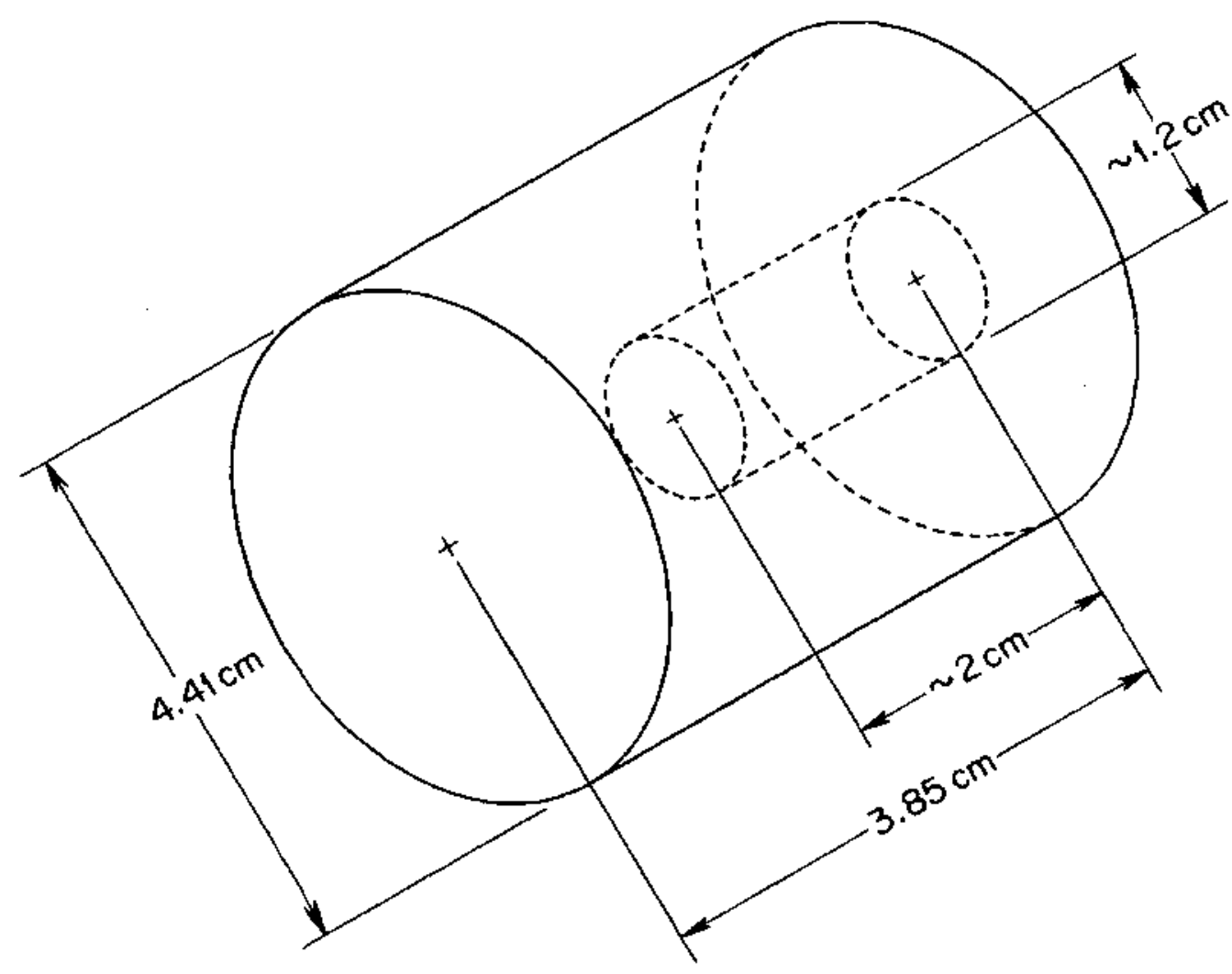

Fig. 5. Lithium Drifted Germanium Detector: Form and Dimensions. 


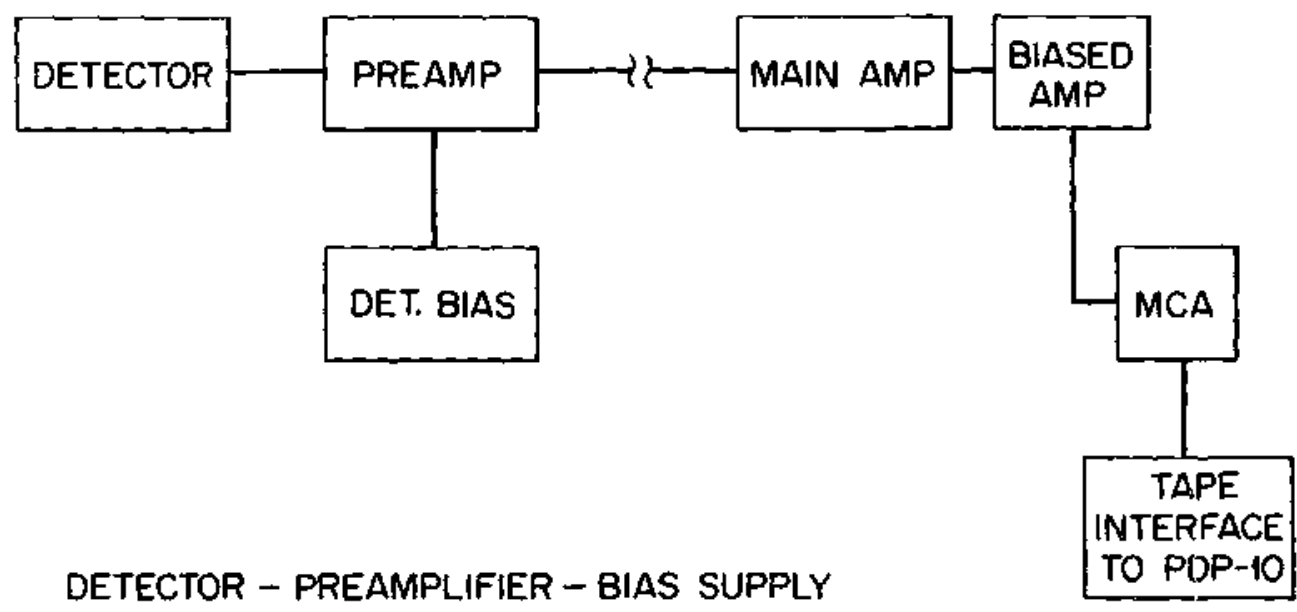
EQUIVALENT CIRCUIT

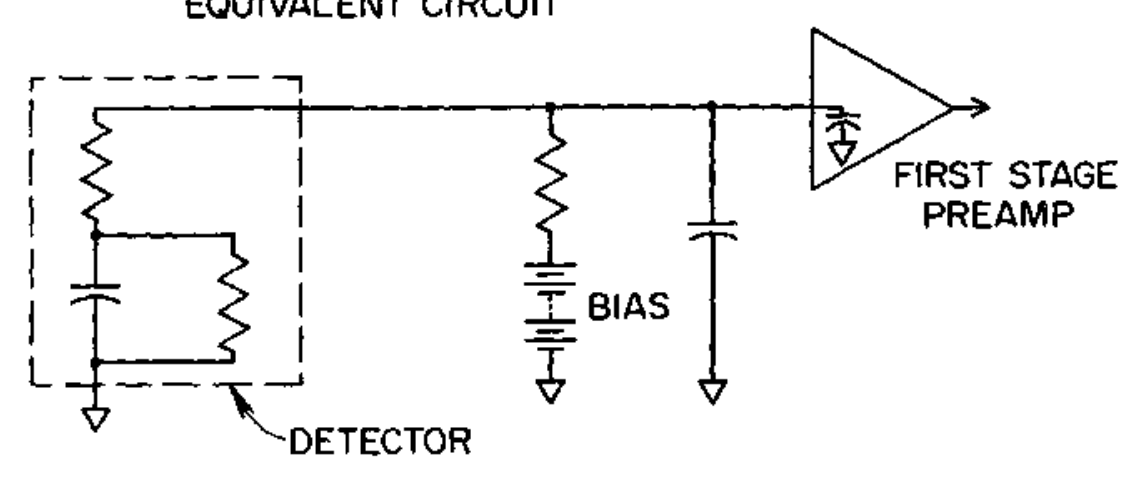

Fig.6. Block Diogram of Ge(Li) Spectrometer System and Diagram of input Circuitry. 


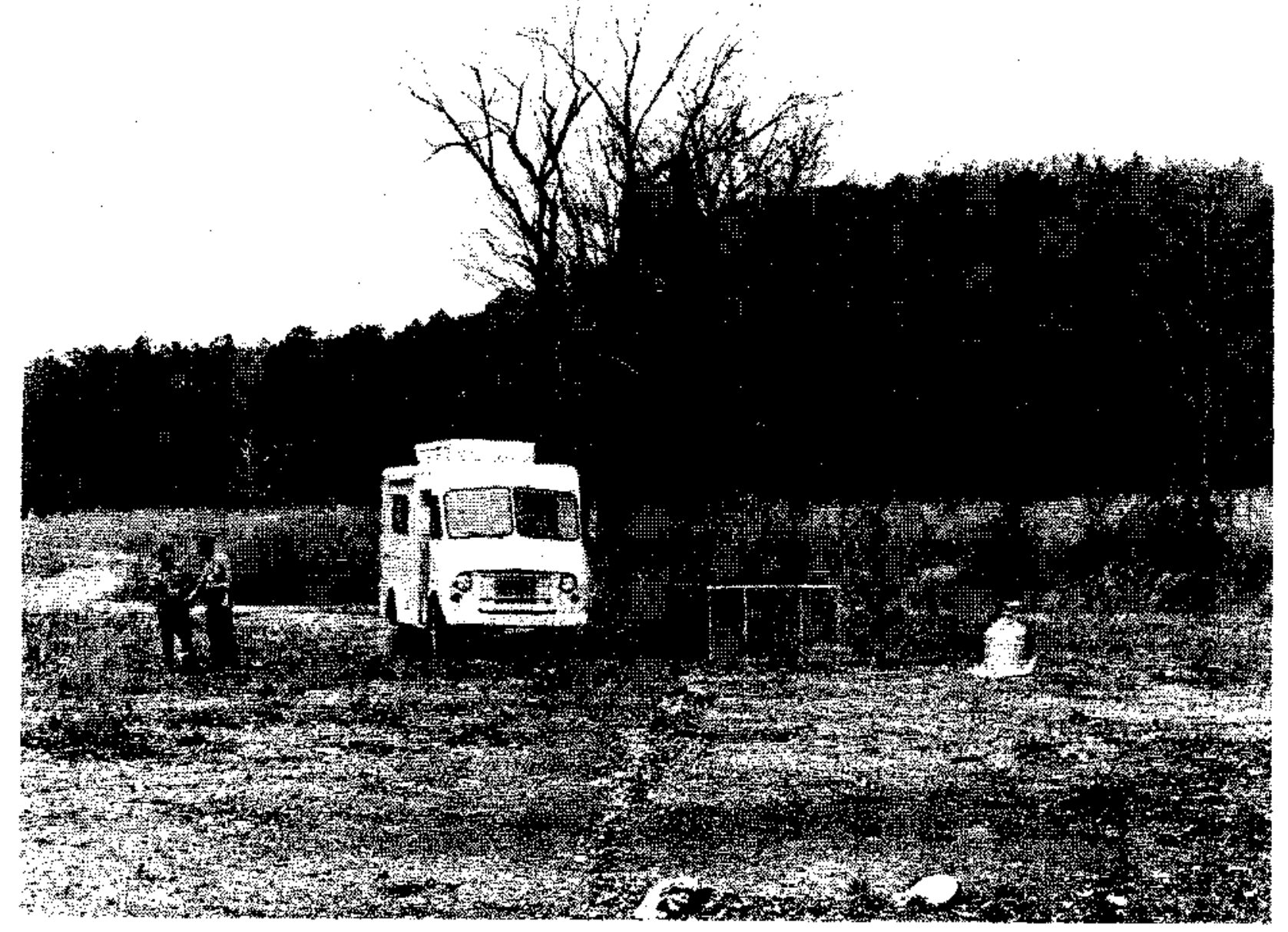

Fig. 7. View of Field Spectrometry and Air Sampling Equipment as used Typically. 


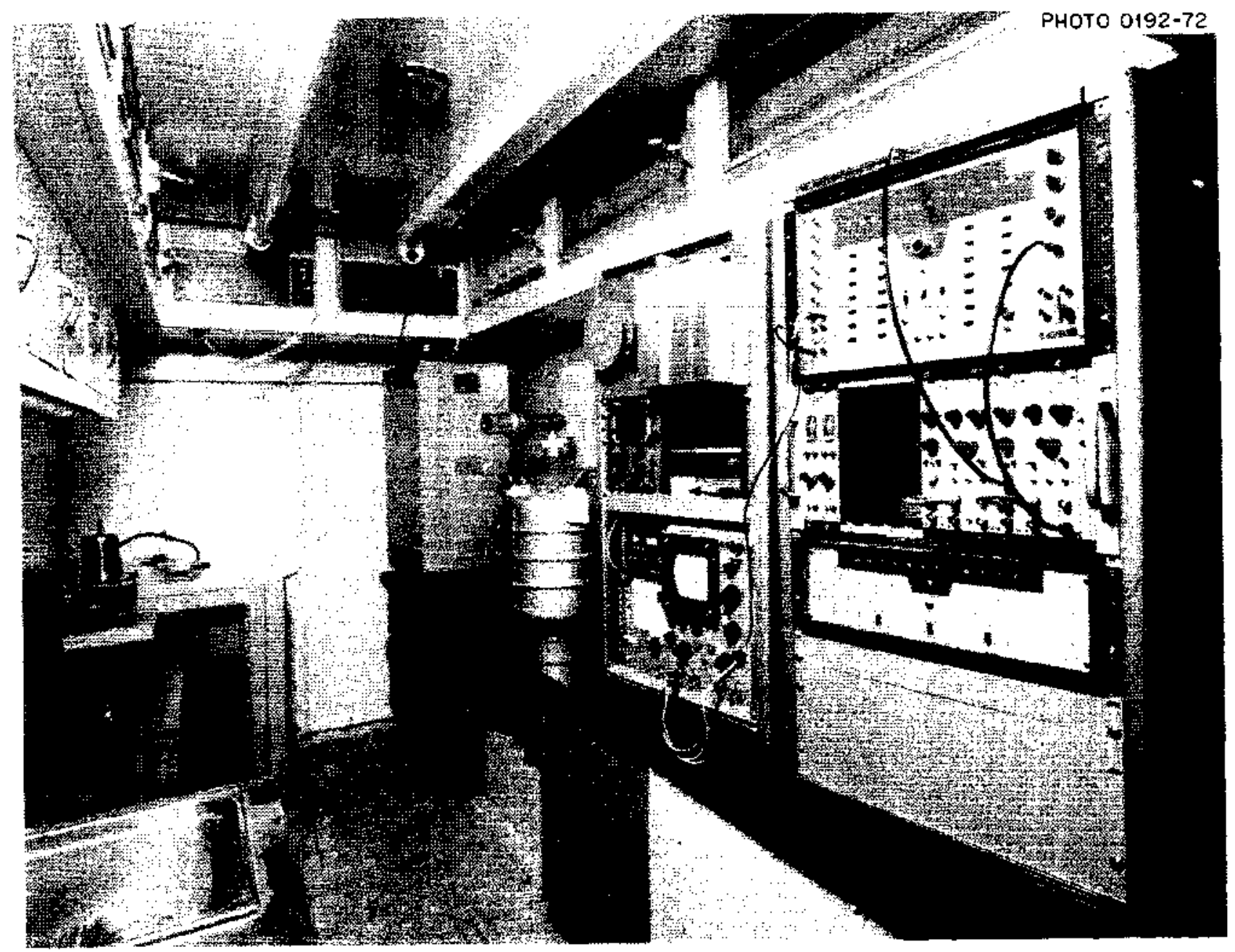

Fig.8. View of Interior of Van Laboratory. 
electron microscope, and (3) various types of radiochemical equipment, including neutron-induced fission facilities.

Field Experiments

In the early design of the field experiments, discussions were held with researchers who had previously reported results from studies or surveys in the southeastern and New England areas of the United States. Later, contacts were established with the State Departments of Public Health in Florida, Georgia, and Kentucky and their cooperation was given in final arrangements for the studies in their respective states. After a study of the Georgia granite area around Stone Mountain and a comparison of reports containing earlier work in Georgia and New England, the New England study was deleted because the physical data there should compare closely with Stone Mountain.

The main objectives of the field experiments were the measurements of the photon fiuences from the ground as a function of energy, radiochemical sampling of soil and rock, and measurements of radioactivity on particulates in the air. Air samples were analyzed for radioactivity in the field, but size distributions of the collected particulates were made in the laboratory.

Measurements with $G e(L i)$ detectors were made at several sites near the Oak Ridge National Laboratory (ORNL), at two sites in Florida, one site in Georgia, and two sites in Kentucky, as shown in Table 5. Measurements with 
Table 5. Field Measurement Sites and Survey Instrument Readings

\begin{tabular}{|c|c|c|}
\hline General Location & Site Specification & $\begin{array}{l}\text { Average Exposure Rate } \\
(\mu \mathrm{rad} / \mathrm{hr})^{*}\end{array}$ \\
\hline Oak Ridge, Tennessee & $\begin{array}{l}\text { 01d EGCR* area (no contamination ever allowed } \\
\text { at this site) } \\
\text { Cesium field used for ecology studies } \\
\text { Former storage area for contaminated equipment, } \\
\text { chiefly } 2350 \text { contamination } \\
\text { Shale outcrop area near Tennessee } 58-95 \text { intersection }\end{array}$ & $\begin{array}{l}8 \\
20 \\
20-30 \\
25\end{array}$ \\
\hline $\begin{array}{l}\text { Whitley City, } \\
\text { Kentucky }\end{array}$ & $\begin{array}{l}\text { Eleven miles west; Yamacraw section; three miles } \\
\text { south of Kentucky 92--valley with smouldering slag } \\
\text { heap (mining ceased approximately 1950) }\end{array}$ & 15 \\
\hline Manchester, Kentucky & One mile south of Manchester in drive-in theater & 15 \\
\hline $\begin{array}{l}\text { Atlantic Beach, } \\
\text { Florida }\end{array}$ & $\begin{array}{l}\text { Beach home of relative of staff member, Florida } \\
\text { State Department of Public Health }\end{array}$ & $\begin{array}{c}18-25 \\
\text { (Granite Rock Area) } \\
8-10 \\
\text { (Clear Beach) } \\
25-35 \\
\text { (B 1ack Sand) }\end{array}$ \\
\hline Bartow, Florida & Civic center grounds in park playground & $180-200$ \\
\hline $\begin{array}{l}\text { Stone Mountain, } \\
\text { Georgia }\end{array}$ & $\begin{array}{l}\text { Granite quarry area three miles east of public } \\
\text { center buildings }\end{array}$ & $\begin{array}{l}20 \\
\text { (Average) }\end{array}$ \\
\hline Georgia + & $\begin{array}{l}\text { Highways and other paved or graveled areas using } \\
\text { granite aggregate }\end{array}$ & $10-30$ \\
\hline Florida + & $\begin{array}{l}\text { Highways and other paved or graveled areas using } \\
\text { phosphate rock aggregate, especially in Polk } \\
\text { County area }\end{array}$ & $20-200$ \\
\hline
\end{tabular}


scintillation survey instruments alone were made in numerous places in all four states, and especially along highways that were constructed with uranium or thorium bearing materials as aggregate. In general, spectroscopic measurements were made on the flattest and smoothest terrain having the highest radiation background as determined by the scintillation survey instrument. A notable exception was at Bartow, Florida, where the highest background was too high for proper performance of the MCA. The Bartow measurements were made at a site having a dose rate of approximately 100 microrads per hour.

\section{Procedures}

Calibration

Before use can be made of the pulse height data obtained from any gamma-ray spectrometer, calibration is required. Two factors must be considered, pulse height versus incident photon energy and counts per incident photon. For a simple, source geometry (e.g., a source, small enough to be considered a point, is placed along the detector axis at a fixed distance from the front face of the detector) efficiency can be determined by using sources of known energy and yield. Such an approach is useless when the source consists of a plane below the detector. In this case, one may combine a knowledge of the efficiency for a source on the plane directly below the detector and the angular response of the detector to obtain an efficiency 
integrated over the total usefut solid angle (Anspaugh 1972). The difficulty of measuring the angular response at enough angles, particularly at angles near 180 degrees, coupled with the essentially three-dinensional response function that must be handled, makes this approach a difficult one. Moreover, the angular integration is necessary regardless of the distribution function selected to represent the concentration of the radionuclides on or in the plane. Therefore, an approach more readily realized by experimentalists is the assumption of a point detector already discussed. The data necessary to implement this approach are obtained by measuring the response of the detector to known sources piaced at a number of distances from the can hollsing the detector.

Assuming a point detector, the product of the efficiency in counts per source gamma ray and the distance squared should be a constant for a given energy. That is, $\varepsilon d^{2}=k\left(E_{Y}\right)$. Assume $d$ is composed of two factors, 2 , the distance from the source to the surface of the detector enclosure, and $c$, the distance from there to the effective center of the detector. Then, $E(l+c)^{2}=k$ or $\varepsilon^{\frac{1}{2}}(l+c)=$ $k^{\frac{3}{2}}$ so that the result is an equation for a straight ine of the form $y=m x+b$ with $y=1 / e^{\frac{3}{2}}, x=l, m=1 / k^{\frac{1}{2}}$ and $b=$ $c / x^{\frac{1}{2}}$. Conversely if a quadratic form is used, the parameters may be written $y=1 / \varepsilon, x=\ell, a_{0}=c^{2} / k, a_{1}=$ $2 c / k$ and $a_{2}=1 / k$. 
Data were taken with a set of sources whose energies are well known and whose yield were given to \pm 5 percent. The sources used were cobalt-57 with gamma rays at 121.9 and $136.3 \mathrm{keV}$, sodium-22 with an annihilation gamma ray of 511.0 keV and a gamma ray at $1274.6 \mathrm{keV}$, manganese-54 with a gamma ray at $834.8 \mathrm{keV}$ and cobalt-60 with gamma rays at 1173.2 and 1332.5 keV. All source strengths were about one microcurie of activity at the time they were assayed. Corrections for decay were made to obtain the number of gamma rays per second each source yielded at the time of the experiment. Perhaps sources with assays more precise than 5 percent would have been desirable but this uncertainty was less than that for most of the measurements of naturally occurring gamma rays. Because the highest energy in this source set was well below the highest natural energy of interest (that1ium-208 at $2614.5 \mathrm{keV}$ ), it was supplemented with an yttrium-88 source (gamma rays at 898.0 and $1836.1 \mathrm{keV}$ ) from a somewhat aged International Atomic Energy Agency (IAEA) standard source set and a small sodium-24 source (gamma rays at 1368.5 and $2753.9 \mathrm{keV})$ made by exposing $\mathrm{NaCl}$ to the Health Physics Research Reactor (HPRR). In the latter case data obtained with the known sources had to be used to find a source yield.

A number of measurements were made with the basic source set. They were made in front of the detector along its axis and at right angles to this axis at positions above 
and below and on either side of the detector. Except in a direction below the detector measurements were made at 10 , $20,40,60$, and 80 centimeters from the detector enclosure. Three independent runs were made at each distance to minimize errors in the distance measurements. The sources were positioned by mounting them in the center of a sheet of paper stretched over a six-inch ring mounted on a ring stand. Below the detector, measurements were made only once, at $10,20,40$, and 60 centimeters. Only one set of measurements were made because a number of other measurements were made with the source on the floor below the detector. In each case, a source was simultaneously measured in each of the five positions. The differences in the energies allowed correlation of each measurement with its proper position. A set of measurements at 10 and 20 centimeters from the estimated center of the detector were also made as a function of angle, in 15 increments. These were made to be used with the floor measurements if the technique of Anspaugh (1972) was used for data reduction. A1 1 of these measurements were made in a low-scatter room at some distance from the insulated thin steel walls and over a floor consisting of thin steel sheets. The low yield of the yttrium-88 and sodium-22 sources 1 imited measurements to 10 and 40 centimeters.

The counts in the peak channel were extracted from the data by a computer program. Numerous programs have 
performed this function and many have been described in previous publications. Most were felt to be too elaborate for this application since they are mostly for nuclear physics applications where the energies to be measured are mostly unknown and the possibility of doublets and triplets must be considered. In this application most of the energies of interest have been well established and do not involve doublets or triplets. The program written for this purpose used a smoothing technique to obtain a second difference of the data. Where this difference value was negative and exceeded its uncertainty by a factor of 2.6 (99 percent confidence) for at least three channels, a weighted average of the channel numbers was made using these data. such a weighted average corresponds to a centroid calculation. With this value for the center of the peak, a point was chosen eight channels on either side and three channels average, to establish a background. By assuming that a linear function described the background, at least over a 17-channel interval, the data were summed and the calculated background subtracted. When this net count was negative, due to two peaks occurring less than 16 channels apart, the interval was decreased and the net counts recalculated. Programs using Gaussian fitting routines were also tested, but the results did not justify the added complication in the data reduction. 
The net counts/second were divided by source yields to obtain counts/gamma ray. These values were averaged using a weighted average based upon a quadratic approach discussed earlier. The effective centers varied considerably but the values of $m$ and a yielded consistent values for $k$. Ultimately the values from the linear approach were used. Besides being somewhat more consistent, the uncertainties in these values could be calculated readily. These uncertainties permitted weighted averages to be made. Moreover, the limited data from yttrium- 88 and sodium-22 could only be handled in a linear fashion and these points were believed to be necessary.

To obtain the values for $k$ at all energies from 100 to $2700 \mathrm{keV}$ a power function was fitted to the data. Although an approximation, it was thought to be consistent with the overall quality of the data.

Calibration of the energy scale was much more precise. When weighted averages of all of the centroid values were used, the coefficients of a quadratic function were obtained from a least squares technique. This function fitted the data to within 0.03 percent over the entire energy range. A 1 inear function also fitted the data to within 0.3 percent so that no effort was made to correct the data for the small fluctuations in energy represented by each channel. 
Experimental Data

Gamma-ray spectra were measured at a wide variety of locations with widely varying sources of natural background. Not all of the measurements were made in geometries suitable for the type of data reduction already discussed. Those that were suitable came from a wide variety of locations: (1) over a concrete slab floor in a metal-sided building, (2) near a field that was charged with cesium-l37 for ecology experiments, (3) over an old radioactive waste storage ground, (4) over the slag pile of a coal mine in Whitley City, Kentucky, (5) at a playground in Bartow, Florida--a city in the midst of the florida phosphate mining region, and (6) at the quarry associated with stone Mountain, Georgia.

All of these data were limited somewhat by the data handling equipment available. These data were obtained in a series of energy intervals using a 512-channel multichannel analyzer. This necessarily piecemeal approach to the data acquisition led to number of problems in reducing the data. The form used for taking the data included a measurement of a cobalt-60 source coupled with nearby setting of a precision pulser as the calibration. Each subsequent set of data was spanned by points recorded from the precision pulser. The centroids and counts in the peaks were obtained from the data using a computer program that operated with the same algorithms used in the 
calibration program described above.

Assuming the precision pulser was linear (a good assumption), it was calibrated by using the pulser peaks associated with the cobalt-60 data to determine a zero channel correction for these data. This correction was used to find a ratio between the measured data and the standard data. With this ratio the exact energies of the pulser peaks were calculated using the quadratic formula determined during the calloration. Hext, ratios of the calculated energies to the energy values on the pulser were obtained. This precisely calibrated the pulser scale to an energy scale. A calibration factor was obtained by averaging the two ratios. It should be noted that precise energy values are not required for the first step of finding the zero correction as long as there is a linear relationship between pulser settings.

For each subsequent set of data in a given run the energy represented by the recorded pulser settings was obtained by using the correction factor to calculate an energy per channel for each data set, these values were coupled with the centrold values found by the computer for the pulser data. To make some allowance for the not quite linear response of the detector as a function of energy, the energy per channel was divided into 1332.5 to find the equivalent peak channel for cobalt-60. A ratio of this value to the calibration peak channel gave a correction 
factor so that the centrofds of unknown peaks could be converted to energles using the quadratic formula. To do so also required using the pulser data to obtain a zero channel correction. It is recognized that divfsion of the cobalt-60 energy by the energy per channel of the data set assumes a linear $E$ versus channel relationship. As a result energy values were considered to have at least a 0.2 percent error.

In all cases the gamma-ray energies were those published in Nuclear Data by Wakat (1971). Thus, the energies calculated were compared with this listing to determine their origin. These data were also correlated with the data of Martin (1970), also in Nuclear Data. This second listing generally correlated well but contained much less information than the first.

Since a uniform deposition of radionuclides in the soil was assumed, the factor

$$
R=\frac{2 \phi k}{\nu_{e}}\left[x \int_{x}^{\infty} \frac{e^{-y}}{y^{2}} d y\right]
$$

where the quantity in brackets is the function commoniy referred to as $E_{2}\left(\mu_{a} D\right)$, was calculated for a number of energies from 100 to $3000 \mathrm{keV}$ (see Table 6). The values for the earth attenuation coefficients were determined from data published by Storm and Israel (1970)

A program in "basic" 
language was used to calculate the $E$ values. $R$ values for the energies in the data were found above 200 keV by a Gaussian backward interpolation technique. Little useable data were obtained below $200 \mathrm{keV}$. The resulting factors were used to determine the gamma rays per cubic centimeter for each observed energy. By including the yield (gammas/decay) for each identified line, a concentration in curies/cubic centimeter could be found and from half-lives a concentration in atoms/cubic centimeter. Some representative final data are shown in Tables 7-13. A surprising number of the observed gamma-ray energies could not be identified as belonging to members of either the uranium-238 or thorium-232 series.

Discussion of Results

In the tables of identiffed gamma rays, the final column should be a constant for any given isotope in a given data set. Considerable deviations exist in the data. Some possible reasons for such differences can be postulated. If the gamma-ray energy was assigned incorrectly, an improper isotope may have been found and thus incorrect values would be obtained. Any errors in calculating the area of the peaks would also show up in proportional errors in these values. The simple summing technique can produce a total that is lower than it should be, when the peak being measured is near to another peak or near the Compton edge of a strong peak. There is some evidence that this might have 
Table 6. Ratio $R$ of Counts in Photopeak to Gamma Rays Emitted Per Cubic Centimeter of Soil

\begin{tabular}{rlllll}
\hline EY & Ha D & $E_{2}(\mu \mathrm{a})$ & ue & $k$ & $R$ \\
\hline 100 & $1.72 \mathrm{E}-3$ & 0.9883 & 0.1008 & 0.7940 & 40.481 \\
150 & 1.89 & 0.9873 & 0.0690 & 0.5596 & 41.637 \\
200 & 2.04 & 0.9865 & 0.0651 & 0.4365 & 34.396 \\
300 & 2.20 & 0.9856 & 0.0661 & 0.3076 & 23.850 \\
400 & 2.26 & 0.9853 & 0.0671 & 0.2400 & 18.326 \\
500 & 2.27 & 0.9852 & 0.0671 & 0.1980 & 15.117 \\
600 & 2.26 & 0.9853 & 0.0671 & 0.1691 & 12.912 \\
800 & 2.21 & 0.9856 & 0.0646 & 0.1320 & 10.472 \\
1000 & 2.14 & 0.9859 & 0.0627 & 0.1088 & 8.896 \\
1500 & 1.96 & 0.9869 & 0.0579 & 0.0767 & 6.798 \\
2000 & 1.82 & 0.9877 & 0.0545 & 0.0598 & 5.636 \\
3000 & $1.61 \mathrm{E}-3$ & 0.9890 & 0.0497 & 0.0422 & 4.367 \\
\hline
\end{tabular}


occurred in some cases. Different sources give a reasonably wide variation of abundance values for a given energy. These uncertainties would have an effect, particularly when low abundance lines were involved. If the data varied with energy in some systematic way, then assumption of uniform distribution might be suspect. In fact, such data might be used to calculate a correct distribution factor. Such does not appear to be the case for these data.

The summary data include weighted means and deviations when more than one line was observed from a given isotope. While the levels that were observed would give considerable weight to the assumption that spectrometry is a technique capable of measuring the low levels being considered for protection around power reactors, the uncertainties in these averaged values may give a somewhat more realistic basis for evaluating the capabilities of the technique. 
Table 7. Identified Gamma Ray Lines at EGCR Site

\begin{tabular}{|c|c|c|c|c|}
\hline EY keV) & $\mathrm{Ci} / \mathrm{cc}$ of $\mathrm{E}_{\gamma}$ & $\begin{array}{l}\text { Probable } \\
\text { Isotope }\end{array}$ & $\gamma /$ Decay & $\mathrm{Ci} / \mathrm{cc}$ of $\mathrm{Soil}$ \\
\hline 330.2 & $1.15 \pm 0.41 \times 10^{-13}$ & ${ }^{234} \mathrm{~Pa}$ & 0.0100 & $1.15 \pm 0.41 \times 10^{-11}$ \\
\hline 352.3 & $1.22 \pm 0.25 \times 10^{-13}$ & ${ }^{214} \mathrm{pb}$ & 0.3600 & $3.39 \pm 0.69 \times 10^{-13}$ \\
\hline 609.5 & $1.43 \pm 0.42 \times 10^{-13}$ & ${ }^{214}{ }_{B j}$ & 0.4700 & $3.04 \pm 0.89 \times 10^{-13}$ \\
\hline 661.3 & $1.34 \pm 0.24 \times 10^{-13}$ & ${ }^{137} \mathrm{Cs}$ & 0.8600 & $1.56 \pm 0.28 \times 10^{-13}$ \\
\hline 787.4 & $2.99 \pm 0.46 \times 10^{-13}$ & $214_{B i}$ & 0.0120 & $2.49 \pm 0.38 \times 10^{-11}$ \\
\hline 1461.0 & $5.06 \pm 0.43 \times 10^{-13}$ & $40_{K}$ & 0.1100 & $4.60 \pm 0.39 \times 10^{-12}$ \\
\hline \multirow[t]{7}{*}{1806.4} & $6.56 \pm 2.54 \times 10^{-14}$ & $212_{B i}$ & 0.0015 & $4.37 \pm 1.69 \times 10^{-11}$ \\
\hline & \multicolumn{4}{|c|}{ Summary } \\
\hline & $214 \mathrm{pb}$ & $3.39 \pm 0.69$ & $\times 10^{-13}$ & $\mathrm{Ci} / \mathrm{CC}$ \\
\hline & ${ }^{214} B i$ & $5.76 \pm 3.17$ & $\times 10^{-13}$ & $\mathrm{Cj} / \mathrm{Cc}$ \\
\hline & $212_{B i}$ & $4.37 \pm 1.69$ & $\times 10^{-11}$ & $\mathrm{Ci} / \mathrm{CC}$ \\
\hline & $40_{K}$ & $4.60 \pm 0.39$ & $\times 10^{-12}$ & $\mathrm{Ci} / \mathrm{cc}$ \\
\hline & ${ }^{137} \mathrm{Cs}$ & $1.56 \pm 0.28$ & $\times 10^{-13}$ & $\mathrm{Ci} / \mathrm{CC}$ \\
\hline
\end{tabular}


Table 8. Identified Gamma Ray Lines at Cesium Field Site

\begin{tabular}{lcccc}
\hline $\mathrm{E}_{\gamma}(\mathrm{keV})$ & $\mathrm{Ci} / \mathrm{cc}$ of $\mathrm{E}_{\gamma}$ & $\begin{array}{c}\text { Probable } \\
\text { Isotope }\end{array}$ & $\gamma /$ Decay & $\mathrm{Ci} / \mathrm{cc}$ of Soil \\
\hline 328.0 & $1.19 \pm 0.62 \times 10^{-13}$ & ${ }^{228} \mathrm{Ac}$ & 0.0530 & $2.25 \pm 1.17 \times 10^{-12}$ \\
351.9 & $2.33 \pm 0.66 \times 10^{-13}$ & ${ }^{214} \mathrm{~Pb}$ & 0.3600 & $6.47 \pm 1.83 \times 10^{-13}$ \\
510.9 & $5.61 \pm 5.16 \times 10^{-14}$ & ${ }^{208} \mathrm{~T} 1$ & 0.0940 & $5.97 \pm 5.49 \times 10^{-13}$ \\
583.7 & $2.90 \pm 0.72 \times 10^{-13}$ & ${ }^{208} \mathrm{~T} 1$ & 0.3100 & $9.35 \pm 2.32 \times 10^{-13}$ \\
609.7 & $2.10 \pm 0.51 \times 10^{-13}$ & ${ }^{214} \mathrm{Bi}$ & 0.7400 & $4.46 \pm 1.09 \times 10^{-13}$ \\
661.5 & $4.48 \pm 0.50 \times 10^{-13}$ & ${ }^{137} \mathrm{Cs}$ & 0.8600 & $5.21 \pm 0.58 \times 10^{-14}$ \\
786.2 & $5.87 \pm 0.64 \times 10^{-13}$ & ${ }^{214} \mathrm{Bi}$ & 0.0120 & $4.89 \pm 0.53 \times 10^{-11}$ \\
910.3 & $1.12 \pm 0.37 \times 10^{-13}$ & ${ }^{210} \mathrm{~T} 1$ & 0.0300 & $3.73 \pm 1.23 \times 10^{-12}$ \\
954.9 & $6.46 \pm 0.70 \times 10^{-13}$ & $2122_{\mathrm{Bi}}$ & 0.0032 & $2.02 \pm 0.22 \times 10^{-10}$ \\
1461.1 & $1.20 \pm 0.06 \times 10^{-12}$ & ${ }^{40} \mathrm{~K}$ & 0.1100 & $1.09 \pm 0.05 \times 10^{-11}$
\end{tabular}

Summary

$$
\begin{array}{ll}
{ }^{214} \mathrm{~Pb} & 6.47 \pm 1.83 \times 10^{-13} \mathrm{Cj} / \mathrm{cc} \\
{ }^{214} \mathrm{Bi} & 4.66 \pm 9.96 \times 10^{-13} \mathrm{Ci} / \mathrm{cc} \\
{ }^{210} \mathrm{~T} 1 & 3.73 \pm 1.23 \times 10^{-12} \mathrm{Ci} / \mathrm{cc} \\
{ }^{228} \mathrm{Ac} & 2.25 \pm 1.17 \times 10^{-12} \mathrm{Ci} / \mathrm{cc} \\
{ }^{212} \mathrm{Bi} & 2.02 \pm 0.22 \times 10^{-10} \mathrm{Ci} / \mathrm{cc} \\
{ }^{208} \mathrm{~T} 1 & 8.84 \pm 1.21 \times 10^{-13} \mathrm{Ci} / \mathrm{cc} \\
{ }^{40} \mathrm{~K} & 1.09 \pm 0.05 \times 10^{-11} \mathrm{Ci} / \mathrm{cc} \\
{ }^{137} \mathrm{Cs} & 5.21 \pm 0.58 \times 10^{-14} \mathrm{Ci} / \mathrm{cc}
\end{array}
$$


Table 9. Identified Gamma Ray Lines at Storage Area Site

$E_{\gamma}(\mathrm{keV}) \quad \mathrm{Ci} / \mathrm{cc}$ of $\mathrm{E}_{\gamma} \quad \begin{aligned} & \text { Probable } \\ & \text { Isotope }\end{aligned} \quad \mathrm{d} /$ Decay $\quad \mathrm{Ci} / \mathrm{cc}$ of Soil

\begin{tabular}{lllll}
\hline $238.1 *$ & $3.44 \pm 0.70 \times 10^{-13}$ & ${ }^{212} \mathrm{~Pb}$ & 0.4700 & $7.32 \pm 1.49 \times 10^{-13}$ \\
293.4 & $1.49 \pm 0.42 \times 10^{-13}$ & ${ }^{234} \mathrm{~Pa}$ & 0.0420 & $3.55 \pm 1.00 \times 10^{-12}$ \\
$339.3^{*}$ & $1.08 \pm 0.57 \times 10^{-13}$ & ${ }^{228} \mathrm{Ac}$ & 0.1500 & $7.20 \pm 3.80 \times 10^{-13}$ \\
352.1 & $2.52 \pm 0.41 \times 10^{-13}$ & $214 \mathrm{~Pb}$ & 0.3600 & $7.00 \pm 1.14 \times 10^{-13}$ \\
510.3 & $1.70 \pm 0.38 \times 10^{-13}$ & ${ }^{208} \mathrm{Tl}$ & 0.0940 & $1.81 \pm 0.40 \times 10^{-12}$ \\
583.7 & $2.82 \pm 0.55 \times 10^{-13}$ & ${ }^{208} \mathrm{Tl}$ & 0.3100 & $9.10 \pm 1.77 \times 10^{-13}$ \\
609.7 & $3.95 \pm 0.57 \times 10^{-13}$ & ${ }^{214} \mathrm{~Pb}$ & 0.4700 & $8.40 \pm 1.21 \times 10^{-13}$ \\
661.4 & $3.19 \pm 0.09 \times 10^{-12}$ & ${ }^{137} \mathrm{Cs}$ & 0.8600 & $3.71 \pm 0.10 \times 10^{-12}$ \\
727.2 & $4.44 \pm 4.24 \times 10^{-14}$ & ${ }^{212} \mathrm{Bi}$ & 0.0720 & $6.17 \pm 5.89 \times 10^{-13}$ \\
911.2 & $2.57 \pm 0.31 \times 10^{-13}$ & ${ }^{210} \mathrm{Tl}$ & 0.0300 & $8.57 \pm 1.03 \times 10^{-12}$ \\
1240.2 & $8.93 \pm 4.46 \times 10^{-14}$ & $214 \mathrm{Bi}$ & 0.0600 & $1.49 \pm 0.74 \times 10^{-12}$ \\
1462.0 & $6.99 \pm 0.59 \times 10^{-13}$ & ${ }^{40} \mathrm{~K}$ & 0.1100 & $6.35 \pm 0.54 \times 10^{-12}$ \\
1767.4 & $2.02 \pm 0.33 \times 10^{-13}$ & $214 \mathrm{Bi}$ & 0.1700 & $1.19 \pm 0.19 \times 10^{-12}$ \\
2617.5 & $4.21 \pm 0.43 \times 10^{-13}$ & $208 \mathrm{Tl}$ & 0.3600 & $1.17 \pm 0.12 \times 10^{-12}$
\end{tabular}

Summary

$$
\begin{array}{ll}
{ }^{234} \mathrm{~Pa} & 3.55 \pm 1.00 \times 10^{-12} \mathrm{Ci} / \mathrm{cc} \\
{ }^{214} \mathrm{~Pb} & 7.00 \pm 1.14 \times 10^{-13} \mathrm{Ci} / \mathrm{cc} \\
{ }^{214} \mathrm{Bi} & 9.51 \pm 1.74 \times 10^{-13} \mathrm{Ci} / \mathrm{cc} \\
{ }^{210} \mathrm{Tl} & 8.57 \pm 1.03 \times 10^{-12} \mathrm{Ci} / \mathrm{cc}
\end{array}
$$

(Cont'd.) 
Table 9. (Cont'd.)

$$
\begin{array}{lc} 
& \text { Summary } \\
{ }^{228} \mathrm{Ac} & 7.20 \pm 3.80 \times 10^{-13} \mathrm{Ci} / \mathrm{cc} \\
212 \mathrm{~Pb} & 7.32 \pm 1.49 \times 10^{-13} \mathrm{Ci} / \mathrm{cc} \\
{ }^{212} \mathrm{Bi} & 6.17 \pm 5.89 \times 10^{-13} \mathrm{Ci} / \mathrm{cc} \\
{ }^{208} \mathrm{~T} 1 & 1.13 \pm 0.21 \times 10^{-12} \mathrm{Ci} / \mathrm{cc} \\
{ }^{40} \mathrm{~K} & 6.35 \pm 0.54 \times 10^{-12} \mathrm{Ci} / \mathrm{cc} \\
{ }^{137} \mathrm{Cs} & 3.71 \pm 0.10 \times 10^{-12} \mathrm{ci} / \mathrm{cc}
\end{array}
$$

*The isotope corresponding to this energy could not be positively identified for an as $\$$ ciated energy uncertainty of $\pm 0.2 \%$ but apparently could be positively identified for an energy uncertainty of $\pm 0.4 \%$. 
Table 10. Identified Gamma Ray Lines at Whitley City, Ky., Site

\begin{tabular}{|c|c|c|}
\hline$E_{\gamma}(\mathrm{keV})$ & $\mathrm{Ci} / \mathrm{cc}$ of $\mathrm{E}_{\gamma}$ & $\begin{array}{l}\text { Probable } \\
\text { Isntone }\end{array}$ \\
\hline
\end{tabular}

$$
235.9
$$

$$
2.64 \pm 0.47 \times 10^{-13} \quad 234 \mathrm{~m}_{\mathrm{Pa}}
$$

241.3

$$
1.61 \pm 0.24 \times 10^{-13} \quad{ }^{224} \mathrm{Ra}
$$

0.0370

$4.35 \pm 0.65 \times 10^{-12}$

$294.78 .41 \pm 1.60 \times 10^{-14}$

$214 \mathrm{~Pb}$

0.1900

$4.43 \pm 0.84 \times 10^{-13}$

338

$5.69 \pm 2.12 \times 10^{-14} \quad{ }^{228} \mathrm{AC} \quad 0.1500 \quad 3.79 \pm 1.41 \times 10^{-13}$

352.1

$2.31 \pm 0.20 \times 10^{-13} \quad 214 \mathrm{~Pb}$

0.3600

$6.42 \pm 0.56 \times 10^{-13}$

$510.8 * 7.17 \pm 1.47 \times 10^{-14} \quad{ }^{208} \mathrm{Tl}$

0.0940

$7.63 \pm 2.63 \times 10^{-13}$

584.5

$$
1.47 \pm 0.29 \times 10^{-13}{ }^{208} \mathrm{~T}
$$

0.3100

$4.74 \pm 0.94 \times 10^{-13}$

610.2

$$
3.97 \pm 0.30 \times 10^{-13}
$$

${ }^{214} \mathrm{Bi}$

0.4700

$8.45 \pm 0.64 \times 10^{-13}$

$723.2 *$

$$
1.25 \pm 0.41 \times 10^{-13}
$$

${ }^{214} \mathrm{Bi}$

0.0070

$1.79 \pm 0.59 \times 10^{-11}$

767.6

$$
1.71 \pm 0.34 \times 10^{-13}
$$

${ }^{214} \mathrm{Bi}$

0.0500

$3.42 \pm 0.68 \times 10^{-12}$

$836.57 .41 \pm 0.72 \times 10^{-13}$

${ }^{214} \mathrm{Bi}$

0.0080

$9.26 \pm 0.90 \times 10^{-11}$

911.

$$
2.08 \pm 0.42 \times 10^{-13}
$$

${ }^{210} \mathrm{Tl}$

0.0300

$6.93 \pm 1.40 \times 10^{-12}$

966.8

$$
4.65 \pm 4.18 \times 10^{-14}
$$

${ }^{228}$ AC

0.2000

$2.32 \pm 2.09 \times 10^{-13}$

$1002.4 \quad 1.05 \pm 0.07 \times 10^{-12} \quad 234 \mathrm{~m} \mathrm{~Pa} \quad 0.0060$

$1.75 \pm 0.12 \times 10^{-10}$

1120.2

$$
1.44 \pm 0.47 \times 10^{-13}
$$

$214 \mathrm{Bi}$

0.1700

$8.47 \pm 2.76 \times 10^{-13}$

$1441.5^{*} \quad 1.36 \pm 0.46 \times 10^{-13}$

${ }^{214} \mathrm{Bi} \quad 0.0020$

$6.80 \pm 2.30 \times 10^{-11}$

$1462.89 .07 \pm 0.79 \times 10^{-13}$

${ }^{40} \mathrm{~K} \quad 0.1100$

$8.25 \pm 0.72 \times 10^{-12}$

2611.7

$$
2.15 \pm 0.22 \times 10^{-13} \quad{ }^{208} \mathrm{Tr} \quad 0.3600 \quad \frac{5.97 \pm 0.61 \times 10^{-13}}{(\text { Cont'd. })}
$$




\section{5}

Table 10. (Cont'd)

\section{Summary}

$$
\begin{array}{ll}
234 \mathrm{~m}_{\mathrm{Pa}} & 1.75 \pm 0.12 \times 10^{-10} \mathrm{Ci} / \mathrm{cc} \\
214_{\mathrm{Pb}} & 5.81 \pm 0.92 \times 10^{-13} \mathrm{Ci} / \mathrm{cc} \\
214_{\mathrm{Bi}} & 8.73 \pm 7.21 \times 10^{-13} \mathrm{Ci} / \mathrm{cc} \\
210_{\mathrm{T}} & 6.93 \pm 1.40 \times 10^{-12} \mathrm{Ci} / \mathrm{cc} \\
{ }^{228_{\mathrm{AC}}} & 3.33 \pm 0.68 \times 10^{-13} \mathrm{Ci} / \mathrm{cc} \\
{ }^{224} \mathrm{Ra} & 4.35 \pm 0.65 \times 10^{-12} \mathrm{Ci} / \mathrm{cc} \\
{ }^{208} \mathrm{Tl} & 5.68 \pm 0.67 \times 10^{-13} \mathrm{Ci} / \mathrm{cc} \\
40_{\mathrm{K}} & 8.25 \pm 0.72 \times 10^{-12} \mathrm{Ci} / \mathrm{cc}
\end{array}
$$

*The isotope corresponding to this energy could not be positively identified for an associated energy uncertainty of $\pm 0.2 \%$ but apparently could be positively identified for an energy uncertainty of $\pm 0.4 \%$. 
Table 11. Identified Gamma Ray Lines at Atlantic Beach, Fla., Site Ey $(\mathrm{keV}) \quad \mathrm{Ci} / \mathrm{cc}$ of $\mathrm{E}_{\gamma} \quad \begin{aligned} & \text { Probable } \\ & \text { Isotope }\end{aligned} \gamma /$ Decay $\quad \mathrm{Ci} / \mathrm{cc}$ of Soil

\begin{tabular}{|c|c|c|c|c|}
\hline $473.3^{*}$ & $1.41 \pm 0.75 \times 10^{-13}$ & ${ }^{226} \mathrm{Ra}$ & 0.0008 & $1.76 \pm 0.94 \times 10^{-10}$ \\
\hline $486.1^{*}$ & $7.69 \pm 3.27 \times 10^{-14}$ & $214 \mathrm{~Pb}$ & 0.0033 & $2.33 \pm 0.99 \times 10^{-11}$ \\
\hline 511.1 & $2.28 \pm 0.46 \times 10^{-13}$ & ${ }^{208} \mathrm{Tl}$ & 0.0940 & $2.43 \pm 0.49 \times 10^{-12}$ \\
\hline $581.5^{*}$ & $4.06 \pm 0.49 \times 10^{-13}$ & ${ }^{208} \mathrm{Tl}$ & 0.3100 & $1.31 \pm 0.16 \times 10^{-12}$ \\
\hline $607.4^{*}$ & $7.38 \pm 0.42 \times 10^{-13}$ & $214_{B i}$ & 0.4700 & $1.57 \pm 0.09 \times 10^{-12}$ \\
\hline 718.9 & $1.73 \pm 0.11 \times 10^{-12}$ & ${ }^{226} \mathrm{Ra}$ & 0.0042 & $4.12 \pm 0.26 \times 10^{-10}$ \\
\hline 733.7 & $1.30 \pm 0.77 \times 10^{-13}$ & ${ }^{234} \mathrm{~Pa}$ & 0.0900 & $1.44 \pm 0.86 \times 10^{-12}$ \\
\hline $912.3 *$ & $2.98 \pm 1.32 \times 10^{-13}$ & ${ }^{210} \mathrm{Tl}$ & 0.0300 & $9.93 \pm 4.40 \times 10^{-12}$ \\
\hline 934.4 & $2.10 \pm 0.13 \times 10^{-12}$ & $214_{B i}$ & 0.0300 & $7.00 \pm 0.43 \times 10^{-11}$ \\
\hline $969.2^{\star}$ & $2.95 \pm 0.62 \times 10^{-13}$ & $228_{A C}$ & 0.2000 & $1.48 \pm 0.31 \times 10^{-12}$ \\
\hline $1116.7^{*}$ & $3.11 \pm 0.53 \times 10^{-13}$ & ${ }^{214_{B i}}$ & 0.1700 & $1.83 \pm 0.31 \times 10^{-12}$ \\
\hline 1404.0 & $2.43 \pm 0.93 \times 10^{-13}$ & $214_{B i}$ & 0.0170 & $1.43 \pm 0.55 \times 10^{-11}$ \\
\hline 1460.0 & $2.70 \pm 0.15 \times 10^{-12}$ & $40 \mathrm{~K}$ & 0.1100 & $2.45 \pm 0.14 \times 10^{-11}$ \\
\hline 1761.6 & $3.37 \pm 0.38 \times 10^{-13}$ & $214_{B i}$ & 0.1700 & $1.98 \pm 0.22 \times 10^{-12}$ \\
\hline 2616.9 & $7.94 \pm 0.45 \times 10^{-13}$ & ${ }^{208} \mathrm{~T} 1$ & 0.3600 & $2.21 \pm 0.12 \times 10^{-12}$ \\
\hline
\end{tabular}


Table 11. (Cont'd.)

$$
\begin{aligned}
& \text { Summary } \\
& { }^{234} \mathrm{~Pa} \quad 1.44 \pm 0.86 \times 10^{-12} \mathrm{Ci} / \mathrm{CC} \\
& { }^{226} \mathrm{Ra} 3.95 \pm 0.61 \times 10^{-10} \mathrm{ci} / \mathrm{cc} \\
& { }^{214} \mathrm{pb} \quad 2.33 \pm 0.99 \times 10^{-11} \mathrm{Ci} / \mathrm{cc} \\
& { }^{214^{B i}} \quad 1.67 \pm 1.30 \times 10^{-12} \mathrm{ci} / \mathrm{cc} \\
& { }^{210} \mathrm{T1} 9.93 \pm 4.40 \times 10^{-12} \mathrm{Ci} / \mathrm{cc} \\
& { }^{228} 8_{\mathrm{AC}} \quad 1.48 \pm 0.31 \times 10^{-12} \mathrm{Ci} / \mathrm{cc} \\
& { }^{208} \mathrm{T1} 1.91 \pm 0.44 \times 10^{-12} \mathrm{Ci} / \mathrm{cc} \\
& { }^{40} \mathrm{~K} \quad 2.45 \pm 0.14 \times 10^{-11} \mathrm{Ci} / \mathrm{cc}
\end{aligned}
$$

*The isotope corresponding to this energy could not be positively identi. fied for an associated energy uncertainty of $\pm 0.2 \%$ but apparentily could be positively identified for an energy uncertainty of $\pm 0.4 \%$. 
TabTe 12. Identified Gamma Ray Lines at Bartow, Fla., Site [Second Run (Playground)]

\begin{tabular}{|c|c|c|c|c|}
\hline$E_{\gamma}(\mathrm{keV})$ & $\mathrm{Ci} / \mathrm{Cc}$ of $\mathrm{EY}_{Y}$ & $\begin{array}{l}\text { Probable } \\
\text { Isotope }\end{array}$ & $\gamma /$ Decay & $\mathrm{Ci} / \mathrm{Cc}$ of $\mathrm{S}$ \\
\hline 240. & $1.08 \pm 0.29 \times 10^{-12}$ & ${ }^{224} \mathrm{Ra}$ & 0.0370 & $2.92 \pm 0.78 \times 10^{-11}$ \\
\hline 293.5 & $2.15 \pm 0.12 \times 10^{-12}$ & ${ }^{234} \mathrm{~Pa}$ & 0.0420 & $.12 \pm 0.29 \times 10^{-11}$ \\
\hline 351. & $3.94 \pm 0.20 \times 10^{-12}$ & 21 & 0.3600 & $1.09 \pm 0.06 \times 10^{-11}$ \\
\hline 609.9 & $7.02 \pm 0.25 \times 10^{-12}$ & 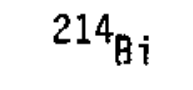 & 0.4700 & $1.49 \pm 0.05 \times 10^{-11}+$ \\
\hline $724.8 *$ & $3.56 \pm 1.28 \times 10^{-13}$ & 21 & 0.0720 & $4.94 \pm 1.78 \times 10^{-12}$ \\
\hline 767.8 & $9.15 \pm 1.91 \times 10^{-13}$ & & 0.0500 & $1.83 \pm 0.38 \times 10^{-11}$ \\
\hline 936.3 & $3.98 \pm 1.81 \times 10^{-13}$ & & 0.0300 & $1.33 \pm 0.60 \times 10^{-11}$ \\
\hline 124.7 & $2.71 \pm 0.14 \times 10^{-12}$ & & 0 . & $1.59 \pm 0.08 \times 10^{-10}$ \\
\hline 9. & $3.35 \pm 1.07 \times 10^{-13}$ & & 180 & $1.86 \pm 0.59 \times 10^{-11}$ \\
\hline 40.0 & $1.27 \pm 0.11 \times 10^{-12}$ & & 00 & $2.12 \pm 0.18 \times 10^{-11}$ \\
\hline 81. & $7.81 \pm 0.76 \times 10^{-13}$ & & 500 & $1.56 \pm 0.15 \times 10^{-11}$ \\
\hline 18 & $2.00 \pm 0.86 \times 10^{-13}$ & & 0.0500 & $4.00 \pm 1.72 \times 10^{-12}$ \\
\hline 11.2 & $5.67 \pm 0.72 \times 10^{-13}$ & & 200 & $2.84 \pm 0.36 \times 10^{-11}$ \\
\hline 564.2 & $1.06 \pm 0.58 \times 10^{-13}$ & & 20 & $8.83 \pm 4.83 \times 10^{-12}$ \\
\hline 730.7 & $6.06 \pm 0.55 \times 10^{-13}$ & & 300 & $2.02 \pm 0.18 \times 10^{-11}$ \\
\hline 764.4 & $3.21 \pm 0.09 \times 10^{-12}$ & & 0.1700 & $1.89 \pm 0.05 \times 10^{-11}$ \\
\hline $852.5^{\star}$ & $5.25 \pm 0.45 \times 10^{-13}$ & & 0.0200 & $2.62 \pm 0.22 \times 10^{-11}$ \\
\hline $124.7 *$ & $2.60 \pm 0.26 \times 10^{-13}$ & & 0.0100 & $2.60 \pm 0.26 \times 10^{-11}$ \\
\hline 08.3 & $1.04 \pm 0.04 \times 10^{-12}$ & & 0.0500 & $2.08 \pm 0.08 \times 10^{-11}$ \\
\hline 0.4 & $2.95 \pm 0.39 \times 10^{-13}$ & & 0.0165 & $1.79 \pm 0.24 \times 10^{-11}$ \\
\hline & $1.98 \pm 0.31 \times 10^{-14}$ & & 0.3600 & $5.50 \pm 0.86 \times 10^{-14}$ \\
\hline
\end{tabular}

(Cont'd.) 
Table 12. (Cont'd.)

Summary

$$
\begin{array}{ll}
{ }^{234} \mathrm{~Pa} & 6.37 \pm 3.45 \times 10^{-11} \mathrm{Ci} / \mathrm{cc} \\
226 \mathrm{Ra} & 1.79 \pm 0.24 \times 10^{-11} \mathrm{Ci} / \mathrm{cc} \\
{ }^{214} \mathrm{~Pb} & 1.09 \pm 0.06 \times 10^{-11} \mathrm{Ci} / \mathrm{cc} \\
214 \mathrm{Bi} & 1.79 \pm 0.29 \times 10^{-11} \mathrm{Cj} / \mathrm{cc} \\
{ }^{210} \mathrm{Tl} & 4.00 \pm 1.72 \times 10^{-12} \mathrm{Ci} / \mathrm{cc} \\
{ }^{224} \mathrm{Ra} & 2.92 \pm 0.78 \times 10^{-11} \mathrm{Ci} / \mathrm{cc} \\
{ }^{212} \mathrm{Bi} & 4.94 \pm 1.78 \times 10^{-12} \mathrm{Ci} / \mathrm{cc} \\
{ }^{208} \mathrm{Tl} & 5.50 \pm 0.86 \times 10^{-14} \mathrm{Ci} / \mathrm{cc}
\end{array}
$$

*The isotope corresponding to this energy could not be positively identified for an associated energy uncertainty of $\pm 0.2 \%$ but apparently could be positively identified for an energy uncertainty of $\pm 0.4 \%$.

this concentration assumes no contribution from the first escape line, $1120.4 \mathrm{keV}$, of bismuth-214. 
Table 13. Identified Gamma Ray Lines at Stone Mountain, Ga., Site

\begin{tabular}{|c|c|c|c|c|}
\hline$E_{\gamma}(\mathrm{keV})$ & $\mathrm{Ci} / \mathrm{Cc}$ of $\mathrm{E}_{\gamma}$ & $\begin{array}{l}\text { Probable } \\
\text { Isotope }\end{array}$ & $r /$ Decay & $\mathrm{Ci} / \mathrm{cc}$ of Soil \\
\hline 293.4 & $6.16 \pm 0.72 \times 10^{-13}$ & ${ }^{234} \mathrm{~Pa}$ & 0.0420 & $1.47 \pm 0.17 \times 10^{-11}$ \\
\hline $352.8^{*}$ & $1.58 \pm 0.11 \times 10^{-12}$ & 214 & 0.3600 & $4.39 \pm 0.31 \times 10^{-12}$ \\
\hline 822.4 & $6.36 \pm 1.50 \times 10^{-13}$ & & 0.0016 & $3.98 \pm 0.94 \times 10^{-10}$ \\
\hline 898.8 & $2.64 \pm 0.23 \times 10^{-12}$ & & 0.0410 & $6.44 \pm 0.56 \times 10^{-11}$ \\
\hline $936.7 *$ & $9.23 \pm 1.49 \times 10^{-13}$ & & 0.0300 & $3.08 \pm 0.50 \times 10^{-11}$ \\
\hline $1081.5^{*}$ & $1.69 \pm 1.00 \times 10^{-13}$ & & 0.0043 & $3.93 \pm 2.33 \times 10^{-11}$ \\
\hline $1112.9 *$ & $3.64 \pm 0.17 \times 10^{-12}$ & & 0.0700 & $5.20 \pm 0.24 \times 10^{-11}$ \\
\hline 1125.3 & $9.80 \pm 1.50 \times 10^{-13}$ & & 0.0170 & $5.76 \pm 0.88 \times 10^{-11}$ \\
\hline $1158.1 *$ & $3.81 \pm 1.46 \times 10^{-13}$ & & 0.0180 & $2.12 \pm 0.81 \times 10^{-11}$ \\
\hline $1381.4^{*}$ & $3.27 \pm 0.98 \times 10^{-13}$ & & 0.0500 & $6.54 \pm 1.96 \times 10^{-12}$ \\
\hline $1463.4^{\star}$ & $3.92 \pm 0.13 \times 10^{-12}$ & & 0.1100 & $3.56 \pm 0.12 \times 10^{-11}$ \\
\hline 1510.2 & $1.33 \pm 0.57 \times 10^{-13}$ & & 0.0200 & $6.65 \pm 2.85 \times 10^{-12}$ \\
\hline 1649.7 & $2.67 \pm 0.80 \times 10^{-13}$ & & 0.0200 & $1.34 \pm 0.40 \times 10^{-11}$ \\
\hline 1680.6 & $6.29 \pm 5.96 \times 10^{-14}$ & $214_{B}$ & 0.0020 & $3.14 \pm 2.98 \times 10^{-11}$ \\
\hline 1765.3 & $9.32 \pm 0.78 \times 10^{-13}$ & & 0.1700 & $5.48 \pm 0.46 \times 10^{-12}$ \\
\hline 2205.3 & $3.10 \pm 0.34 \times 10^{-13}$ & & 0.0500 & $6.20 \pm 0.68 \times 10^{-12}$ \\
\hline 2612.3 & $2.17 \pm 0.22 \times 10^{-13}$ & & 0.3600 & $6.02 \pm 0.61 \times 10^{-13}$ \\
\hline
\end{tabular}

Summary

$$
\begin{array}{ll}
{ }^{234} \mathrm{~Pa} & 2.02 \pm 1.52 \times 10^{-11} \mathrm{Ci} / \mathrm{cc} \\
214 \mathrm{~Pb} & 4.39 \pm 0.31 \times 10^{-12} \mathrm{ci} / \mathrm{cc} \\
214 \mathrm{Bi} & 5.93 \pm 2.55 \times 10^{-12} \mathrm{Ci} / \mathrm{cc}
\end{array}
$$

(Cont'd.) 
Table 13. (Cont'd.)

$$
\begin{array}{lc} 
& \text { Summary } \\
210 \mathrm{T1} & 4.18 \pm 1.70 \times 10^{-11} \mathrm{Ci} / \mathrm{cc} \\
212 \mathrm{Bi} & 3.93 \pm 2.33 \times 10^{-11} \mathrm{Ci} / \mathrm{cc} \\
208 \mathrm{~T} 1 & 6.02 \pm 0.61 \times 10^{-13} \mathrm{Ci} / \mathrm{Cc} \\
{ }^{40} \mathrm{~K} & 3.56 \pm 0.12 \times 10^{-11} \mathrm{Ci} / \mathrm{CC}
\end{array}
$$

*The isotope corresponding to this energy could not be positively identified for an associated energy uncertainty of $\pm 0.2 \%$ but apparently could be positively identified for an energy uncertainty of $\pm 0.4 \%$. 


\section{CHAPTER II I}

\section{EMANATION OF RADON FROM CONCRETE}

\section{Theory}

Radon-222, formed in the decay of uranium-238 (see Chapter I), can escape into the atmosphere from the earth's crust and from various building materials. Once in the atmosphere the radon-222 will decay into the heavy metal elements; radium-A (polonium-218) with 3.05 minute halflife, radium-B (lead-214) with a 26.8 minute half-life, radium-C (bismuth-214) with a 19.7 minute half-life, and radium-C' (polonium-214) with a 150 microsecond half-life. These short half-life atoms, when present in suffictent concentrations, represent an inhalation hazard to man. These concentrations can be estimated by measuring the alpha particle activity from air drawn through a dust particle membrane filter. In developing the equations descriptive of the time dependence of the collection and assay of the alpha particle activity of the dust on the membrane filter, the 7.69 HeV alpha particle emitted by decay of RaC' is included in the decay of RaC. Because of the short half-life of ?ac' (150 microseconds), compared to the 19.7 minute halflife of ths precursor, RaC, this alpha particle activity can be attributed to RaC for mathematical convenience though it 
will be shown in the data as Rac'. If the dust sample is assayed within a few minutes after termination of the collection of the sample, the 6.0 HeV alpha particles produced from decay of RaA will also be observed. This activity is characteristic of the 3.05 minute half-ife of the RaA.

From the wel1-known characteristics of radioactivity decay (Rutherford 1904 ), the number of decays $\left(\mathrm{dn}_{i}\right)$ of a particular radionuclide is equal to the number of nuclei $\left(n_{j}\right)$, times the decay constant $\left(\lambda_{j}\right)$ which characterizes the instability of the nucleus according to the fractional decay per unit time, multiplied by the differential time interval $(d t), i, e$, ,

$$
d n_{i}(t)=-\lambda n_{i}(t) d t
$$

and the time rate of radioactive decay can then be expressed in the form of

$$
\frac{d n_{i}(t)}{d t}=-\lambda_{i} n_{i}(t)
$$

The decay constant is equal to $0.693 / T_{i}$ where $T_{i}$ 
is the half-life of the particular radionuclide of interest. In this study it is desirable to know the number of radon daughter atoms of a specific type collected on a membrane filter having a flow rate of $v$ liters per unit time if $q$ is the air concentration of the radon in atoms per liter. Assume that the decay chain has the form $A \rightarrow B \rightarrow C$ where $A, B$, and $C$ represent the radon daughters formed successively in the uranium decay chain. Then, the number of atoms of RaA collected on the filter is

$$
d n_{A}(t)=q_{A} \cdot v \cdot d t-\lambda_{A} n_{A}(t) d t
$$

where $q_{A} \cdot v$. dt is the number of atoms collected from the air in time $d t$ and $\lambda_{A} n_{A} d t$ is the number of atoms of $R a A$ decaying to $R a B$ daughter in the time $d t$ assuming 100 percent collection efficiency. The time rate of collection is

$$
\frac{d n_{A}(t)}{d t}=q_{A} \cdot v-\lambda_{A} n_{A}(t)
$$


Likewise, the observed number of atoms of RaB is the number Which the membrane collects from the air $\left(q_{B} \cdot v \cdot d t\right)$, plus those produced by the decay of $R a A,\left({ }_{A_{A}}{ }^{n} d t\right)$, winus the number decaying to $R a C$ in elapsed time $d t\left(q_{B} n_{B} d t\right)$, while the sample is being collected, f.e.,

$$
d n_{B}(t)=q_{B} \cdot v \cdot d t+\lambda_{A} n_{A}(t) d t-\lambda_{B} n_{B}(t) d t
$$

and the time rate of decay is

$$
\frac{d n_{B}(t)}{d t}=q_{B} v+\lambda_{A} n_{A}(t)-\lambda_{B} n_{B}(t)
$$

This technique can be extended to the ith atom in the decay chain and the corresponding time rate of decay is

$$
\frac{d n_{j}(t)}{d t}=q_{j} v+\lambda_{i-1} n_{i-1}(t)-\lambda_{i} n_{i}(t)
$$


which is a linear differential equation of the first order, 1.e..

$$
\frac{d y}{d x}+\alpha y=f(x) \text {, }
$$

and has a general solution of the form

$$
y=e^{-\alpha x}\left[y_{0}+\int f(x) e^{\alpha x} d x\right] .
$$

Boundary conditions are established by assuming that no nuclei are collected if the sample time is zero, i.e., $n=$ 0 if $t=0$.

The solution of Equation (22) according to Equation(24) for the first three radon daughters yields 
RaA

$$
n_{A}(t)=q_{A} v\left[\frac{1-e^{-\lambda_{A} t}}{\lambda_{A}}\right] \text {, }
$$

$\operatorname{RaB} \quad n_{B}(t)=q_{A} v\left[\frac{1-e^{-\lambda_{B} t}}{\lambda_{B}}+\frac{e^{-\lambda_{B} t}-e^{-\lambda_{A} t}}{\lambda_{B}-\lambda_{A}}\right]+q_{B} v\left[\frac{1-e^{-\lambda_{B} t}}{\lambda_{B}}\right]$,

and $\operatorname{RaC} n_{C}(t)=q_{A} v\left[\frac{1-e^{-\lambda} C^{t}}{{ }^{\lambda_{C}}}+\frac{e^{-\lambda_{C} t}-e^{-\lambda_{B} t}}{{ }^{\lambda_{C}}-\lambda_{B}}+\frac{\lambda_{B} e^{-\lambda_{B} t}}{\left(\lambda_{B}-\lambda_{A}\right)\left(\lambda_{C}-\lambda_{B}\right)}\right.$

$+a_{B} v\left[\frac{e^{-\lambda} C^{t}-e^{-\lambda} B t}{\left(\lambda_{C}-\lambda_{B}\right)}+\frac{1-e^{-\lambda} C^{t}}{{ }^{\lambda} C}\right]+q_{C} v\left[\frac{1-e^{-\lambda} C^{t}}{{ }^{\lambda} C}\right]$.

$\left.-\frac{\lambda_{B} e^{-\lambda_{A} t}}{\left(\lambda_{B}-\lambda_{A}\right)\left(\lambda_{C}-\lambda_{A}\right)}-\frac{\lambda_{B} e^{-\lambda_{C} t}}{\left(\lambda_{C}-\lambda_{B}\right)\left(\lambda_{C}-\lambda_{A}\right)}\right]$ 
A physical interpretation of Equation (25) can be obtained if one considers qut to be the number of atoms caught by the collection membrane if the nuclide does not undergo radioactive decay. The survival probability of a number of radioactive atoms $n_{0}$ over a time $t$ can be written as

$$
\frac{n}{n_{0}}=e^{-\lambda t}
$$

where $n$ is the number of undecayed radioactive nuclei after elapsed time $t$. It must be emphasized that $n$ must be sufficiently large to insure small statistical deviations. These statistical deviations are due to the random nature of spontaneous decay. If this survival probability is averaged over the entire time the sample is being collected $(t)$, then the mean survival probability is

$$
\frac{\int_{0}^{t} e^{-\lambda t} d t}{\int_{0}^{t} d t}=\frac{1}{\lambda t}\left(1-e^{-\lambda t}\right)
$$


and it is easily seen that Equation (25) is simply the product of the number of radioactive atoms collected by the membrane ( $q v t$ ) and the mean survival probability of the collected radioactive atoms.

The set of equations described by Equation (22) can be written in matrix notation as

$$
N=V L Q
$$

or

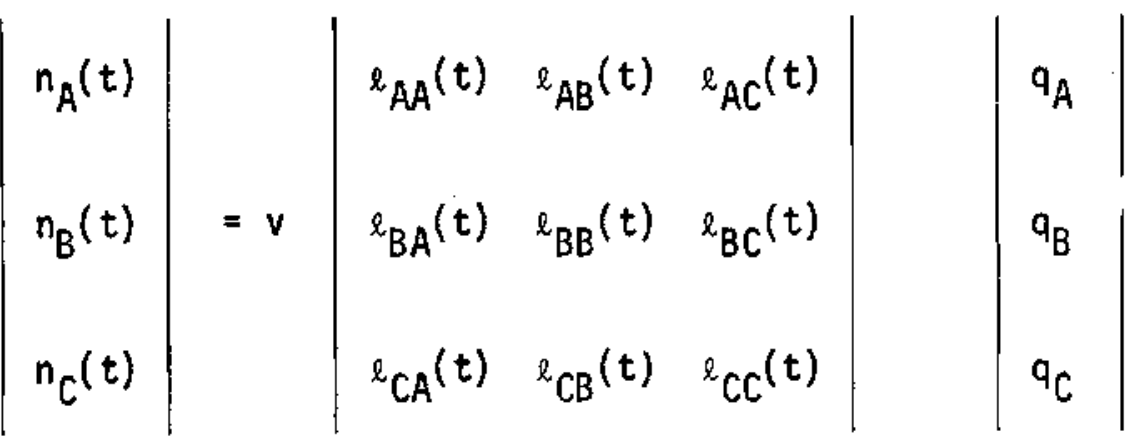


where

$$
\begin{aligned}
& \ell_{A A}(t)=\frac{1-e^{-\lambda_{A} t}}{\lambda_{A}} \text {, } \\
& { }^{\ell_{A B}}(t)=0, \\
& { }^{e_{A C}}(t)=0, \\
& l_{B A}(t)=\frac{1-e^{-\lambda_{B} t}}{\lambda_{B}}+\frac{e^{-\lambda_{B} t}-e^{-\lambda_{A} t}}{\left(\lambda_{B}-\lambda_{A}\right)} \text {. } \\
& \ell_{B B}(t)=\frac{1-e^{-\lambda_{B} t}}{\lambda_{B}} \text {, } \\
& \ell_{B C}(t)=0, \\
& { }^{\ell} C A(t)=\frac{1-e^{-\lambda} C^{t}}{{ }^{\lambda} C}+\frac{e^{-\lambda} C^{t}-e^{-\lambda_{B} t}}{\left(\lambda_{C}-\lambda_{B}\right)}+\frac{\lambda_{B} e^{-\lambda_{B} t}}{\left(\lambda_{B}-\lambda_{A}\right)\left(\lambda_{C}-\lambda_{B}\right)}
\end{aligned}
$$

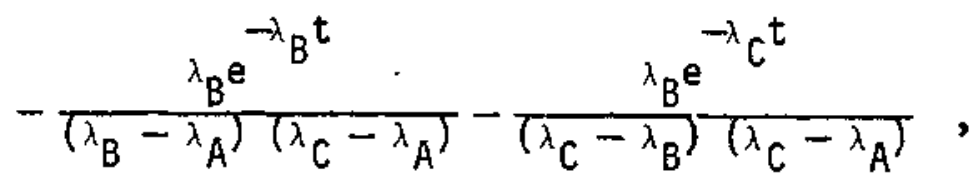

$$
\begin{aligned}
& { }^{\ell} C B(t)=\frac{e^{-\lambda} C^{t}-e^{-\lambda_{B} t}}{\left(\lambda_{C}-\lambda_{B}\right)}+\frac{1-e^{-\lambda} C^{t}}{{ }^{\lambda_{C}} C} \text {. } \\
& \text { and } e_{C C}(t)=\frac{1-e^{-\lambda} C^{t}}{{ }^{\lambda} C} \text {. }
\end{aligned}
$$


The matrix equation can be inverted to give the radon daughter concentration in air in terms of the radon daughter atoms collected on the membrane filter, i.e.,

$$
Q=\frac{1}{v} L^{-1} N
$$

The number of radon daughter atoms collected on the filter can be obtained from counts of the activity of the radon daughters taken as a function of time after the sampling of the air was terminated. Assume that the RaA, RaB, and $R a C$ atoms have been collected on the membrane for a sampling time $t$. Now the collection has ceased, but the radioactive decay processes continue throughout the period the sample is counted. The number of RaA atoms collected was $n_{A}$, but some of these nuclei will decay between the time of collection and the time of counting. Let a time parameter now be defined so that $\tau=0$ at the end of the sample collection and the elapsed time $t$ is the time interval between collection and counting. The number of radon parents, $A$, at counting time $\tau$ is $n_{A}$ where

$$
d n_{A}(\tau)=-\lambda_{A} n_{A}(\tau) d \tau
$$


Integration of Equation (34) yields

$$
n_{A}(\tau)=B e^{-\lambda} A^{\tau}
$$

and evaluation according to the boundary condition $n_{A}(\tau)=$ $n_{A}(t)$ when $t=0$ yields

$$
n_{A}(\tau)=n_{A}(t) e^{-\lambda A^{\tau}}
$$

The number of $B$ daughters at counting time can be found according to

$$
d n_{B}(\tau)=\lambda_{A} n_{A}(\tau) d \tau-\lambda_{B} n_{B}(\tau) d \tau,
$$

or

$$
\frac{d n_{B}(\tau)}{d \tau}+\lambda_{B} n_{B}(\tau)=\lambda_{A} n_{A}(\tau)
$$

but

$$
\frac{d n_{B}(\tau)}{d \tau}+\lambda_{B} n_{B}(\tau)=\lambda_{A} n_{A}(t) e^{-\lambda_{A} \tau},
$$

and the solution is

$$
n_{B}(\tau)=e^{-\lambda B^{\tau}} \int e^{-\lambda B^{\tau} \tau}\left[\lambda_{A} n_{A}(t) e^{-\lambda A^{\tau}}\right] d \tau+\alpha e^{-\lambda B^{\tau}},
$$

or

$$
n_{B}(\tau)=\frac{\lambda_{A} n_{A}(t) e^{-\lambda_{A} A^{\tau}}}{\lambda_{B}-\lambda}+\alpha e^{-\lambda B^{\tau}} .
$$


From the boundary condition $n_{B}(\tau)=n_{B}(t)$ when $\tau=$ 0 , a In Equation (41) is evaluated and

$$
n_{B}(\tau)=n_{A}(t)\left[\left(\frac{\lambda_{A}}{\lambda_{B}-\lambda_{A}}\right)\left(e^{-\lambda_{A} \tau}-e^{-\lambda_{B} \tau}\right)\right]+n_{B}(t) e^{-\lambda_{B} \tau} .
$$

In a similar manner, it is found that

$$
\begin{aligned}
n_{C}(\tau)= & n_{A}(t)\left\{\lambda _ { A } \lambda _ { B } \left[\frac{e^{-\lambda} A^{\tau}}{\left(\lambda_{B}-\lambda_{A}\right)\left(\lambda_{C}-\lambda_{A}\right)}-\frac{e^{-\lambda_{B} \tau}}{\left(\lambda_{C}-\lambda_{B}\right)\left(\lambda_{B}-\lambda_{A}\right)}\right.\right. \\
& \left.+\frac{e^{-\lambda} C^{\tau}}{\left(\lambda_{C}-\lambda_{A}\right)\left(\lambda_{C}-\lambda_{B}\right)}\right]+\left[n_{B}(t) \frac{\lambda_{B}}{{ }^{\lambda} C-\lambda_{B}}\left(e^{-\lambda_{B} B^{\tau}}-e^{-\lambda C^{\tau}}\right)\right] \\
& +n_{C}(t)\left(e^{-\lambda^{\tau}}\right) .
\end{aligned}
$$

Equations (36), (42), and (43) have been incorporated into two methods of calculating the radon daughter concentrations in air from count rates of alpha particle 
activity collected on a membrane filter (Tsivoglou et al. 1953 and Martz et al. 1969). Both of these methods have been formulated into matrix relationships suitable for use with Equation (33). In the following discussions of these methods, the one given by Martz et al. is referred to as the spectrometry method because the alpha particle activity from RaA and RaC is measured separately. The method given by Tsivogiou et al. measures count rates of the combined alpha particle activity from RaA and RaC. Results from both methods were in good agreement, but the spectrometry method yields smaller uncertainties in the calculated radon daughter concentrations. A discussion on the uncertainties in the radon daughter concentrations computed by the two methods of taking count rates is given by Martz et al. (1969).

\section{Isivoglou Method}

This method uses the count rates of total alpha particle activity from $R a A$ and $R a C$ at three times $\left(\tau_{1}, \tau_{2}\right.$, and $\tau_{3}$ ) after the termination of the sampling. The conbined count rate, $c_{1}$, from $R a A$ and $R a C$ at any time, $\tau_{i}$, is given by the relation

$$
\left.c_{i}\left(\tau_{i}\right)=g\left[\lambda_{A} n_{A}\left(\tau_{i}\right)+\lambda_{C}{ }^{n} C^{\left(\tau_{i}\right.}\right)\right]
$$


where $g$ is the geometry factor of the detector used to assay the sample. Substitution of the equations for $n_{A}(\tau), n_{B}(\tau)$ and $n_{C}(\tau)$ in this equation qives the relation

$$
\begin{aligned}
& c_{i}\left(\tau_{i}\right)=g\left\{n _ { A } ( t ) \left[\lambda_{A} e^{-\lambda_{A} \tau_{i}}+\frac{\lambda_{A} \lambda_{B}{ }^{\lambda} C}{\left(\lambda_{B}-\lambda_{A}\right)\left(\lambda_{C}-\lambda_{A}\right)}\left(e^{-\lambda_{A} \tau_{i}}-e^{-\lambda C^{\tau} i}\right)\right.\right. \\
& \left.+\frac{\lambda_{A}{ }^{\lambda}{ }^{\lambda} C}{\left(\lambda_{B}-\lambda_{A}\right)\left(\lambda_{C}-\lambda_{B}\right)}\left(e^{-\lambda C^{\tau} i}-e^{-\lambda_{B} \tau_{i}}\right)\right] \\
& \left.+n_{B}(t)\left[\frac{\lambda_{B}{ }^{\lambda}}{{ }^{\lambda} C^{-\lambda} \lambda_{B}}\left(e^{-\lambda} c^{\tau} \mathbf{i}-e^{-\lambda} C^{\tau} \dot{i}\right)\right]+n_{C}(t)\left(\lambda c^{-\lambda} C^{\tau} \mathbf{i}\right)\right) \text {, }
\end{aligned}
$$

or

$$
c_{j}\left(\tau_{i}\right)=g\left[m_{i A}\left(\tau_{j}\right) n_{A}(t)+m_{i B}\left(\tau_{j}\right) n_{B}(t)+m_{j C}\left(\tau_{i}\right) n_{c}(t)\right],
$$

and

$$
\left|\begin{array}{l}
c_{1}\left(\tau_{1}\right) \\
c_{2}\left(\tau_{2}\right) \\
c_{3}\left(\tau_{3}\right)
\end{array}\right|=g\left|\begin{array}{lll}
m_{1 A}\left(\tau_{1}\right) & m_{1 B}\left(\tau_{1}\right) & m_{1 C}\left(\tau_{1}\right) \\
m_{2 A}\left(\tau_{2}\right) & m_{2 B}\left(\tau_{2}\right) & m_{2 C}\left(\tau_{2}\right) \\
m_{3 A}\left(\tau_{3}\right) & m_{3 B}\left(\tau_{3}\right) & m_{3 C}\left(\tau_{3}\right)
\end{array}\right|,\left|\begin{array}{l}
n_{A}(t) \\
n_{B}(t) \\
n_{C}(t)
\end{array}\right|,
$$


or

$$
C=g / N \text {. }
$$

This relationship can be inverted to give

$$
N=\frac{1}{g} M^{-1} C
$$

which when substituted into Equation (33) yields

$$
Q=\frac{1}{g v} L^{-1} M^{-1} C
$$

Thus the concentrations of $R a A, R a B$, and RaC can be obtained by computer calculation of the inverse matrix elements of $L$ and $M$ given in previous equations. The use of a matrix for counting rates and matrix multiplication gives the concentrations $q_{A}, q_{B}$, and $q_{C}$ as matrix elements of $Q$. The computer program (Racon I) used in this method of analysis is avallable upon request. 
87

Spectrometry Method

This method uses count rates from $\operatorname{RaA}\left(c_{A}\right)$ at $\tau_{1}$ and from $\operatorname{RaC}\left(\mathrm{C}_{\mathrm{C}}\right)$ at $\tau_{2}$ and $\tau_{3}\left(\tau_{2}<\tau_{3}\right)$ after the termination of the air sampling. The times $\tau_{1}$ and $\tau_{2}$ may be equal as in the discussion of this method by Marti et al. (1969). In this method the three counting rate equations are

$\left(\operatorname{RaA}\right.$ at $\left.\tau_{1}\right)$

$$
\begin{aligned}
c_{1}\left(\tau_{1}\right) & =g \lambda_{A} n_{A}\left(\tau_{1}\right) \\
& =g n_{A}(t)\left[\lambda_{A} e^{-\lambda_{A} \tau_{1}}\right],
\end{aligned}
$$

$\left(\operatorname{RaC}\right.$ at $\left.\tau_{2}\right)$

$$
\begin{aligned}
& c_{2}\left(\tau_{2}\right)=g \lambda_{C} n_{C}\left(\tau_{2}\right) \\
& =g\left\{{ } _ { n _ { A } } ( \tau _ { 2 } ) \left[\frac{{ }_{A}{ }^{\lambda} B^{\lambda} C}{\left(\lambda_{B}-\lambda_{A}\right)\left(\lambda_{C}-\lambda_{A}\right)}\left(e^{-\lambda} A^{\tau} 2-e^{-\lambda_{B}{ }^{\tau} 2}\right)\right.\right. \\
& \left.+\frac{{ }^{\lambda} A_{B} B^{\lambda} C}{\left(\lambda_{B}-\lambda_{A}\right)\left(\lambda_{C}-\lambda_{B}\right)}\left(e^{-\lambda} C^{\tau} 2-e^{-\lambda} B^{\tau} 2\right)\right] \\
& +n_{B}(t)\left[\frac{{ }^{\lambda} B^{\lambda} C}{\left(\lambda_{C}-\lambda_{B}\right)}\left(e^{-\lambda_{B}{ }^{\tau} 2}-e^{-\lambda} C^{\tau} 2\right)\right] \\
& +n_{C}(t)\left(\lambda_{C} e^{-\lambda_{C} \tau_{2}}\right) \mid
\end{aligned}
$$


and

$\left(\operatorname{RaC}\right.$ at $\left.\tau_{3}\right)$

$$
\begin{aligned}
& c_{3}\left(\tau_{3}\right)=g \lambda_{c} c_{c}\left(\tau_{3}\right) \\
& =g \int n_{A}(t)\left[\frac{\lambda_{A} \lambda_{B} \lambda_{C}}{\left(\lambda_{B}-\lambda_{A}\right)\left(\lambda_{C}-\lambda_{A}\right)}\left(e^{-\lambda_{A} A^{\tau} 3}-e^{-\lambda_{B} \tau^{2}}\right)\right. \\
& \left.+\frac{{ }^{\lambda_{A} \lambda_{B} \lambda_{C}}}{\left(\lambda_{B}-\lambda_{A}\right)\left(\lambda_{C}-\lambda_{B}\right)}\left(e^{-\lambda^{2} C^{\tau} 3}-e^{-\lambda_{B}{ }^{\top} 3}\right)\right] \\
& +n_{B}(t)\left[\frac{\lambda_{B} \lambda_{C}}{\left(\lambda_{C}-\lambda_{B}\right)}\left(e^{-\lambda_{B}{ }^{\tau} 3}-e^{-\lambda_{C} C^{\tau}}\right)\right] \\
& \left.+n_{C}(t)\left(\lambda_{C} e^{-\lambda_{C} \tau_{3}}\right)\right) \text {. }
\end{aligned}
$$

Summarizing Equations (37), (39), and (41) into matrix notation, the result is

$$
C=g M N
$$

$\left|\begin{array}{c}c_{1}\left(\tau_{1}\right) \\ c_{2}\left(\tau_{2}\right) \\ c_{3}\left(\tau_{3}\right)\end{array}\right|=g\left|\begin{array}{ccc}m_{1 A}\left(\tau_{1}\right) & m_{1 B}\left(\tau_{1}\right) & m_{1 C}\left(\tau_{1}\right) \\ m_{2 A}\left(\tau_{2}\right) & m_{2 B}\left(\tau_{2}\right) & m_{2 C}\left(\tau_{2}\right) \\ m_{3 A}\left(\tau_{3}\right) & m_{3 B}\left(\tau_{3}\right) & m_{3 C}\left(\tau_{3}\right)\end{array}\right|\left|\begin{array}{l}n_{A}(t) \\ n_{B}(t)\end{array}\right|(58$


89

where

$$
\begin{aligned}
& m_{1 A}\left(\tau_{1}\right)=\lambda_{A} e^{-\lambda} A^{\tau_{1}} \\
& m_{1 B}\left(\tau_{1}\right)=0 \\
& m_{1 C}\left(\tau_{1}\right)=0
\end{aligned}
$$

$$
\begin{aligned}
& m_{2 A}\left(\tau_{2}\right)=\frac{\lambda_{A} \lambda_{B} \lambda_{C}}{\lambda_{B}-\lambda_{A}}\left[\frac{e^{-\lambda A^{\tau} 2}-e^{-\lambda C^{\tau} 2}}{\lambda_{B}-\lambda_{A}}+\frac{e^{-\lambda C^{\tau} 2}-e^{-\lambda_{B} \tau_{2}}}{{ }^{\lambda_{C}}-\lambda_{B}}\right] \\
& m_{2 B}\left(\tau_{2}\right)=\frac{{ }_{B}{ }^{\lambda} C}{\lambda_{C}-\lambda_{B}}\left(e^{-\lambda_{B} \tau_{2}}-e^{-\lambda^{\tau}{ }^{\tau} 2}\right) \\
& m_{2 c}\left(\tau_{2}\right)=\lambda_{c} e^{-\lambda} c^{\tau} 2
\end{aligned}
$$

$$
\begin{aligned}
& m_{3 A}\left(\tau_{3}\right)=\frac{{ }_{A} \lambda_{B} \lambda_{C}}{\lambda_{B}-\lambda_{A}}\left[\frac{e^{-\lambda_{A} \tau_{3}}-e^{-\lambda} C^{\tau} 3}{\lambda_{C}-\lambda_{A}}+\frac{e^{-\lambda_{C} C^{\tau} 3}-e^{-\lambda_{B} \tau_{3}}}{{ }^{\lambda_{C}}-\lambda_{B}}\right] \\
& m_{3 B}\left(\tau_{3}\right)=\frac{{ }_{B}{ }^{\lambda} C}{{ }^{\lambda_{C}}-\lambda_{B}}\left(e^{-\lambda_{B} \tau_{3}}-e^{-\lambda_{C} C^{\top} 3}\right) \\
& m_{3 c}\left(\tau_{3}\right)=\lambda c^{e^{-\lambda} c^{\tau} 3} .
\end{aligned}
$$


The elements of $H$ can be calculated from the set of equations given in Equation (59) and the inverse matrix $M^{-1}$ for use in Equation (50). The matrix $M$ and the matrix $C$ are different from those used in the Tsivoglou Hethod. The matrices $L$ and $L^{-1}$ are the same for both methods, assuming the sampling times were equal. In other words, the same count rate spectral data can be analyzed by both methods. A second computer program (Racon II) using this method of analysis is also avajlable on request.

Method of Error Analysis

The method of error analysis is simplified by the use of matrix Equation (50) in the form

$$
\eta=\frac{l}{g v} K C
$$

where

$$
K=L^{-1} M^{-1} \text {. }
$$


Because of the small uncertainties in the decay constants, the sampling time, and the counting times involved in the calculations of the matrix elements of $L$ and $M$, the uncertainty of $q_{i}$ is

$$
\left(\Delta q_{i}\right)^{2}=\sum_{j=1}^{3} k_{i j}^{2}\left(t, \tau_{j}\right)\left[\frac{c_{j}}{g v}\right]^{2}\left[\frac{\left(\Delta c_{j}\right)^{2}}{c_{j}^{2}}+\frac{(\Delta g)^{2}}{g^{2}}+\frac{(\Delta v)^{2}}{v^{2}}\right]
$$

where $\Delta q_{j}=$ the variance in $q_{j}$, where $i=A, B$, and $c, \Delta c_{j}$ - the uncertainty in the count rate $c_{j}, \Delta g=$ the uncertainty in the geometry factor $q$, and $\Delta v=$ the uncertainty in the sampling flow rate $v$.

\section{Instrumentation}

A four stage cascade impactor followed by a millipore filter holder (see Figure 9) was used for air sampling for radon daughters carried by particulates; the design and use of this equipment has been given by May (1947). The physics of impaction sampling is well presented by Fuchs (1964).

A silicon surface-barrier diode detector was used for measurements of alpha spectra, since the available resolution of $20 \mathrm{keV}$ allows accurate determinations of the alpha energies. In order to obtain the highest efficiency and best resolution, a nearly monomolecular layer of the 
nuclide of interest was placed as near the detector surface as possible, and an evacuated counting chamber was used. This technique is quite satisfactory when the nuclide being studied has a long half-life. However in cases where short half-life nuclides are to be counted, this type of counter is inconventent. Further, because the diodes should not be biased in the pressure range near 0.1 torr due to the danger of breakdown, a counter which has a convenient air lock for admitting the samples quickly is needed so that the slow lowering and raising of the bias voltage will be unnecess ary.

A solution is a counting setup that operates at atmospheric pressure with the source, which is a dust sample on filter in this case, piaced a minimum distance from the detector. Although the technique allows rapid measurement of the samples and averts the other problems of measurement in a vacuum, it leads to energy loss of the alpha particles in the air between the source and the detector. The distance cannot be decreased much below 0.5 centimeters due to the geometry of the diode. A 6.4 MeV alpha particle traversing air at 760 torr and $20^{\circ} \mathrm{C}$ along the minimum distance between the detector and source will lose above 270 kev of energy. The energy response of the system is nonlinear, i.e., a less energetic alpha particle will lose a greater amount of energy and a more energetic alpha 

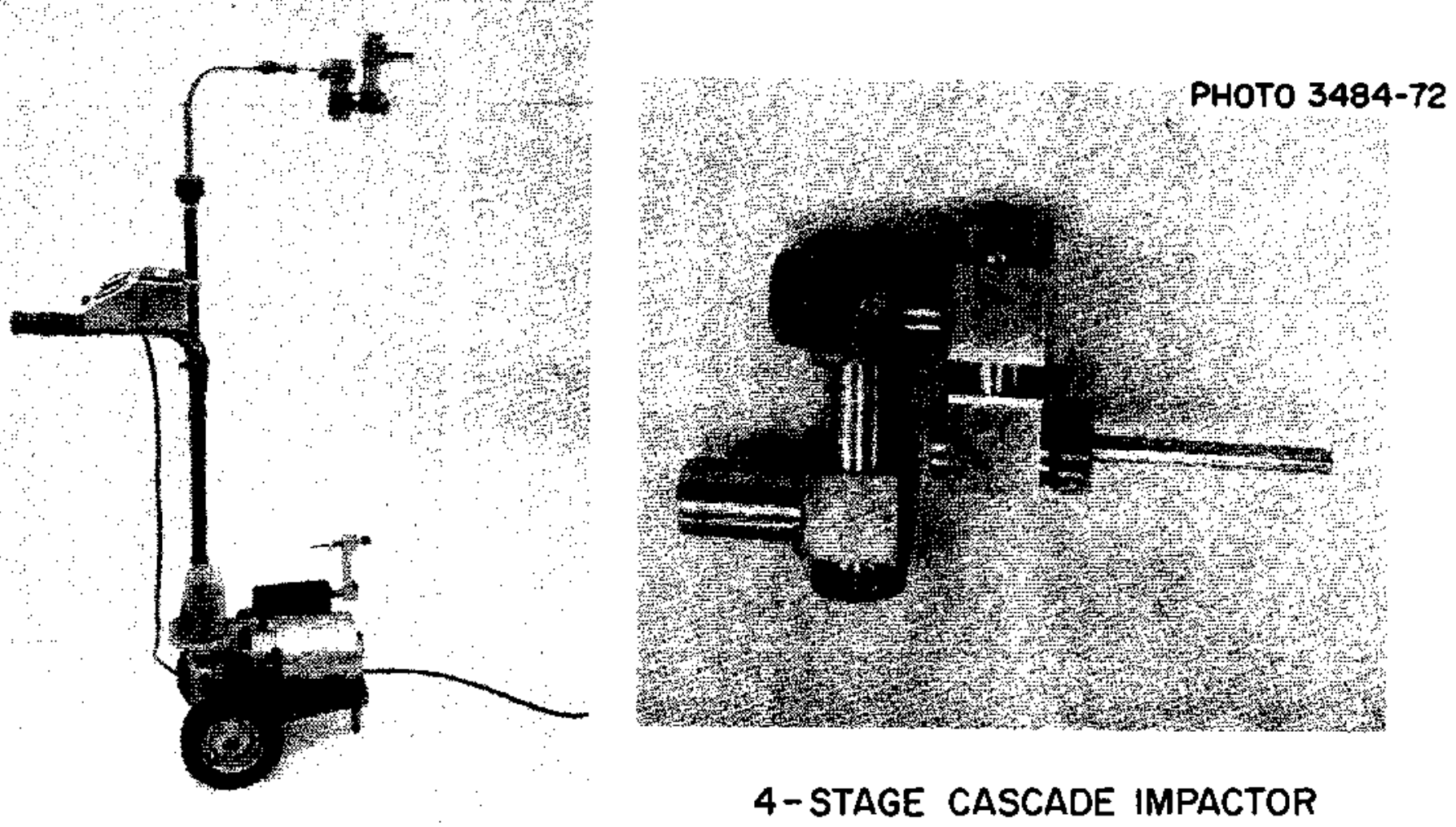

AIR SAMPLING SYSTEM

Fig. 9. Air Sampling Apparatus used in Field and Close-up of the Cascade Impactor. 
particle will lose a smaller amount of energy in traversing this distance.

To improve upon this situation, an existing gas flow proportional counter was modified to hold the diode detector. A source-to-detector distance of 0.525 centimeters was the minimum that could be obtained with this arrangement. By flowing helium through the chamber, the energy loss by a $6.4 \mathrm{MeV}$ alpha particle was reduced to about 80 keV. In fact, alpha energy loss is the lowest in helium of any gas, hydrogen being higher due to its diatomic nature. Exploded disassembled and assembled views of the counter are shown in Figures 10 and 11 . Figure 12 compares a measurement of a plutonium-239 source made in a vacuum, in alr, and in hellum. By using helium, a counter operating at atmospheric pressure can be used with little loss in resolution and considerable gain in sample-handing simplicity. The use of helium also reduced the nonlinearity in the energy response of the system caused by the variation of stopping power with alpha particle enerzy. An energy calibration can be obtained with a thorium-228 source which emits alpha particles having six energies between 5.35 and 8.78 MeV. The ability to leave the high voltage on the diode not only minimized the calibration problem but prevented problems in reapplying the high voltage. Commercially available electronics systems, similar to those 
PHOTO 2910-72

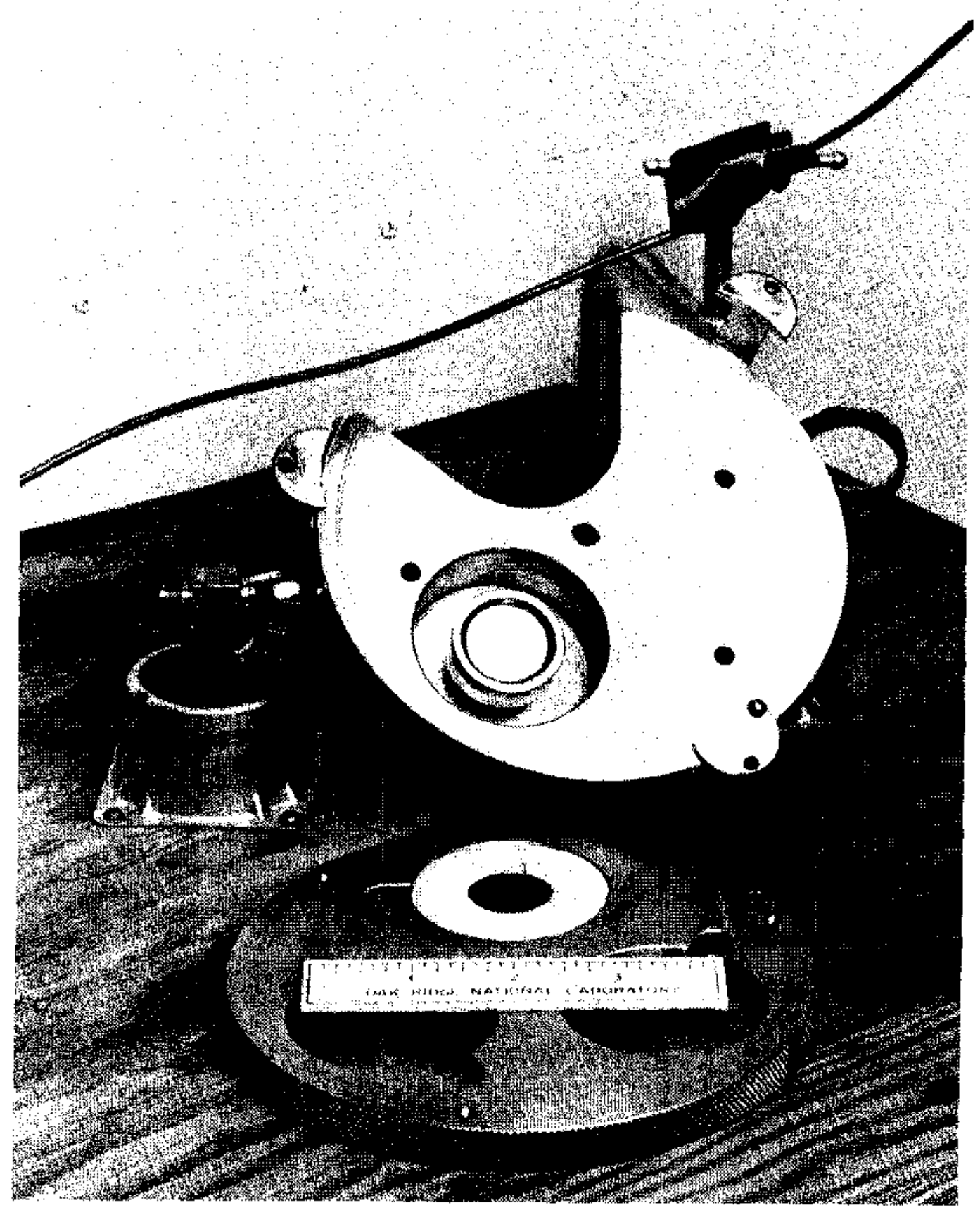

Fig. 10. Exploded View of Alpha Counter Showing Position of the Surface Barrier Diode Detector. 


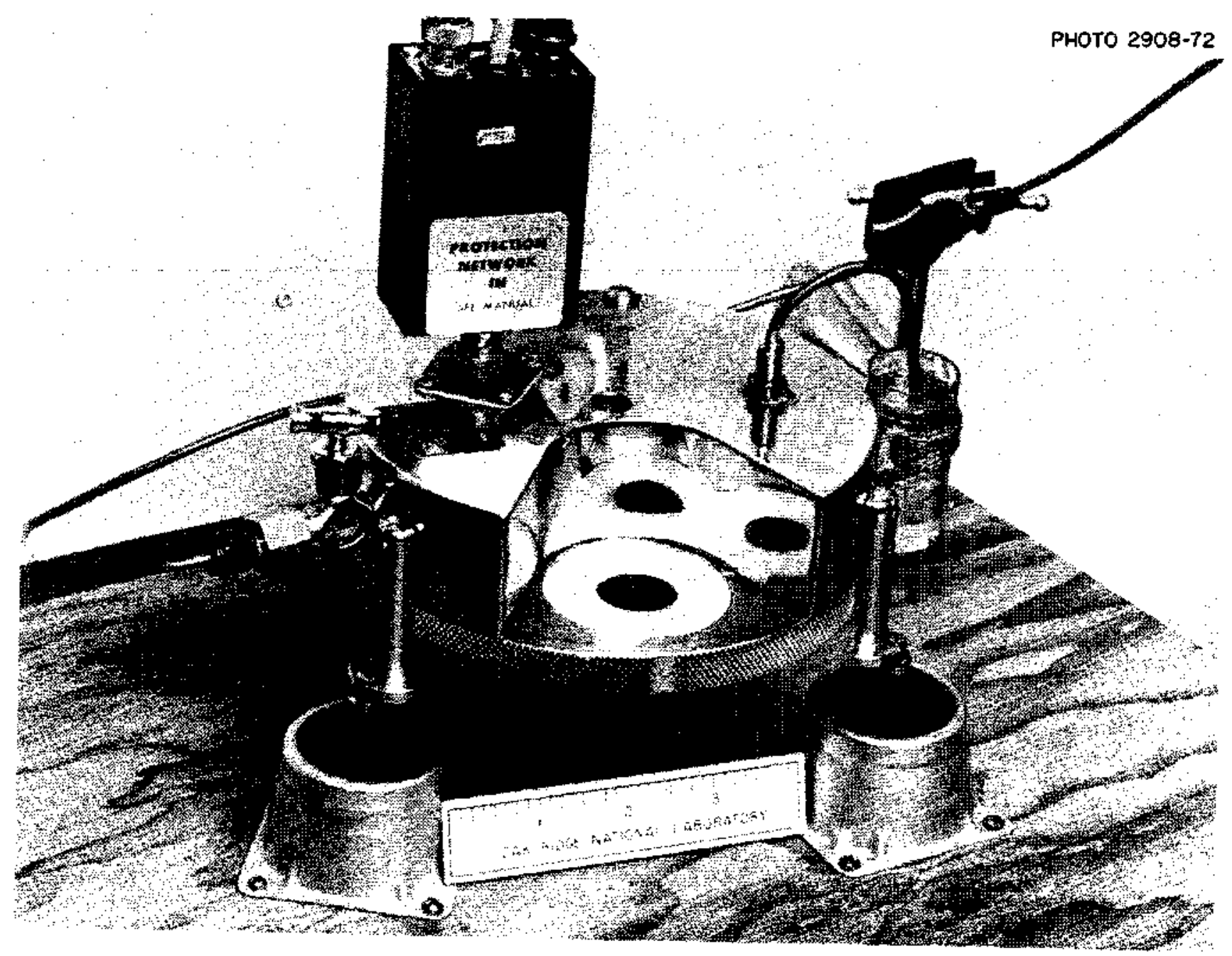

Fig. 11. The Assembled Alpho Counter. 


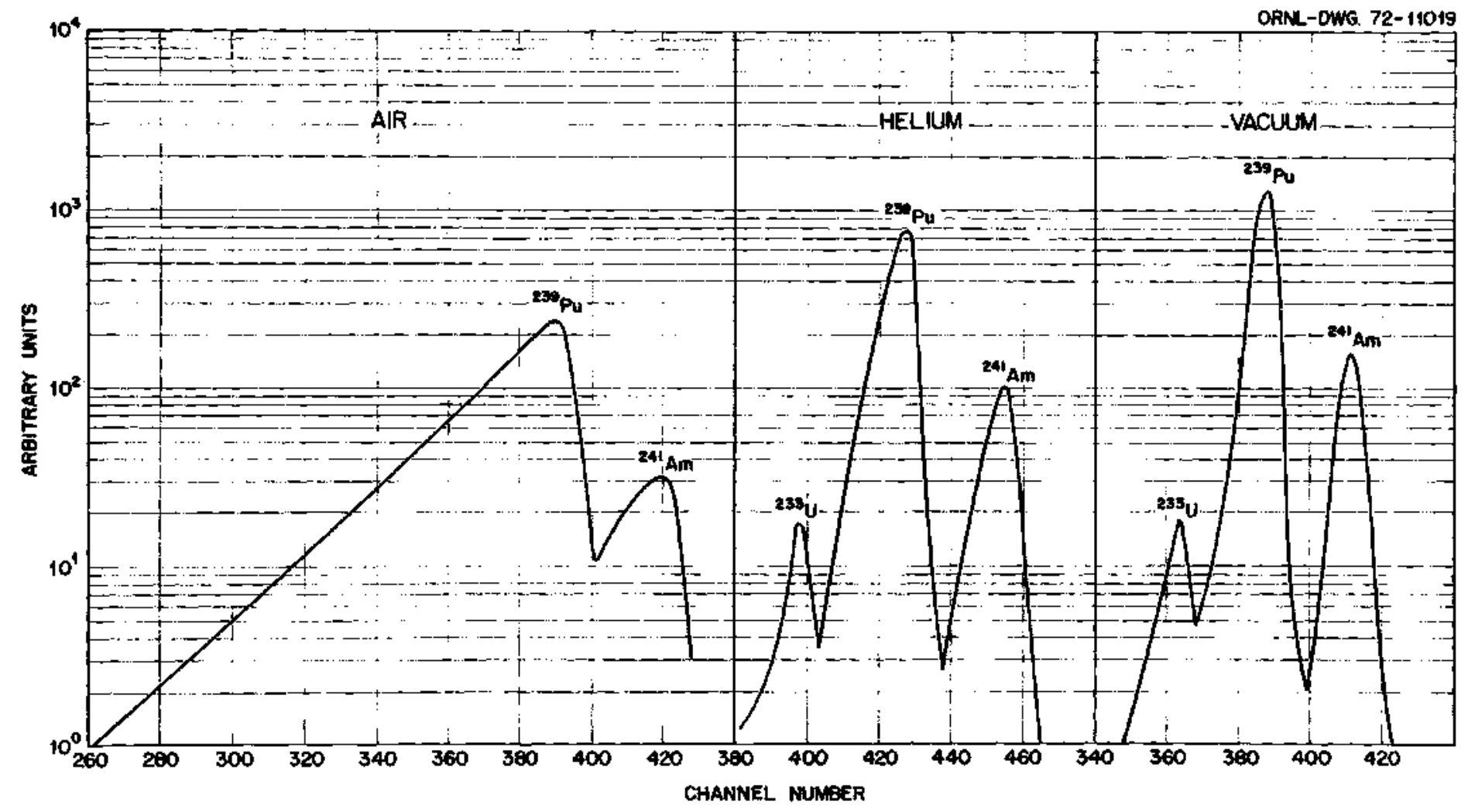

Fig. 12. The Alpho Counter Response Curves for a Nominal ${ }^{239} \mathrm{Pu}$ Source Counted in Air, in Heliurn, and in Vacuum. 
used with the gamma-ray spectrometer were used a iso with this detector.

other problems that are due to the nature of the source itself are encountered when measuring alpha particies from air samples. A sample taken in a dusty environment can exhiblt poor alpha resolution due to self-absorption in the source. The same is true for samples collected on a standard paper filter for which the collected particles are trapped at various depths in the filter. In this study, good alpha particle resolution was obtained with a millipore filter having an average pore size of 0.45 microns. Examples of typical alpha particle spectrum from a dust sample collected for 10 minutes at an ajr flow of 17 iters per minute and assayed at 4 to 5,14 to 15 , and 29 to 30 minutes after the termination of the sampling is shown in Figure 13. The alpha particle pulse spectrum was recorded using a 512 channel analyzer.

Alternate methods of obtaining data would be simply to replace the multichannel analyzer with a single channel analyzer and a scaler or to replace the multichannel analyzer by two single-channel analyzers and two scalers. In the first case, the number of counts in the RaA and RaC peaks would be measured together as a function of time, and in the second case, the total number of counts in the RaA and Rac peaks would be measured separately as a function of time. 


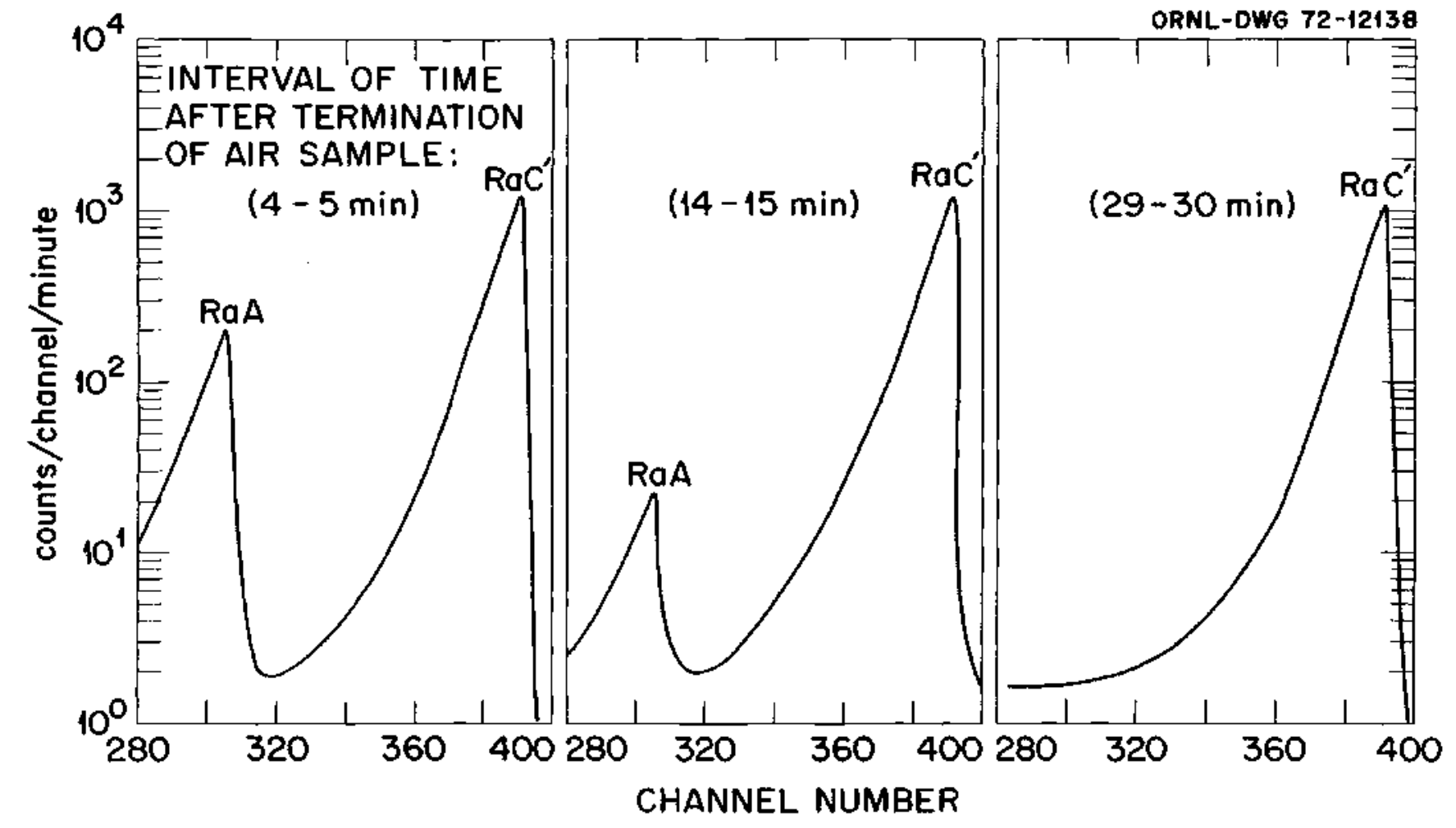

Fig. 13. Examples of Response Curve and Relative Count Rates for RaA and $\mathrm{RaC}^{\prime}$ as a Function of Time after Termination of Air Sampling. 
Results using all three of these methods were good when the count rates from multichannel data were calculated as follows

$$
c\left(t_{m}\right)=\frac{\text { Counts }}{\text { Live Time }}
$$

where live time was that recorded during a clock time interval from $t_{1}$ to $t_{2}$ and

$$
t_{m}=\frac{t_{2}-t_{1}}{2}
$$

where $t_{m}$ is the midpoint of the clock time counting interval. The counting rates were sufficiently low that the dead time corrections for the other two counting methods using single channel analyzers or scalers were negligible. The multichannel data were preferred because the spectrum could be recorded for future reference. Although the real count rate is changing in a nonlinear fashion durlng the 
counting interval, the count rate averaged over an interval of counting time is a good approximation to the instantaneous or real count rate provided the counting time used in the decay equations is from the termination of air sampling to the midpoint time of the counting interval. Consider the real counting rate, $c(t)$, over a counting interval as shown in Figure 14.

Let $c\left(t_{m}\right)$ be the real count rate at the midpoint time $t_{m}$ of the counting interval $\Delta t=t_{2}-t_{1}$. The average count rate $\langle c\rangle$ over the interval is

$$
\langle c\rangle=\frac{\int_{t_{1}}^{t_{2}} c(t) d t}{\int_{t_{1}}^{t_{2}} d t}
$$

and the ratio of the average count rate over the interval to the real count rate at the midpoint time of the interval is

$$
\frac{c c>}{c\left(t_{m}\right)}=\frac{\int_{t_{1}}^{t_{2}} c\left(t_{m}\right) e^{-\left(t-t_{m}\right)} d t}{c\left(t_{m}\right) \int_{t_{1}}^{t_{2}} d t}
$$




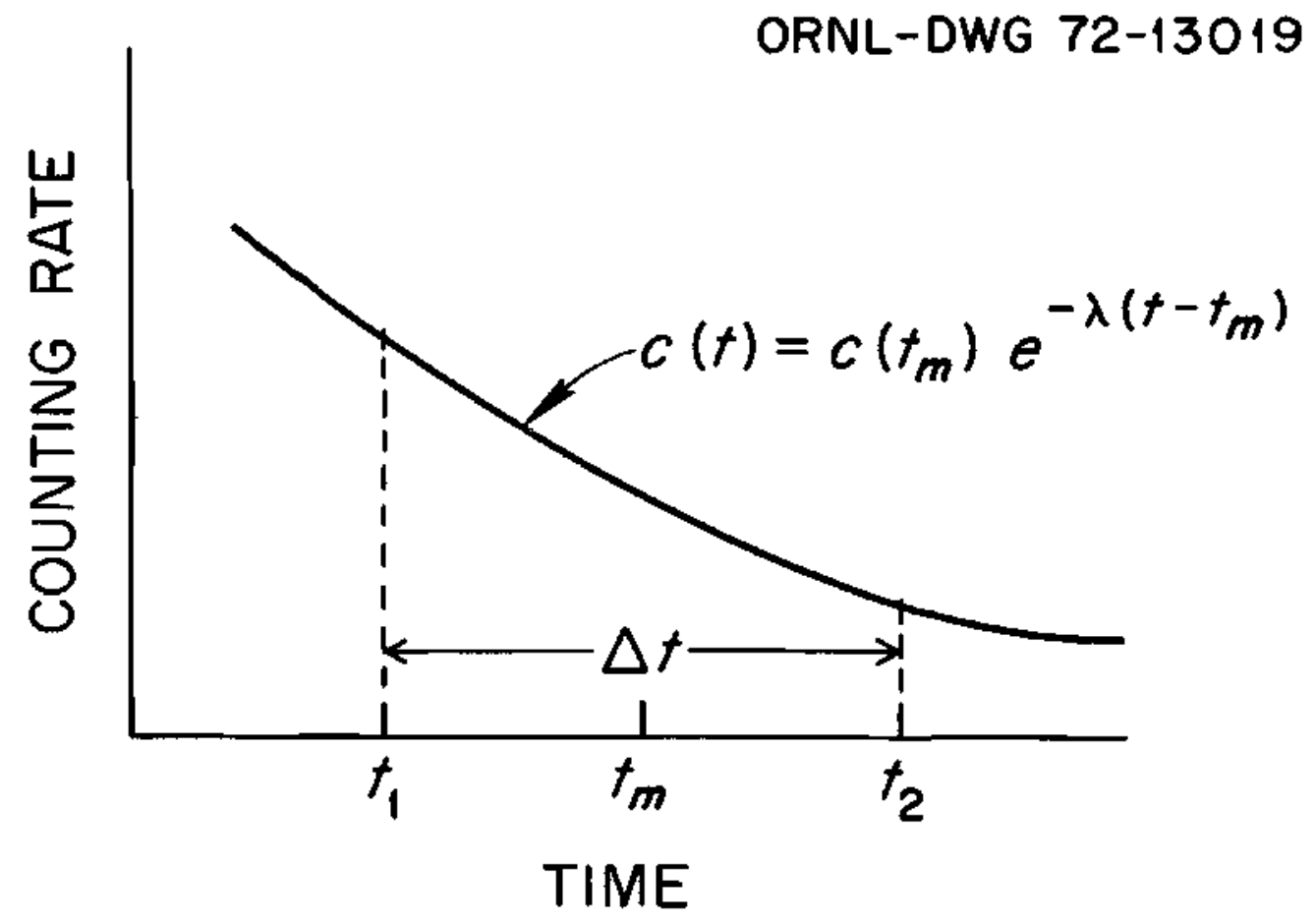

Fig. 14. Diagram of Segment of Radon Daughter Decay Curve and Relations Used in Determining Average Count Rates as a Function of Time. 
or

$$
\begin{aligned}
\frac{\langle c\rangle}{c\left(t_{m}\right)} & =\frac{e^{-\lambda\left(t_{1}-t_{m}\right)}-e^{-\lambda\left(t_{2}-t_{m}\right)}}{\lambda\left(t_{2}-t_{1}\right)} \\
& =\frac{e^{\lambda \Delta t / 2}-e^{-\lambda \Delta t / 2}}{\lambda \Delta t} \\
& =\frac{2 \sinh (\lambda \Delta t / 2)}{\lambda \Delta t} .
\end{aligned}
$$

For RaA with 3.05 minute (183 second) half-life the above relation yields:

\begin{tabular}{ll}
\multicolumn{1}{c}{$\Delta t$} & $\frac{\langle c\rangle / c\left(t_{m}\right)}{20 \text { seconds }}$ \\
30 & 1.000 \\
60 & 1.001 \\
90 & 1.002 \\
120 & 1.004 \\
150 & 1.009 \\
130 & 1.014 \\
133 & 1.019
\end{tabular}


Hence, the count rate averaged over one half-life of 183 seconds is in error by only 2 percent, if it is used as the real count rate at the midpoint time $t_{m}$ of the counting interval. For RaC with a longer half-life of 19.7 minutes, the approximation yields even closer results when the counting intervals are one to two minutes. In this study, counting intervals of this length were adequate for the activity collected on the sampling membranes.

A geometry factor, $g$, defined as the ratio of the number of alpha particles counted by the system to the number emitted by a clrcular source coaxial with the detector is shown by the solid curve in figure 15. As shown in the figure, the geometry factor varies with the radius of the circular plane source. Equations given by Jaffey (1954) were used in calculating the theoretical values of $g$ shown by the solid curve in the figure. These theoretical values were based on a separation distance of 0.525 centimeters between the detector and source, and a sensftive area of four square centimeters specified by the supplier of the detector. Experimental measurements of the geometry factor of the system using calibrated americium-241 and thorium-230 sources having an active surface area with a radius of 0.4 centimeters are also shown in the figure. The error bars on the experimental points indicate the uncertainties in the calibration of the sources by the supplier at the 99.7 percent confidence level. Dashed curves are used to 


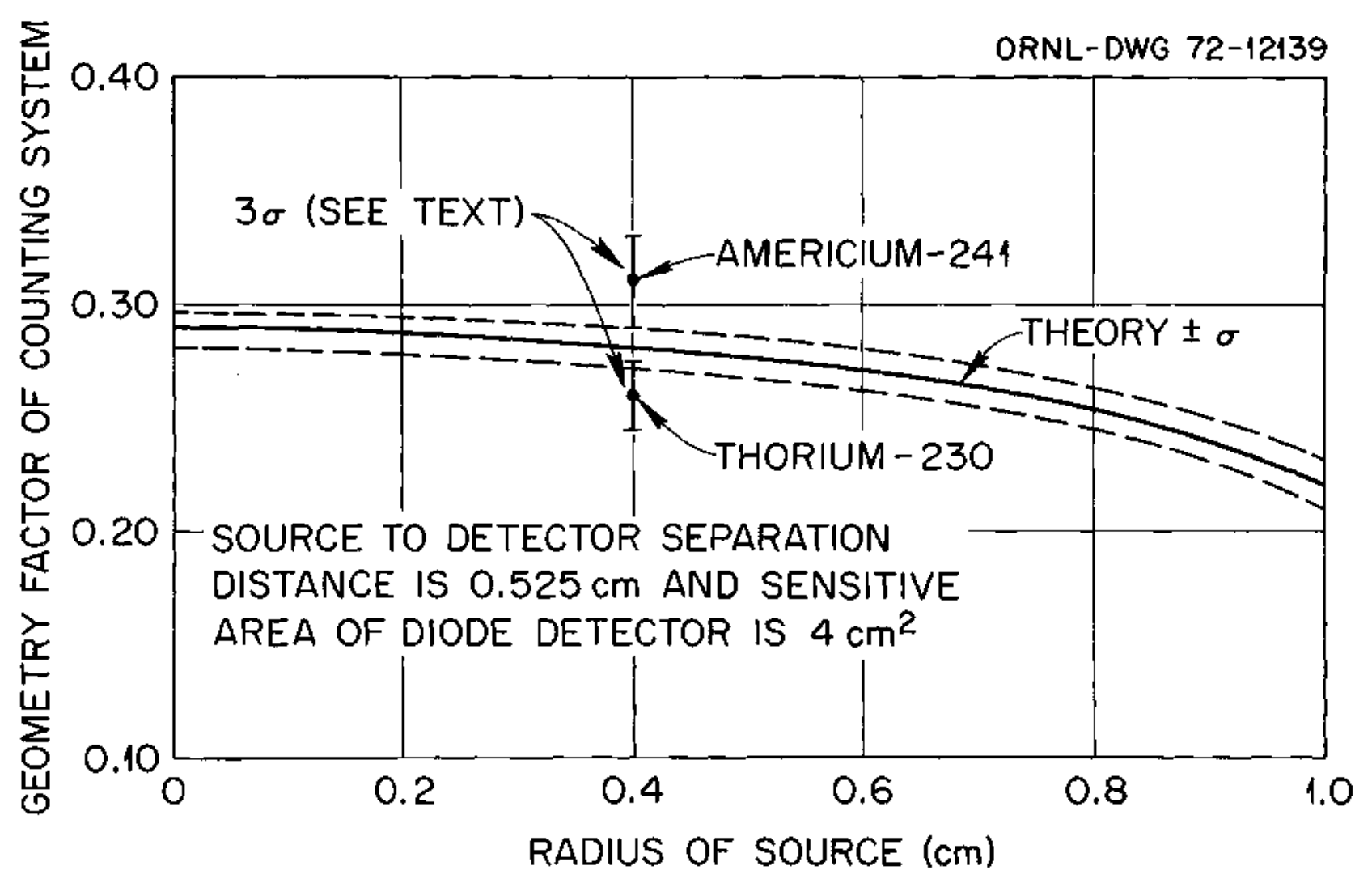

Fig.15. Computed Geometry Factor for Alpha Counter as Function of Source Sample Radius with Two Experimental Points Determined with ${ }^{241} \mathrm{Am}$ and ${ }^{230} \mathrm{Th}$. 
indicate a 0.025-centimeter error in the experimental measurements in locating the source at the 0.525-centimeter separation distance between the membrane filter holder and the diode detector.

The $g$ value used for the membrane filters which collect dust over an area with a radius of 0.925 -centimeters can be seen from Figure 15 to be approximately 0.240 . Based on the above comparison between the theoretical and experimental values of the geometry factor, the uncertainty in this $g$ value used for analyzing the radon daughter concentrations in air from counts of activity on the membrane filter was estimated to be 5 percent or less.

Experiment

Experimental studies of the emanation of radon from concrete were conducted with a type of concrete chosen because of its similarity to that used in forming concrete from shates, cinders, and other low density aggregates. In order to provide sufficiently high radon yield without unmanageably large surfaces, some preliminary studies were made with commercially available building blocks and with samples of uranium ore. The size and configuration of the concrete elements constructed for use were three-foot square slabs of six-inch thickness. The aggregate was a commercially available shale preparation (Shalite) to which uranium ore was added. The uranium ore was carnotite from the Grand Junction area of Western Colorado and assayed 
approximately 0.2 percent uranium by weight. The densities of the finished blocks were 90-95 pounds per cubic foot. The total weight of each block was approximately 400 pounds of which either 50 or 100 pounds were due to the uranium ore. Both the density and appearance of the blocks closely approximated that of shale or cinder blocks.

The commercial shale preparation was used as aggregate to insure a relatively high porosity. In this application, porosity is defined as the ratio of the void volume to the total volume of the medium. Porosity measurements were made with a mercury porosimeter by the Standards Laboratory Group of the $Y-12 \mathrm{Plant}$, and a porosity value of approximately 0.26 was obtained. The experiments were conducted in a relatively airtight enclosure as shown in Figure 16. The walls of the enclosure were polyethylene (0.004 inches) supported on a wooden frame. The Ge(L1) detector described in Chapter II was mounted so as to measure the gamma spectrum from outside the plastic wall. The enclosure was chosen to provide a stable temperature, humidity, and dust distribution. These quantities as well as the barometric pressure were measured as the temperature of the blocks were varied in the course of the experiment. The blocks were cast with 0.5-inch 0.D. copper tubing woven through the midplane parallel to the large faces as shown in Figure 17. A water heating and pumping system was provided for heating the blocks uniformly by means of the 


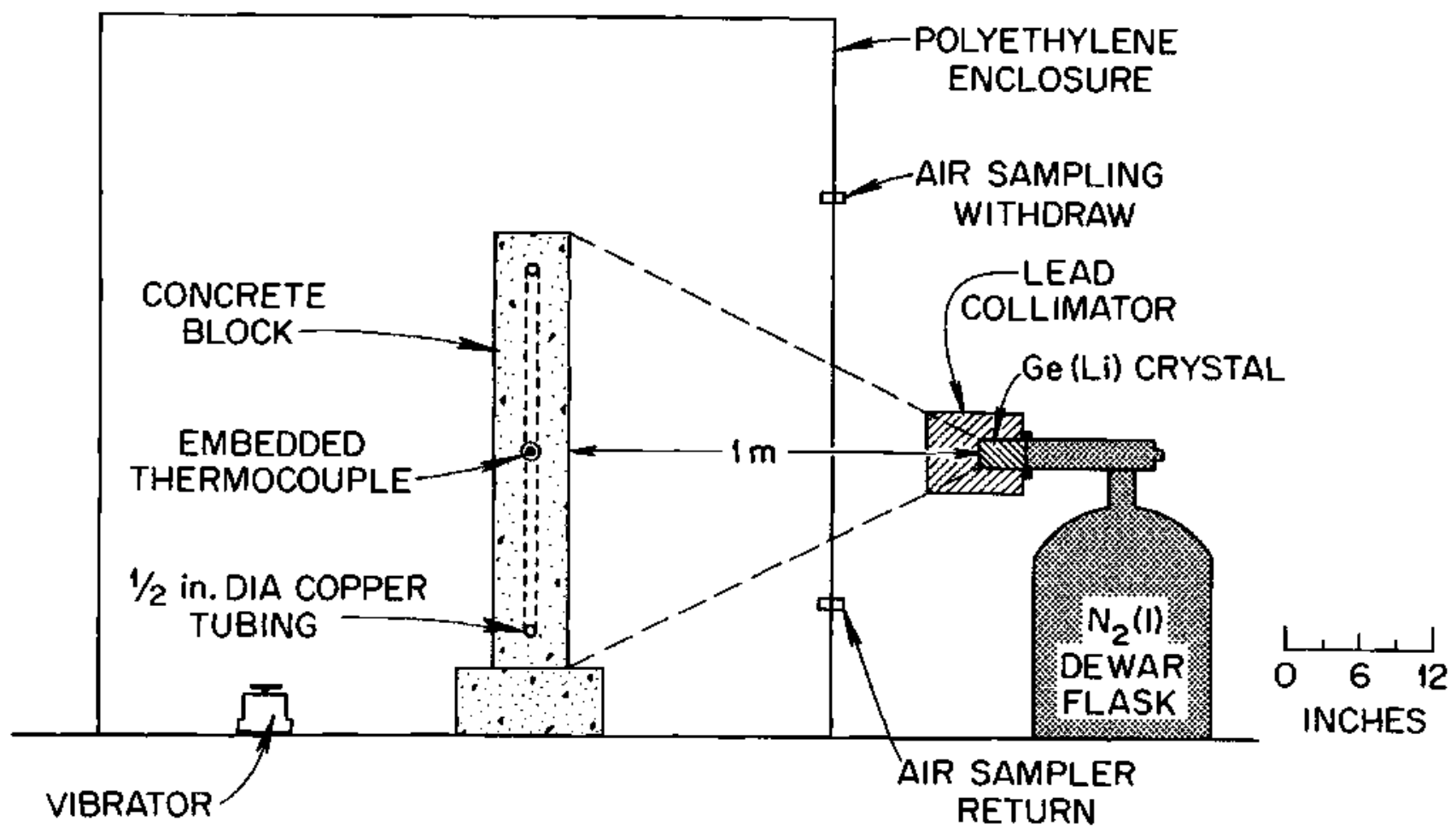

Fig. 16. Diagram of Airtight Enclosure used for Radon Emanation Studies with Concrete Block and $\mathrm{Ge}(\mathrm{Li})$ Detector in Place. 
copper tubing. Temperatures were recorded by five thermocouples located as shown in Figure 17. A sixth thermocouple was used for measuring the air temperature instide the enclosure. Air sampling for the enclosure was accomplished by a closed loop sampling system; the air was withdrawn through the four-stage cascade impactor, a millipore filter, a flow-rate meter, and returned to the enclosure. A flow rate of 17 liters per minute $(0.6$ cubic feet) was used throughout the experiment. As the longest air sampling time required was 10 minutes, the volume of the air in the enclosure which was withdrawn, filtered, and returned was less than 5 percent of the total. However, to help ensure a constant dust particle distribution in the enclosure a vibrator was placed on the floor and the return air stream was also directed at the floor.

The experiment was conducted in the following sequence: (1) Set up a block in enclosure; (2) Measure gama ray spectrum; (3) Measure radon concentrations and particulate size distributions and concentrations, at room temperature (maintained at $23^{\circ} \mathrm{C}$ ) and a fixed humidity, as a function of time; (4) Vary temperature or humidity and remeasure step 3 , repeating until temperature and humidity range were covered insofar as practical; (5) Remove block, coat with a sealant chosen to be of practical interest and repeat Steps 2 and 3 , including measurements of the gamma spectrum as a function of time. From the spectral data it 


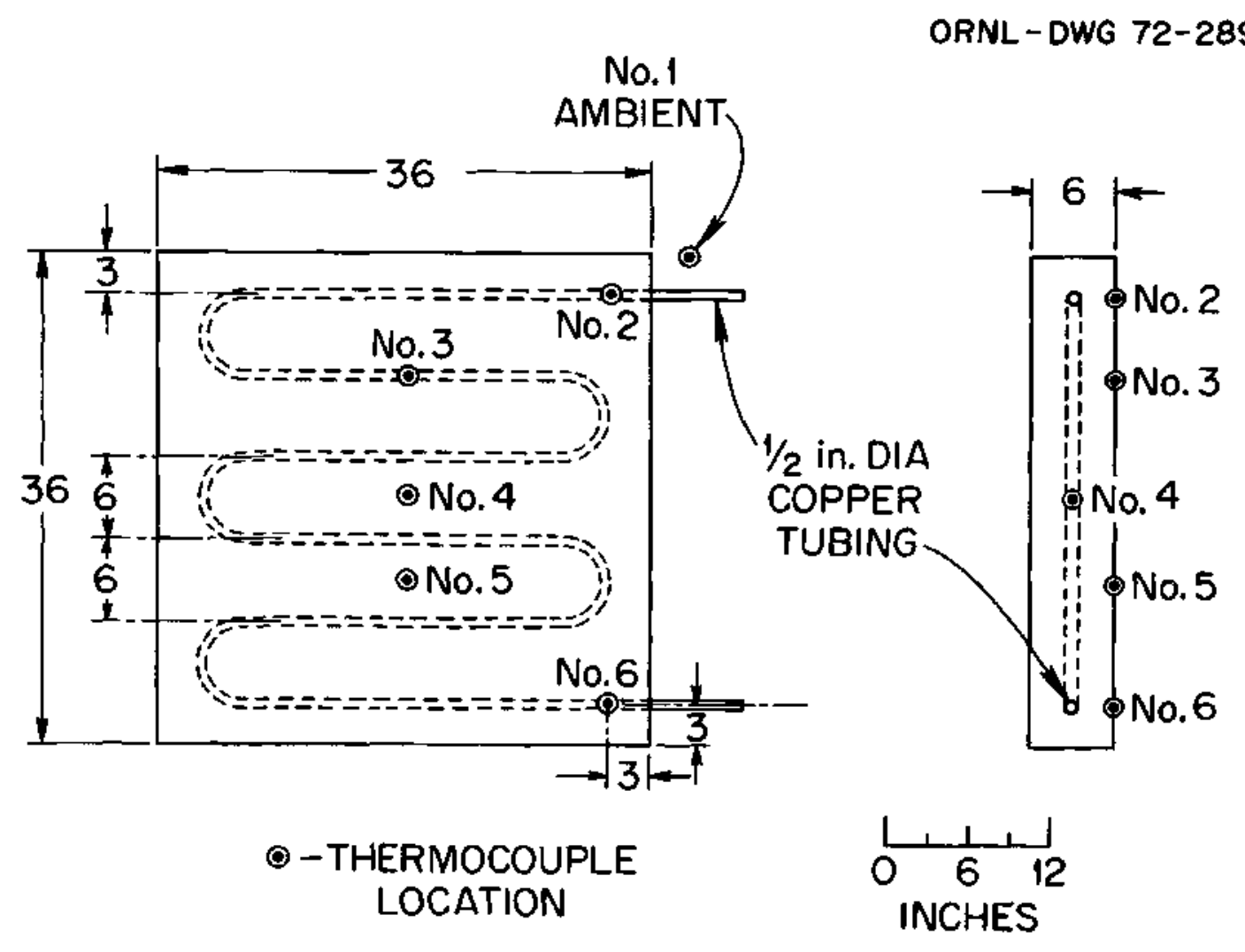

Fig. 17. Diagram of Typical Concrete Block used in Radon Emanation Studies Showing Copper Tubing and Thermocouple Placement. 
was possible to assess the buildup of the specific radon daughters in the concrete behind the sealant.

The radon activity was determined by using the silicon diode detector system described in the preceding section. Dust particle size distributions on the various impactor stages were measured, principally, with the aid of electron micrographs from the scanning electron microscope (SEM). A typical electron micrograph is shown in Figure 18. The size range of particles on the fourth stage of the cascade impactor was 1-5 micrometers mean linear dimension with a monotonic decrease in the particle count with increasing dimension. There were a few larger particles, up to about 10 micrometers. A Royco particle counter was also used as a check on the SEM determinations. Variations in size distributions throughout the experiment were small and do not appear to be significant. As expected, from previous studies, the greatest activity was on the particles having a mean linear dimension of 0.3 micrometers. Generally, less than 10 percent of the activity was on particles having a mean linear dimension equal to or greater than 3 micrometers. Mean linear dimension is used to denote the average dimension in a given direction relative to the micrograph for the randomly oriented and irregularly shaped particles. From these data and the work of Harley and George et al. (1970), it appears that an effective particle dimension for lung exposure of 0.1-0.3 micrometers 


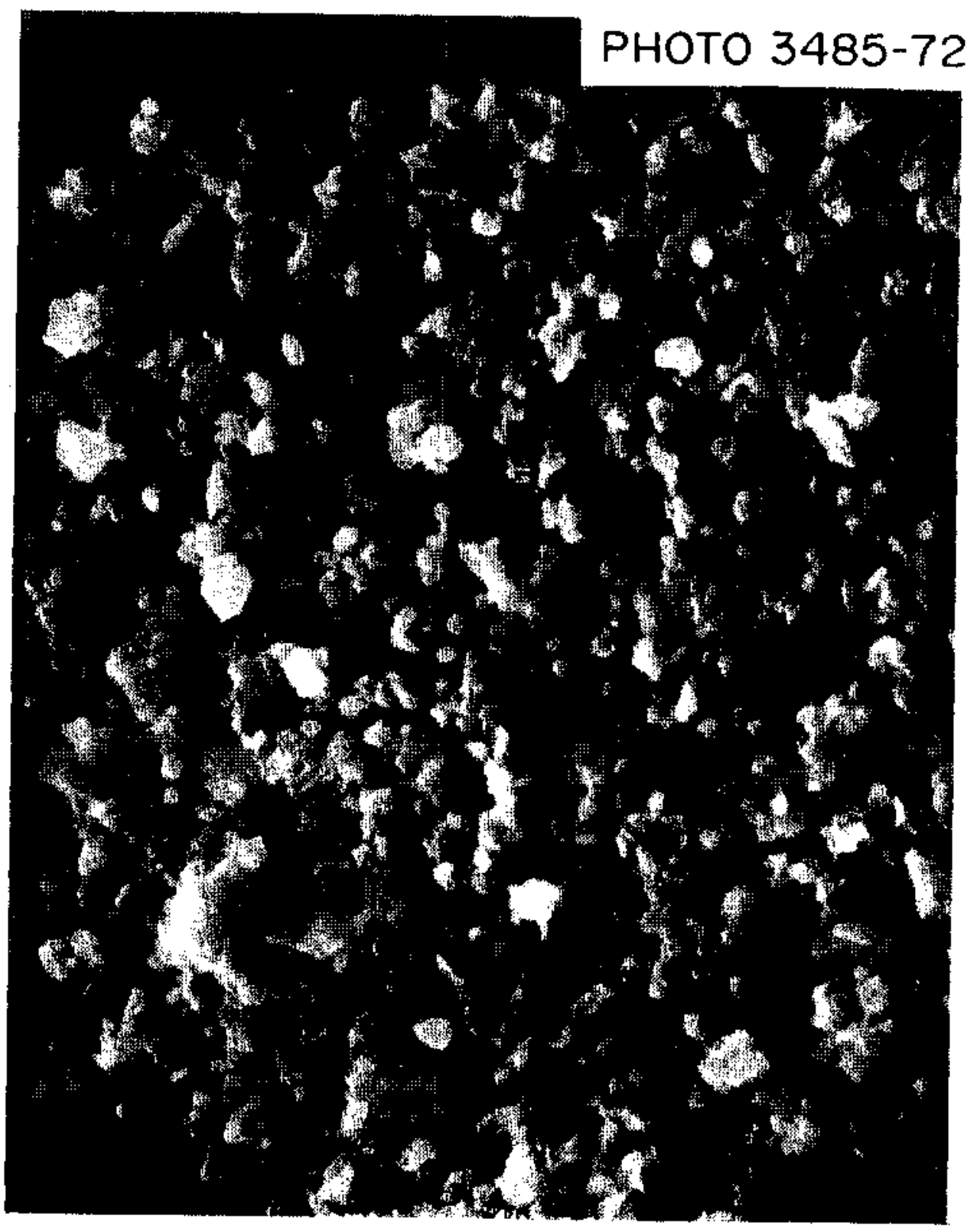

Fig.18. Typical Electron Micrograph for Stage 4 of Cascade Impactor (Magnification 1000x). 
is representative of the atmosphere, generally. The sealants were chosen on the basis of their widespread utilization in home construction. Blocks were sealed by stuccoing with cement plaster, the stucco sealant evaluated as outlined above, and then heavily painted with epoxy paint. A second sealant type was the commercially available asphalt used to cement asphalt or vinyl floor tiles in place.

\section{Results and Analysis}

Results of studies on the effect of temperature on radon emanation from concrete are shown in figure 19. The experimental points in the figure show the concentration of radon daughters in air versus the temperature of the concrete for two block conditions designated as (a) high moisture content and (b) low moisture content. For the condition of high moisture content, the relative humidity in the air of the enclosure varied from 84 percent at a block temperature of $23^{\circ} \mathrm{C}$ to 86 percent at a block temperature of $43^{\circ} \mathrm{C}$. Because these humidity factors were larger than those normally encountered in buildings, the block was dried by heating. During the drying process, the enclosure was open to room air which had a low relative humidity. For low moisture in the block, the relative humidities of the air in the enclosure varied from 58 percent at a block temperature of $23^{\circ} \mathrm{C}$ to 72 percent at a block temperature at $43^{\circ} \mathrm{C}$. In the case of a relative humidity of 80 percent at a block 


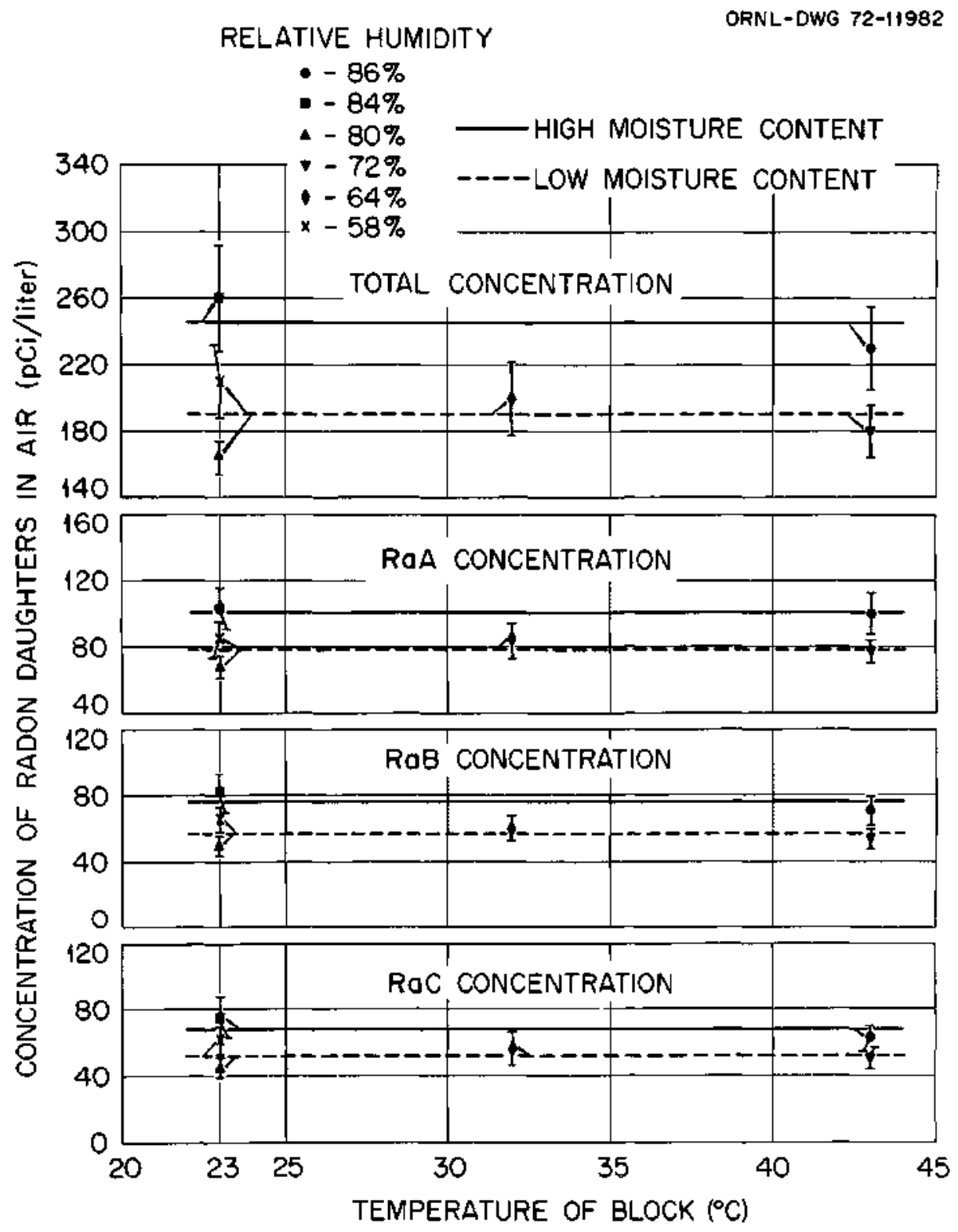

Fig.19. Concentration of Radon Daughters in Emanation Enclosure as a Function of Temperature for High and Low Moisture Content of Concrete Block. 
temperature of $23^{\circ} \mathrm{C}$, the humidity was artificially increased by placing trays of water in the enclosure. In all other cases, the humidity of the air was allowed to come into a natural equilibrium with the moist concrete blocks.

Because of the large size of the concrete blocks, it was difficult to ascertain their moisture content. In these studies, small samples of the moist concrete were weighed before and after drying in a vacuum oven at $150^{\circ} \mathrm{C}$ for 24 hours. The differences in the weights of the samples were used to establish the approximate moisture content of the concrete. In this manner, the low moisture condition was estimated to be 2 to 4 percent by weight and the high moisture condition was estimated to be 6 to 8 percent by weight. The uncertainties in these estimates are large because of the limited space in the avaliable vacuum oven. Results of these studies indicate a negligible temperature effect on the emanation of radon from concrete, between $23^{\circ} \mathrm{C}$ and $43^{\circ} \mathrm{C}$, and a relatively strong dependence of radon emanation on the moisture content of the concrete. Without the measurements of the concentration of radon daughters in air at a block temperature of $23^{\circ} \mathrm{C}$ and a relative humidity of 80 percent, the results might be interpreted to indicate a temperature effect on radon emanation from concrete. However, a decrease in the radon concentration in air with an increase in temperature of the concrete would be contrary to the temperature effect 
reported by Gabrysh and Davis (1955) from studies using crushed samples of uranium bearing rocks.

In the measurements of radon emanation from low moisture concrete, the concentration of radon daughters in afr has an apparent correlation with the relative humidity of the air in the enclosure as shown in figure 20. This apparent correlation is shown in the figure by the straight lines whose equations were obtained by a least squares fit to the experimental data. The effects of the humidity on radon emanation from a highly moist block could not be ascertained due to the small range of relative humidities. However, the data in Figure 19 also show a decrease in the concentration of radon daughters for the equilibrium state at the highest relative humidity in the ambient air.

If the concentration of radon daughters in the air of the enclosure for the low moisture state of concrete are normalized to the same relative humidity using the equations given in Figure 20, the lack of dependence of radon emanation on the temperature of the concrete is obvious. The dependence of radon emanation on the moisture content of the concrete is emphasized by normalizing the concentration of radon daughters in air from a low motsture block to a relative humidity of 80 percent.

In experimental measurements of the ratio of radon concentration to its daughter concentration in the air of the enclosure with blocks of 100 and 50 pounds of 


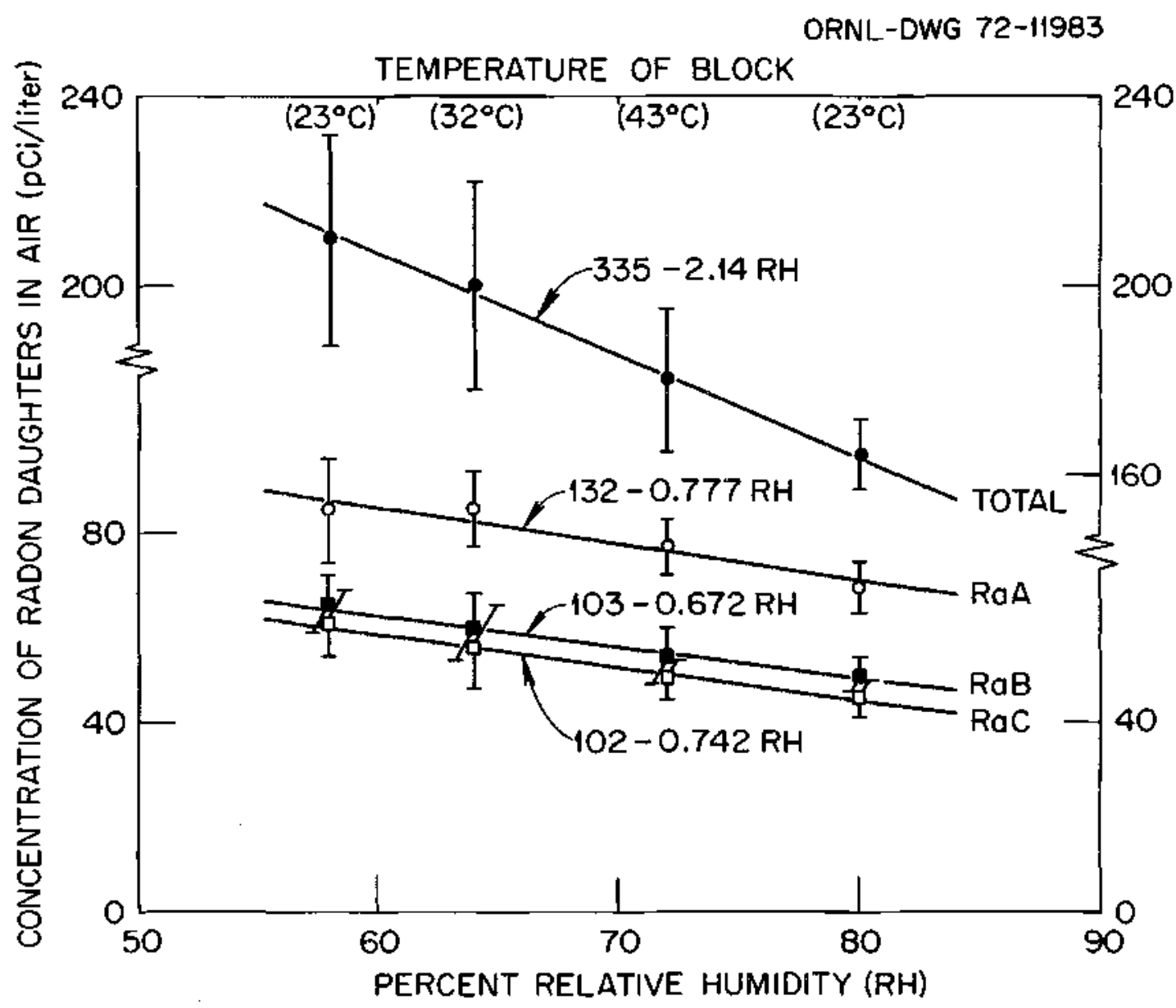

Fig. 20. Concentration of Radon Daughters in Emanation Enclosure as a Function of Humidity. 
carnotite, respectively, a value of $1.60 \pm 0.11$ was obtained, the block containing 100 pounds of carnotite yielding the larger concentrations of radon daughters.

A value of $1.61 \pm 0.05$ was also obtained for the ratio of the radium concentration in the blocks of different uranium content using gamma-ray emission spectra. This average value was obtained by weighing according to the uncertainties in the ratios of the counts in peaks of the emission spectra from the 186,839 , and $2448 \mathrm{keV}$ gamma rays of radium-226. Data on the gamma-ray spectra from these blocks are given in Table 14.

The concentration of polonium-218, or radium- $A$, which is in secular equilibrium with the radon-222 in the air of the enclosure, is related to the total radium-226. The radon-222 in the air of the enclosure is related to that in the concrete by the following expression

$$
q v=f \cdot A_{T}=f \cdot\left(A_{C}+A_{X}\right)
$$

where $q=$ the concentration of RaA in air of enclosure in microcuries per liter, $V=$ volume of the enclosure in liters, $f=$ the escaping fraction of radon from the 
Table 14. Gamma Ray Emission from Bare Concrete Blocks

\begin{tabular}{|c|c|c|c|c|c|c|}
\hline $\begin{array}{l}\text { Experi- } \\
\text { mental } \\
\text { Energy } \\
\text { of } \\
\text { Photo- } \\
\text { peak } \\
(\mathrm{keV})\end{array}$ & $\begin{array}{l}\text { Energy } \\
\text { of } \\
\text { Photon } \\
\text { from } \\
\text { Radon } \\
\text { Pre- } \\
\text { cursors } \\
\text { (keV) }\end{array}$ & $\begin{array}{l}\text { Radon } \\
\text { Pre- } \\
\text { cursors }\end{array}$ & $\begin{array}{l}\text { Abun- } \\
\text { dance } \\
\text { (frac- } \\
\text { tional) }\end{array}$ & $\begin{array}{l}\text { Counts/Sec from } \\
\text { Block with } 50 \mathrm{lbs} \\
\text { of Carnotite }\end{array}$ & $\begin{array}{l}\text { Counts/Sec from } \\
\text { Block with } 100 \text { lbs } \\
\text { of Camotite }\end{array}$ & $\begin{array}{l}\text { Ratio of } \\
\text { Count Rates }\end{array}$ \\
\hline \multirow[t]{2}{*}{186.1} & 185.9 & $234 \mathrm{~Pa}$ & 0.0170 & $(3.65 \pm 0.10) \times 10^{-1}$ & $(5.89 \pm 0.14) \times 10^{-1}$ & $1.61 \pm 0.06$ \\
\hline & 186.1 & ${ }^{226}{ }_{\mathrm{Ra}}$ & 0.0410 & & & \\
\hline 839.0 & 839.0 & ${ }^{226} \mathrm{Ra}$ & 0.0060 & $(5.66 \pm 1.91) \times 10^{-3}$ & $(1.37 \pm 0.24) \times 10^{-2}$ & $2.42 \pm 0.92$ \\
\hline 2447.6 & 2447.6 & ${ }^{226} \mathrm{Ra}$ & 0.0165 & $(8.96 \pm 0.43) \times 10^{-3}$ & $(1.44 \pm 0.06) \times 10^{-2}$ & $1.61 \pm 0.10$ \\
\hline
\end{tabular}


concrete, $A_{T}=$ the total activity of radium-226 or uranium238 in the concrete block in microcuries, $A_{C}=$ the activity of radium-226 or uranium-238 in the carnotite of the block in microcuries, and $A_{X}=$ the activity of radium-226 or uranium-238 in the other materials of the block in microcuries. By use of this equation, we have from the experimental measurement,

$$
\frac{q^{2}}{q^{1}}=\frac{A_{T}^{2}}{A_{T}^{1}}=1.6
$$

so that,

$$
\frac{A_{C}^{2}+A_{X}}{A_{C}^{1}+A_{X}}=\frac{30 \mu C i+A_{X}}{15 \mu C i+A_{X}}=1.6
$$

where the superscripts 1 and 2 are used to specify quantities related to the blocks containing 50 and 100 
pounds of carnotite, respectively. The value of $A_{x}$, the activity of uranium-238 or radium-226 of the block materials other than the carnotite, was found by solution of the above equation to be 10 microcuries. Hence, the total activity of uranium-238 or the activity of radium-226 produced in the block containing 100 pounds of carnotite is 40 microcuries. In order to estimate the fraction of the radon escaping from the concrete, the value of 80 picocuries per liter in the air of the enclosure from the block containing 100 pounds of carnotite was used. This was the value measured for low moisture concrete at a block temperature of $23^{\circ} \mathrm{C}$ and a relative humidity of 58 percent in the air of the enclosure as shown in Figures 19 and 20 . For these conditions, the fraction escaping from the concrete was calculated to be approximately 1 percent. The following relationship, obtained from Equation (70) was used to calculate this value

$$
f=\frac{q \cdot V}{A_{T}}
$$

where $V$ is equal to 3960 cubic liters ( 140 cubic feet), $A_{t}$ is equal to 40 microcuries, and $q$ is equal to 80 picocuries per liter.

In studies on the effects of sealants, no reduction in the concentration of radon daughters in the air of the enclosure and no increase in gamma-ray emission from radon 
daughters in the concrete was observed from blocks that were either stuccoed with cement plaster or coated with asphalt. For a similar stuccoed block coated heavily with epoxy paint, both a reduction in the radon daughter concentration in air and an increase in gamma-ray emission for radon daughters in the concrete was observed.

The concentration of radon daughters in the air of the enclosure before and after the stuccoed block was painted are given in Table 15. The data show that radon escaping from the painted block is less by a factor of four.

Data from the gama-ray emission spectra before and after the stuccoed block was painted are given in Table 16. After a bulldup of 15 to 16 days, which is approximately equal to four half-lives of radon, a 25 percent increase was observed in the gamma-ray emission from radon daughter radionuclides. Buildup in gamma emission from radon daughters due to a sealing of the ground by appreciable precipitation, freezing, or snow cover is discussed by Tanner (1964). The observed buildup of 25 percent in this study is reasonable, although less than 1 percent of the radon escapes from the concrete, because probability of escape from the block is highest for radon produced near the surface, and attenuation of gamma rays by the concrete is less for radon daughters near the surface of the block.

Absorbed dose rate measurements with a Phil dosimeter (Vagner and Hurst 1961) having a large shielded Geiger tube 
Table 15. The Effects of Epoxy Paint on the Escape of Radon from a Stuccoed Concrete B lock

\begin{tabular}{lccc}
\hline $\begin{array}{l}\text { Radon } \\
\text { Daughter } \\
\text { Nuciide }\end{array}$ & $\begin{array}{l}\text { Concentration in Air in pCi/liter } \\
\text { Before Painting }\end{array}$ & After Painting & Ratio \\
\hline RaA & $47.5 \pm 1.9$ & $12.1 \pm 2.0$ & $3.93 \pm 0.66$ \\
RaB & $35.5 \pm 2.8$ & $9.1 \pm 1.7$ & $3.90 \pm 0.79$ \\
RaC & $29.9 \pm 0.7$ & $7.3 \pm 0.8$ & $4.10 \pm 0.46$ \\
Total & $113.0 \pm 4.6$ & $28.6 \pm 3.3$ & $3.95 \pm 0.48$ \\
\hline
\end{tabular}


Table 16. Gama Ray Emission from a Stuccoed Concrete Block Before and After Application of Epoxy Paint

\begin{tabular}{|c|c|c|c|c|c|c|c|}
\hline $\begin{array}{l}\text { Radon } \\
\text { Precursors }\end{array}$ & $\begin{array}{c}\text { Radon } \\
\text { Daughters }\end{array}$ & $\begin{array}{l}\text { Energy of } \\
\text { Photon }\end{array}$ & $\begin{array}{l}\text { Counts/Sec from } \\
\text { Stuccoed Block with } \\
\text { so lbs of Carnotite }\end{array}$ & $\begin{array}{l}1 \text { to } 2 \text { days } \\
\text { after painting }\end{array}$ & $\begin{array}{l}6 \text { to } 7 \text { days } \\
\text { after painting }\end{array}$ & $\begin{array}{l}15 \text { to } 16 \text { days } \\
\text { after painting }\end{array}$ & Ratio \\
\hline${ }^{234} \mathrm{~Pa}$ & & 185.9 & $(2.93 \pm 0.11) \times 10^{-1}$ & $(2.93 \pm 0.12) \times 10^{-1}$ & $(2.94 \pm 0.11) \times 10^{-1}$ & $(2.97 \pm 0.13) \times 10^{-1}$ & $1.014 \pm 0.058$ \\
\hline${ }^{226} \mathrm{Ra}_{\mathrm{a}}$ & & 186.1 & & & & & \\
\hline & $214_{\mathrm{pb}}$ & 352.0 & $(7.92 \pm 0.07) \times 10^{-1}$ & $(8.52 \pm 0.08) \times 10^{-1}$ & $(1.04 \pm 0.01)$ & $(9.95 \pm 0.07) \times 10^{-1}$ & $1.256 \pm 0.014$ \\
\hline & $214_{B i}$ & 609.3 & $(6.52 \pm 0.04) \times 10^{-1}$ & $(7.13 \pm 0.05) \times 10^{-1}$ & $(8.39 \pm 0.05) \times 10^{-1}$ & $(8.22 \pm 0.05) \times 10^{-1}$ & $1.261 \pm 0.011$ \\
\hline & $214_{B i}$ & 1120.4 & $(1.42 \pm 0.02) \times 10^{-1}$ & $(1.58 \pm 0.03) \times 10^{-1}$ & $(1.82 \pm 0.03) \times 10^{-1}$ & $(1.78 \pm 0.03) \times 10^{-1}$ & $1.254 \pm 0.028$ \\
\hline & $214_{B i}$ & 1238.3 & $(5.37 \pm 0.18) \times 10^{-2}$ & $(5.59 \pm 0.23) \times 10^{-2}$ & $(6.92 \pm 0.23) \times 10^{-2}$ & $(6.65 \pm 0.21) \times 10^{-2}$ & $1.238 \pm 0.057$ \\
\hline & $214 i$ & 1764.5 & $(1.08 \pm 0.02) \times 10^{-1}$ & $(1.17 \pm 0.02) \times 10^{-1}$ & $(1.34 \pm 0.02) \times 10^{-1}$ & $(1.32 \pm 0.02) \times 10^{-2}$ & $1.222 \pm 0.029$ \\
\hline & $214_{B 1}$ & 2204.1 & $(2.88 \pm 0.09) \times 10^{-2}$ & $(3.24 \pm 0.11) \times 10^{-2}$ & $(3.70 \pm 0.10) \times 10^{-2}$ & $(3.51 \pm 0.10) \times 10^{-2}$ & $1.219 \pm 0.052$ \\
\hline & $210^{\mathrm{T} 1}$ & 910.0 & $(5.35 \pm 2.26) \times 10^{-3}$ & $(4.91 \pm 2.63) \times 10^{-3}$ & $(6.97 \pm 1.94) \times 10^{-3}$ & $(4.73 \pm 2.25) \times 10^{-3}$ & $0.884 \pm 0.562$ \\
\hline & & & & & \multicolumn{2}{|c|}{ Average Weighted by Uncertainty in Ratio } & $1.247 \pm 0.008$ \\
\hline
\end{tabular}

* Ratio of garma emission from block taken 15 to 16 days after painting to that before painting with epoxy paint. 
at 0.5 meters from both the stuccoed block containing 50 pounds of carnotite and the stuccoed and painted block were the same within uncertainties based on counting statistics. These absorbed dose rates were approximately eight microrads/hour and the uncertainty in the ratio of the two dose measurements was approximately 5 percent. Hence, the increase in the external dose to an individual from sealed concrete due to a buildup in gamma-ray emission from radon daughter products is not significant.

In order to estimate the maximum radon concentrations from concrete walls or floor that could be encountered in homes or buildings, the radon flux has been estimated from the data of this study in terms of the uranium activity per unt volume of concrete. The concentration of radon in the air of the enclosure, $q(R n-222)$, is reiated to the radon flux from the block, $J(R n-222)$, by the relation

$$
J(R n-222) \cdot S=q(R n-222) \cdot V
$$

where $S$ is the surface area of the block and $V$ is the volume of air contained in the enclosure, and the radon flux in terms of the activity of uranium-238 per unit volume of the block, c(U-238), is

$$
\frac{J(R n-222)}{C(U-238)}=\frac{a(R n-222) \cdot v}{C(U-238) \cdot S}
$$


If the same data are used in this calculation that were used in estimating the escape of radon from the block containing the 100 pounds of carnotite, the value of $J(p n-222) / C(U-238)$ is estimated to be $4.5 \times 10^{-4}{ }_{\mu \mathrm{Cj} / \mathrm{m}^{2}}$ of radon-222 $\mathrm{per}{ }_{\mu} \mathrm{Ci} / \mathrm{m}^{3}$ of U-238 in a wall or floor. For a wall or floor with a shaltte aggregate, the radon flux is estimated to be 0.035 $\mu \mathrm{Ci} / \mathrm{m}^{2}$. This estimate is based on the $10{ }_{\mu} \mathrm{Ci}$ of uranium-238 determined to be associated with the shalite and other materials of the blocks used in this study. Of course, the radon flux from a wall or floor would vary, as found in this study, with the moisture content of the concrete and with the type of sealant used on the concrete. 


\section{CHAPTER IV}

\section{DISCUSSION AND COHCLUSIONS}

The most significant conclusions to be drawn are: (1) A Ge(Li) spectrometer having a sensitive volume of 50 cubtc centimeters has sufficient sensitivity and resolution to permit an accurate and conventent analys is in the field of potassium-40 and the naturally occurring radionuclides in the uranium and thorium series; (2) The Ge(Li) spectrometer also provides sufficient sensitivity and resolution to permit identification of radionuclides from nuclear plants at the present low limfts of five millirems/year near the plants: (3) The most important parameter in radon emanation from building materials for a given radium concentration is moisture content; (4) The dose to sections of the human bronchi due to radon concentrations in some relatively common structures equals or exceeds that from the external penetrating gamma rays from uranium and thorium and all their daughters contained in the materials of the structure.

The relative abundances of the gamma emitting isotopes of the uranium and thorium series and of potassium$40 \mathrm{can}$ be inferred from the spectrum as measured with the Ge(Li) spectrometer. A laboratory chemical analysis of soil samples taken at the field measurement sites gives the same relative values as the field spectrometer, except for the 
effects of diseauilibrium in the uranium chain. At some sites, notably Bartow, Florida, the uranium content inferred from gamma spectrometry was high by about a factor of two compared to a determination based upon neutron induced fission activity. The relatively high leachability of uranium compared to radfum appears to be the explanation. Whether or not it is feasible to measure fission product contamination of soll at levels producing $1-5$ mfllirems/year depends upon the energy and half-life of the specific radfonuclide and, of course, on the time after deposition at which measurements are commenced. However, the cesium-137 (from fallout from weapons testing) with a half-life of about 30 years provides a rather severe test, i.e., it delivers a dose rate which decreases insignificantly throughout the year, hence requires the greatest sensftivity for measurement. The dose-rate due to the cesium has been evaluated many times in vartous ways (UNSCEAR 1962 and 1964, FRC 1963 and 1965, Beck 1966, Bennett 1970, EPA 1972, and several others). The estimates for the external dose from cesium-137 in the Eastern Untted States range from less than 1 to more than $2 \mathrm{millirem} /$ year for the year 1970. Comparing spectra from other work with that presented here and correcting for experimental differences, it appears that the maximum dose-rate due to cesium-137 in the "clean" measurement areas used in this study is not more than about 1 millirem/year. As this was readily detectable, dose rates 
of 1 millirem/year of gamma rays could be measured if there were no complicating factors. The most obvious such factor, that of a spectral line lying on or very close to one in the natural radiation environment, is not likely due to the high resolving power of the spectrometer. The importance of spectrometry in identifying gamma-emitting radionuclides is demonstrated by the results of this study. Clearly, a "dose-rate" study is not feasible, regardless of the accuracy and precision of the instruments chosen, because the normal varfation in the natural radiation "dose-rate" is greater than the value ( $1-5 \mathrm{mrad} / \mathrm{yr})$ of the contamination to be measured. Thus spectrometry appears to be the oniy tool available for surveying the environment at such low levels as 1-5 mrad/yr. However, this subject needs extensive investigation in order to delineate the limits of uncertainty and the problems of applicability.

As discussed in Chapter 1. the external gamma ray dose rate to man averages approximately $75 \mathrm{mrad} / \mathrm{yr}$. Doserate measurements made in this study were associated with the spectrometry experiments or were of the survey type, i.e., made with a portable scintillation detector. The dose-rates measured gave good correlation with the total photopeak counts of the nuclides of potassium-40 or of the uranium and thorium series except in those areas contaminated by radionuclides put into the environs by man. From these studies plus data from several sources, notably 
Lowder et al.(1971), 0akley (1971), and Spiers et al.(1964), it appears that the external gamma dose rate for human exposures inside bulidings constructed of granite or of the low-density concretes incorporating expanded Chattanooga shale both average approximately $200 \mathrm{mrad} /$ year. The dose rate range in both cases appears to be $100-500 \mathrm{mrad} / \mathrm{yr}$. This external gamma ray dose is nearly independent of the dose rate due to cosmic radiations or the internal dose due to potassium-40. The internal exposures due to radon daughters discussed below is related most directly to the radium-226 concentrations in the building materials and the radium-226 and 224 concentrations determine most strongly the gamma ray dose rate inside structures built of granite or concrete. In buildings in which the daughters of radium224 are the chief sources of gamma rays, the total dose to man would be very nearly the average doses given in Chapter 1 plus the increase in the gamma ray dose due to the thorium series, especially from radium- 224 to lead-208 because of the short half-life of radon-220 compared to radon-222. However, if the gamma dose rate is elevated due to increased concentrations of uranium, or more directly, of radium-226, the additional internal exposures due to radon-222 and its daughters would be expected unless the building materials were sealed in such a way as to prevent radon-222 emanation. If the materials are sealed, the external uncollided fluence would increase in the typical granite or shale-aggregate 
concrete structure by 25 percent. However, this increase in uncollided photons from the radon daughters provides, in general, a small to negligible part of the total gamma ray fluence. Therefore, sealing the interior surfaces to prevent or decrease radon emanation is generally desirable, especially if good ventilation is feasible. Similar reasoning applies to uranium mines except that sealing exposed mine surfaces appears to be impractical if not impossible at present due to the extended fissures, water seepage, and large areas generally existing in mines.

Radon emanation is controlled strongly by the moisture content of the radium bearing material. There are limited data from other sources which support the findings here (Hahn 1936, Kirikov 1932, Baranov and Novitskaya 1960, and Starik and Melikova 1957), but only Tanner (1964) provides a review of the transport and diffusion theory for radon and it is not clear that any existing theory can predict the behavior of radon in a complex part crystaliine, part non-crystalline, porous, and inhomogeneous solid. However, of the two mechanisms for explaining the enhancement due to moisture in the material, it appears to this author that the relatively high solubility of radon and its subsequent diffusion, through water containing pores, to the surface is the most likely, but this cannot be put on a quantitative basis at present. The failure of a finegrained stucco of 0.25 -inch thickness to lower the emanation 
significantly lends credence to this hypothesis. The fact that an adhesive layer of asphalt cement was also ineffective in decreasing the emanation significantiy is most probably due to the general diffusability of the noble gases through hydrogenous materials. It is clear from the data on radon emanation from concrete (specifically the low density concrete used in this experiment but with evidence that finer porosity concrete does not significantly affect the emanation) that a home constructed of concrete containing only shale aggregate could have radon levels that reach several tens of picocuries per liter under equilibrium conditions. Considering that homes are generally only partially constructed of concrete and that equilibrium conditions are seldom met in occupied structures due to some minimal ventilation, $i t$ is still evident that a few picocuries per liter would not be unusual in the East Tennessee area, as an example. Actually, in a limited survey (Lowder et al. 1971), values of the order of 1 picocurie per liter were obtained in East Tennessee homes under ventilation conditions; the afr exchange rates were not measured. For low ventilation rates such as night be found in cold climates it is reasonable to assume that 10 picocuries per liter would not be uncomimon; this corresponds, by the calculational procedure used in Chapter I, to 1-2 rads/year to the bronchi of an adult for an eight- 
hour day, and up to 6 rads/year for full-time occupancy. This level of occupancy is frequently approached by young children. In a more extensive study involving 841 measurements, Toth (1972) found average concentrations in living rooms of houses in Hungary of $3.05,2.64$, and 2.49 picocuries of $R a A, R a B$, and RaC, respectively. These measurements were made in 14 different towns in Hungary in houses which had not, in general, been ventilated for at least eight hours. However, the average is not of as great interest here as the distributions; Toth found that the concentration of RaA exceeded 10 picocuries per 11 ter in 6 percent of all measurements. Further, he shows that his values are not atypical of other areas of the world having "radioactivity not higher than normal." In structures of interest here there are above average concentrations of uranium in the buflding materials; considering that all occupied structures have some ventilation, the comonly observed levels of up to 10 picocuries/liter in granite and low density concrete structures appear in good accord with the emanation observed here. It is clear then, that it is not unlikeiy that the overall dose to the bronchi of people occupying homes built of uranium bearing materials over a 50-year period at an average of 15 hours/day would approach that at which the incidence of lung cancer in uranium miners is doubled. If a sensitivity factor for children is 
allowed, the effective doses would, of course, be increased. Contrartly, if a repair mechanism is assumed due to the low dose rates and long exposure times, which would appear unlikely for alpha particles due to their high linear energy transfer (LET) an increased incidence would not be expected. Analysis of the air samples taken inside the enclosure for radon emanation studies showed that radon levels reached a constant level in about three days at which time the daughters were in equilibrium. However, for samples taken in dwellings, the ratio of RaC'to RaA ranged from 0.25 to 0.8 , indicating that equilibrium is seldom if ever reached in dwellings.

It should be noted that the internal exposure values for the bronchi discussed in the preceding paragraph are from the same order to an order of magnitude higher than the external whole body dose from gamma rays from the natural radiation environment. Because such internal and external doses are so comparable with those of the uranium miners at which some increased incidence of cancer is observed, epidemiological studies in high radiation areas of the world should show, ultimately, increased somatic effects of radiation; such effects have not yet been observed and/or published in the literature.

As evidenced by extensive literature, the natural radiation environment is both fascinating and frustratingly complex for the many scientists who have studied it. Some 
of the unanswered questions concerning man's exposure to the natural radiation environment were the basis for this research and there remain many other unanswered questions beyond the scope of this research. Some answers were found and a better understanding of the natural radiation environment has been made possible. Still, extensive follow-up research needs to be conducted. Because of the breadth of the studies attempted, a more comprehensive study of many facets of the work appears desirable and necessary. For example, the exact mechanism by which moisture in concrete enhances radon emanation should be determined; that alone would make a good dissertation study. The correlation of fluence and spectral measurements from aircraft with similar measurements on the ground and with soll concentrations of radium (both 220 and 222) would also make an excellent research project.

Throughout this thesis, much of the discussions of standard laboratory techniques, basic statistical analyses, and detailed descriptions of equipment have been severely shortened compared to the usual theses; in some cases they have been deleted entirely. This is taken to be justified, for this thesis, in order to maintain a manageable length and because the author has used such techniques over many years and has several publications concerning such discussions of laboratory and analysis techniques. 
APPENDIX I

DISTRIBUTIONS OF DOSE FROM NATURAL SOURCES II "NORHAL" AREAS

Based on surveys in areas of "normal" levels of the natural radiation environment, the United Nations Scientific Committee on the Effects of Atomic Radiation (UNSCEAR 1966) concluded that the values shown in Table 17 represent average distributions of dose to man from the natural environment. An earlier report of this same conmittee listed the cosmic ray dose dose to man (average whole body dose) as a function of altitude above sea level for regions near the equator and near 50 degrees geomagnetic latitude given in Table 18. As the dose rates vary slowly with latitude, the values for 50 degrees geomagnetic latitude can be applied to the 48 contiguous states of the U.S. Within an accuracy of about 10 percent except for periods of unusual solar activity. 
Table 17. Dose Rates Due to External and Internal

Irradiation from Natural Sources in

"Norma1" Areas*

\begin{tabular}{|c|c|c|c|}
\hline \multirow[b]{2}{*}{ Source of Irradiation } & \multicolumn{3}{|c|}{ Dose Rates (mrad/yr) } \\
\hline & Gonads & $\begin{array}{l}\text { Cells Lining } \\
\text { Bone Surfaces }\end{array}$ & $\begin{array}{l}\text { Bone } \\
\text { Marrow }\end{array}$ \\
\hline
\end{tabular}

External irradiation

$\begin{array}{lccc}\text { Cosmic rays } & & & \\ \text { Ionizing component } & 28 & 28 & 28 \\ \text { Neutrons } & 0.7 & 0.7 & 0.7\end{array}$

Terrestrial radiation

(including air)

50

50

50

Internal Irradiation

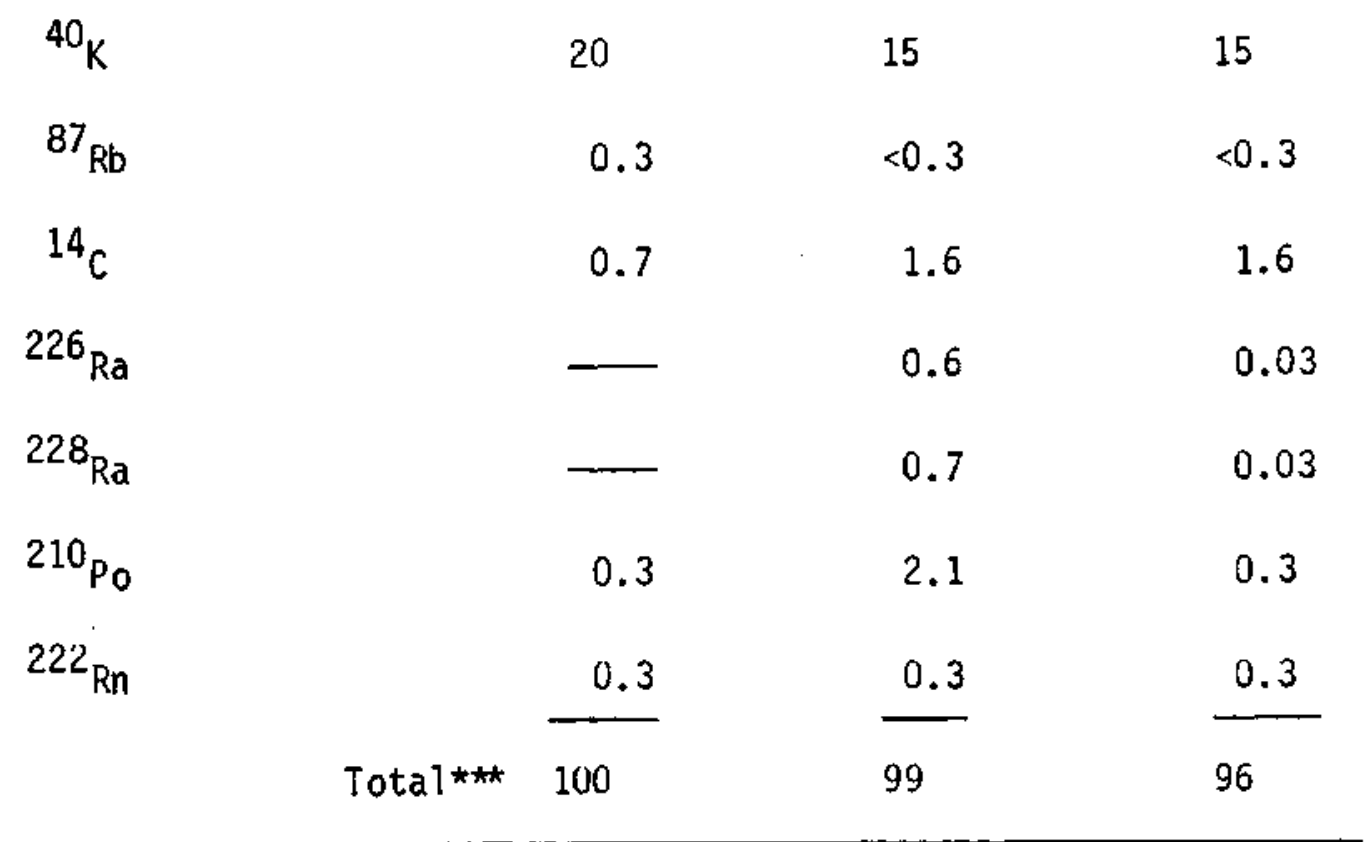

* UNSCEAR 1966.

** The dose rates under this heading were actually calculated for the Haversian canals of bone. Doses to cells lining bone surfaces may be somewhat lower that those quoted here.

***Totals have been rounded off to two significant figures. 
Table 18. Cosmic Ray Intensities and Dose Rates*

\begin{tabular}{|c|c|c|c|c|}
\hline \multirow[b]{2}{*}{$\begin{array}{l}\text { A7 titude } \\
\mathrm{m}\end{array}$} & \multicolumn{2}{|c|}{$\begin{array}{l}\text { Intensity } \\
\text { ion pairs } / \mathrm{cm}^{3} \cdot \mathrm{sec}\end{array}$} & \multicolumn{2}{|c|}{$\begin{array}{l}\text { Dose Rate } \\
\mathrm{mrad} / \text { year }\end{array}$} \\
\hline & $\begin{array}{l}\text { At } 50^{\circ} \\
\text { Latitude }\end{array}$ & $\begin{array}{l}\text { Near } \\
\text { Equator }\end{array}$ & $\begin{array}{l}\text { At } 50^{\circ} \\
\text { Latitude }\end{array}$ & $\begin{array}{l}\text { Near } \\
\text { Equator }\end{array}$ \\
\hline 0 & 2.8 & 2.4 & 41 & 35 \\
\hline 1500 & 4.5 & 3.0 & 66 & 44 \\
\hline 3050 & 8.8 & 6.1 & 128 & 89 \\
\hline 4580 & 18 & 12 & 263 & 175 \\
\hline 6100 & 34 & 23 & 500 & 340 \\
\hline
\end{tabular}

* UNSCEAR 1958. 
The United Nations Scientific Committee has defined the term "Genetically Significant Dose" as "the dose which, if received by every member of the population, would be expected to produce the same total genetic injury to the population as do the actual doses received by the various individuals" (UASCEAR 1958). It is intended to relate linearly to the potential mutagenic effect of radiation, 1.e., to serve as an index of radiation damage to the genetic pool. In general, an observed radiation field, frequently expressed in roentgens, is operated upon by an expression which includes that for the depth dose distribution in the body for the particular radiation, to obtain the average absorbed dose in the gonadal tissues, expressed in rads. This absorbed dose is then used in the mathematical expression:

$$
G S D=\frac{\sum D_{i} N_{i} P_{i}}{\sum N_{i} P_{i}}
$$


where $D$ is the average gonadal dose to individuals of age $i$ recelving the radiation, $A$ is the number of persons in the population of age $i$ who receive the radiation, $p$ is the expected future number of offspring for an individual of age i. This operation eliminates from the GSD that portion of the total absorbed dose that goes to the gonads of persons beyond the childbearing age. Morgan (1971) estimated that the GSD so obtained is approximately half of the absorbed dose for the special case of diagnostic radiology, but it appears that the estimate should be appropriate for the natural radiation environment to within the accuracy intended. Of course, $P$ must remain an estimate because the average mortality rate as a function of age may change with time, and the number of offspring per person of childbearing age may change. 
THE MAXIMUM PERMISSIBLE CONCENTRATION VS. THE HORKING LEVEL

The presently used maximum permissible concentration (MPC) of radon and its daughters was established by the Internal Dose Committees of the International Commission on Radiological Protection and the National Council on Radiation Protection and Measurements (ICRP 1959, IICRP 1959). This concentration of radon, 30 picocuries/liter, was intended to apply to all occupationally exposed persons. The "occupational worker" levels were not applicable to persons under 18 years of age. The level was based on the concept of the maximum permissible dose to most organs being set at 15 rems/year and was obtained by calculating the dose to the basal cells of the bronchial epithelium from radon in equilibrium with its short-lived daughters, RaA, RaC, and RaC'. Based largely on the work of Chamberlain and Dyson (1956) and Shapiro (1956), the Internal Dose Committees agreed on an "unattached" fraction ( $f$ ) of 10 percent for RaA ions or atoms where actual measurements could not be made; this refers to the fraction of the RaA which is not attached to particulates in the air. However, they made provision for more accurate estimates based on experimental determination of $f$ by providing the relation, 


$$
M P C=\frac{3}{1+1000 f}
$$

or, for $f=0.1$ and 100 percent equilibrium, $M P C=30$ picocuries of radon-22 per liter. There were several other considerations and assumptions which do not bear directly on the comparison of MPC and the working level (WL) and will not be given here, but which are given in the committee reports (ICRP 1959, NCRP 1959) and discussed at length by Morgan (1967).

In 1957 the U. S. Public Health Service Introduced the WL. In the introduction of a report by Holaday, (1967) the authors state, "It has therefore been necessary to establish a working level which appears to be safe, yet not unnecessarlly restrictive to industrial operations." The ultimate definition given of the WL was that it is any combination of the short-lived decay products of radon in one liter of air which will result in the emission of 130 GEV of alpha ray energy. This corresponds, numerically, to the alpha energy released by 100 picocuries/liter of radon in equilibrium with the short-lived daughters. The unit was chosen with consideration for sampling techniques then in use in the mines (drawing a one liter sample of mine air into a bottle for analysis in the laboratory).

From the above, it is clear that the ratio between MPC and WL may vary from unity by a large factor depending 

Table 19. Comparative Values of $\mathrm{KL}$ and the MPC as Given by ICRP and NCRP for an Atmosphere of $10^{-7}{ }_{\mu C i} / \mathrm{cc}\left(10^{-11} \mathrm{Ci} / 1\right)$ of ${ }^{222} \mathrm{Rn}$

\begin{tabular}{|c|c|c|c|c|c|c|}
\hline \multirow[t]{2}{*}{$\begin{array}{c}\% \text { Equilibrium } \\
\text { of RaA }\end{array}$} & \multirow[t]{2}{*}{$\begin{array}{l}\% \text { Equilibrium } \\
\text { of } \mathrm{RaB} \text { and } \mathrm{RaC}\end{array}$} & \multirow[t]{2}{*}{$\begin{array}{l}\text { \%Unattachment } \\
\text { of } \operatorname{RaA}\end{array}$} & \multirow[t]{2}{*}{$\begin{array}{l}\text { Actual No. } \\
\text { of MPC }\end{array}$} & \multicolumn{3}{|c|}{$\begin{array}{c}\text { Number of WL Assuming } 100 \% \text { Equilibrium of } \\
\text { RaA, RaB and RaC at Time of } \\
\text { Collection of Sample }\end{array}$} \\
\hline & & & & for $t=0$ & $r t=1$ hour & for $t=4$ hours \\
\hline 100 & 100 & 100 & 30 & $1(30) *[1] * *$ & $1(30)$ & $1(30)$ \\
\hline 100 & 10 & 100 & 30 & $0.55(55)[0.35]^{\star \star}$ & $0.18(170)$ & $0.2(150)$ \\
\hline 100 & 100 & 3 & 1 & $1(1)[1]$ & $1(1)$ & $1(1)$ \\
\hline 100 & 10 & 3 & 1 & $0.55(1.8)[0.35]$ & $0.18(5.7)$ & $0.2(5)$ \\
\hline 10 & 100 & 100 & 3 & $0.55(5.5)[1.6]$ & $0.91(3.3)$ & $0.9(3.3)$ \\
\hline 10 & 10 & 100 & 3 & $0.1(30)[1]$ & $0.1(30)$ & $0.1(30)$ \\
\hline 10 & 100 & 3 & 0.1 & $0.55(0.18)[1.6]$ & $0.91(0.11)$ & $0.9(0.11)$ \\
\hline 10 & 10 & 3 & 0.1 & $0.1(1)[1]$ & $0.1(1)$ & $0.1(1)$ \\
\hline
\end{tabular}

Note: In Table 15, it is assumed the MPC is measured correctly. The WL is measured at time $t$ after the collection, but it is assumed in extrapolating the WL back to $t=0$ that $100 \%$ equilibrium of RaA, RaB and RaC at time of collection was used. It is further assumed the WL is determined on ly by counting the $\alpha$-disintegrations at time $t$ and no energy resolution is used in the counting. All the usual corrections are made for background, absorption, etc.

* All values in parenthesis indicate the ratio of MPC to WL, i.e., for (30) the MPC is 30 times the WL as measured by the above method.

**VaTues in brackets are the ratios of the MeV of the a-radiation of the actual isotopic mixture integrated from time $t=0$ to $\infty$ divided by the MeV of the a-radiation for $100 \%$ equilibrium mixture of $\mathrm{RaA}, \mathrm{RaB}$ and $\mathrm{RaC}$ integrated from zero to infinity and divided by the estimated WL at time zero. In other words, it is the ratio of the fraction of equilibrium MeV from $t=0$ to $\infty$ to the estimated WL. 


\section{GAMMA SPECTRAL DATA FROM THE FIELD}

Because of the variety of soil compositions for which measurements were made with the $G e(L i)$ spectrometer, a range of relative contributions of the various radionuclides was observed. The observed photopeaks, their relative abundances, and the radionuclides to which they vere attributed are given in the following table. No similar data are known to exist, and these have proved to be useful to this study. The data from the multichannel analyzer were fed into the computer using the programs developed in this study, and the table was printed by the computer with no reprinting or editing; this indicates the degree to which the data were handled by the computer. The headings refer to the experiment as follows:

$B G--B$ ackground count

EGCR--Experimental Gas Cooled Reactor Site - A "clean area."

Shalite Blocks--Standard Commercial Building blocks expanded Shale aggregate, i.e., lightweight material of approximately 90 pounds/cubic foot; detector protruding into five sided box built of these blocks. 
Concrete Slab EGCR--A clean concrete slab of regular concrete one foot thick covered by a thin metal butlding.

K-25 Burial Ground-- area formerly used to store heavily contaminated equipment, the primary contaminant being uranium.

Whitley City, Ky.--Extensive coal slag heap in southern Ky. See Chapter II.

Manchester, Ky.--On a drive-in theatre near a coal treatment plant.

Atlantic Beach, Fla,--open beach area, typical of area. Bartow, Fla; First Run--ilunicipal center at Bartow, Fla. Second Run--Playground area at municipal center. Bartow, Fla.

Stone Mountain, Ga.--Stone Quarry area at east side of park area. 
BG EGCR

\begin{tabular}{|c|c|c|c|}
\hline $\begin{array}{l}\text { ENERGY } \\
\text { FOUND }\end{array}$ & $\begin{array}{l}\text { KNOWN } \\
\text { ENERGIES }\end{array}$ & & SOURCE I SOTOPES \\
\hline $\begin{array}{l}\text { FOUND } \\
\text { (KEV) } \\
161 \cdot 2 \\
222.9\end{array}$ & $\begin{array}{l}\text { ENERGIES } \\
\text { W/IN } 0.2 \%\end{array}$ & ABUN DANCE & SOURCE ISOTOPES \\
\hline $\begin{array}{l}330.2 \\
352.3 \\
609.5\end{array}$ & $\begin{array}{l}330 \cdot 6 \\
352 \cdot 0 \\
609 \cdot 3 \\
609 \cdot 4\end{array}$ & $\begin{array}{l}0.0100 \\
0.3600 \\
0.4700 \\
0.1700\end{array}$ & $\begin{array}{l}234 \mathrm{PA} \\
214 \mathrm{~PB}^{*} \\
214 \mathrm{BI} * \\
214 \mathrm{BI} *-1 \mathrm{ST}-\mathrm{ESC} .\end{array}$ \\
\hline $661 \cdot 3$ & $\begin{array}{l}661 \cdot 0 \\
661 \cdot 6 \\
662 \cdot 2\end{array}$ & $\begin{array}{l}0.0000 \\
0.8600 \\
0.0026\end{array}$ & $\begin{array}{l}214 \mathrm{BI} \\
* 137 \mathrm{CS} * \\
226 \mathrm{RA}-\mathrm{DEC}-2 \mathrm{ND}-\mathrm{ESC}\end{array}$ \\
\hline $787 \cdot 4$ & $\begin{array}{l}785.9 \\
787.1\end{array}$ & $\begin{array}{l}0.0086 \\
0.0120\end{array}$ & $\begin{array}{l}214 \mathrm{~PB}^{*} \\
214 \mathrm{BI}\end{array}$ \\
\hline $\begin{array}{r}956 \cdot 6 \\
997 \cdot 4 \\
1137 \cdot 2 \\
1348 \cdot 4\end{array}$ & $\begin{array}{r}955.0 \\
998.2 \\
1139.0\end{array}$ & $\begin{array}{l}0.0130 \\
0.0200 \\
0.0200\end{array}$ & $\begin{array}{l}232 T H-D E C-1 S T-E S C \\
214 B I *-1 S T-E S C \\
210 T L-1 S T-E S C .\end{array}$ \\
\hline $\begin{array}{l}1461 \cdot 0 \\
1806 \cdot 4 \\
1994 \cdot 9 \\
2142 \cdot 3\end{array}$ & $\begin{array}{l}1460.0 \\
1806.0\end{array}$ & $\begin{array}{l}0.1100 \\
0.0015\end{array}$ & $\begin{array}{l}40 \mathrm{~K} \\
212 \mathrm{BI}\end{array}$ \\
\hline
\end{tabular}


SHALELITE BLOCKS

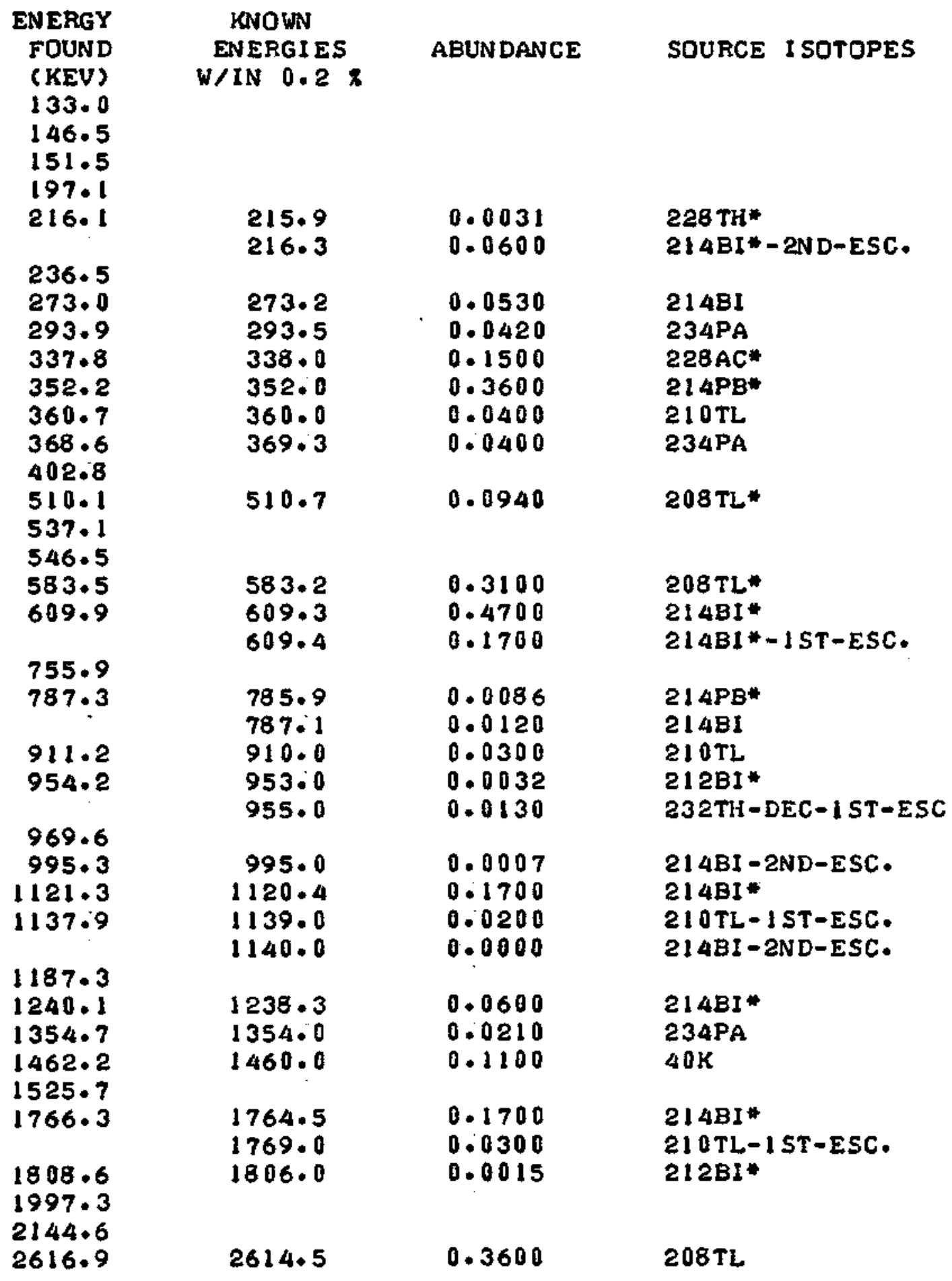


CONCRETE SLAB EGCR

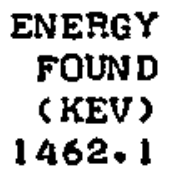

ENERGY (KEV)

1462.1
KNOWN

ENERGIES

W/IN $0.2 \%$

1460.0
ABUN DANCE

0.1100
SOURCE ISOTOPES

$40 \mathrm{~K}$

CESIUM FIELD

\begin{abstract}
ENERGY
FOUND

( KEV)

168.8

237.2

328.0

351.9

412.0

510.9

583.7

609.7

$661 \cdot 5$

786.2

910.3

954.9

1141.4

1191.1

1461.1

1798.7

1999.7

2143.7
\end{abstract}

ABUNDANCE

ENERGIES

W/IN 0.28

328.0

328.6

$352: 0$

510.7

583.2

609.3

609.4

661.0

661.6

662.2

$785 \cdot 4$

785.9

787.1

910.0

953.0

955. 0

1140.0

1460.0
0.0530

0.0018

0.3600

0.0940

0.3100

0.4700

0.1700

0.0000

0.8600

0.0026

0.0097

0.0086

0.0120

0.0300

0.0032

0.0130

0.0000

0.1100
SOURCE ISOTOPES

228AC*

$212 B I *$

$214 \mathrm{~PB}^{*}$

$208 \mathrm{TL} *$

$208 \mathrm{TL} *$

$214 B I *$

$214 \mathrm{BI} *-1 \mathrm{ST}-\mathrm{ESC}$.

$214 \mathrm{BI}$

**137CS**

226RA-DEC-2ND-ESC

$212 B I *$

$214 \mathrm{~PB}$

2I $4 B 1$

$210 T$

$212 B 14$

232TH-DEC-I ST - ESC

$214 B 1-2 N D-E S C$.

$40 K$ 
K-25 STORAGE AREA

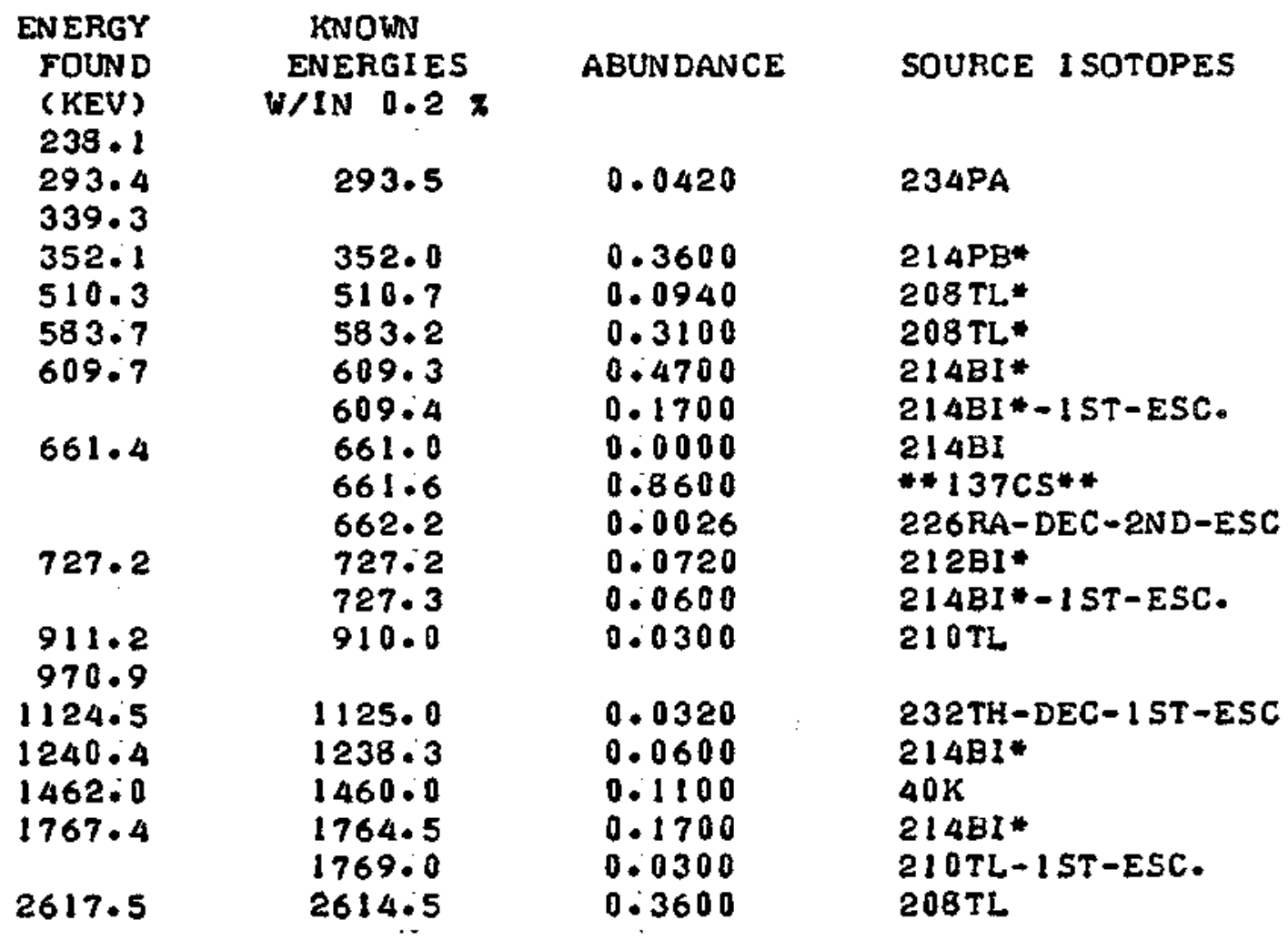


CHAT TANDOGA SHALE

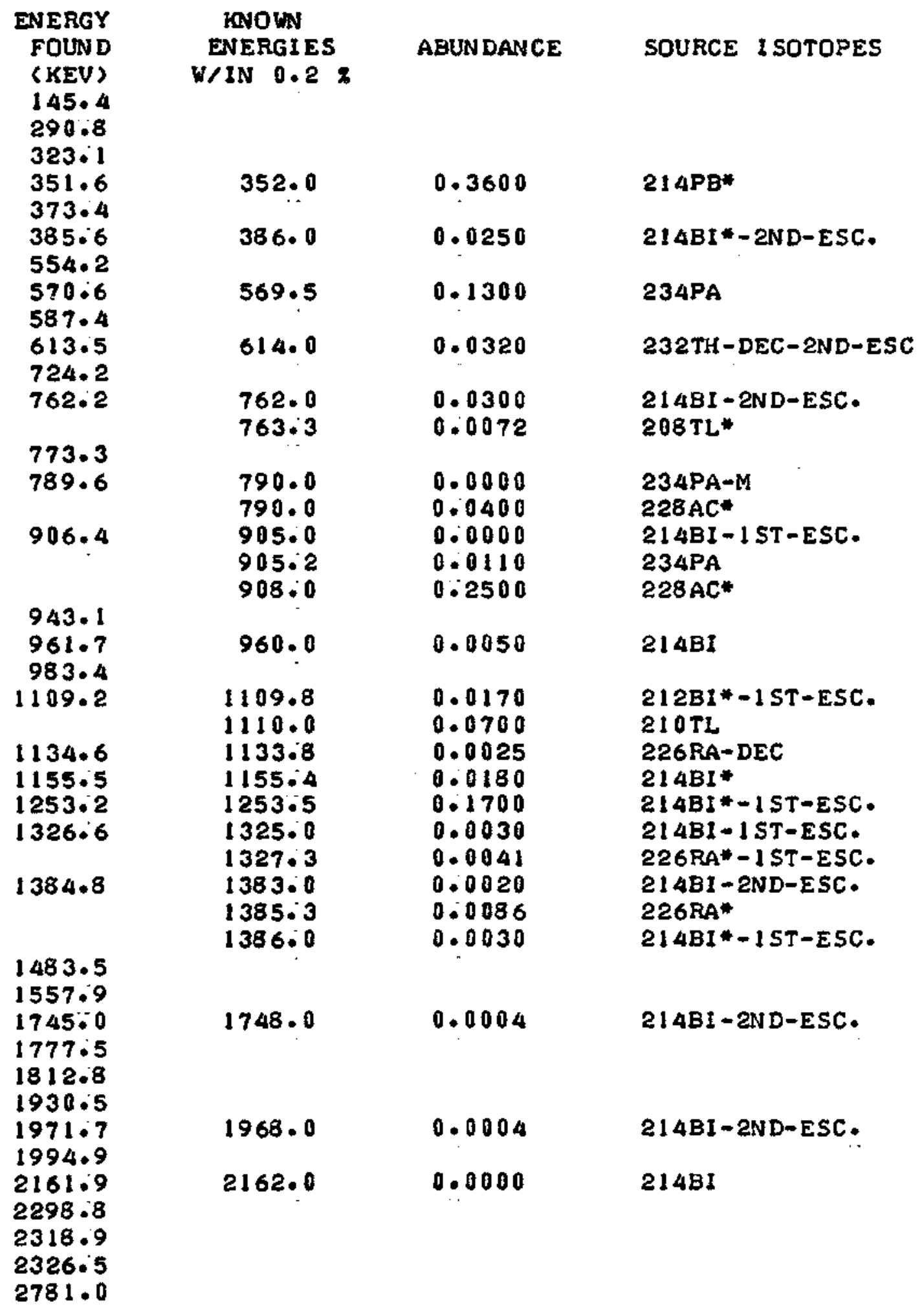


SHINPAUGH HOUSE

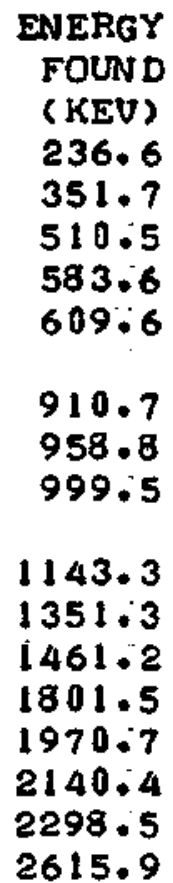

KNOWN
ENERGIES
WIN $0.2 \times$
352.0
510.7
583.2
609.3
609.4
910.0
960.0
998.2
1001.0

ABUNDANCE

SOURCE I SOTOPES

(KEV)

ABUNDANCE

0.3600

0.0940

0.3100

0.4700

0.1700

0.0300

0.0050

0.0200

0.0060

$214 \mathrm{~PB}$

208 TL*

$208 \mathrm{TL} *$

21 $4 \mathrm{BI}$

$214 B I *-I S T-E S C$.

$210 \mathrm{TL}$

$214 \mathrm{BI}$

$214 B I *-1 S T-E S C$.

234PA-M

1354.0

0.0210

234PA

$1460: 0$

0.1100

$40 \mathrm{~K}$

$1968 \cdot 0$

0.0004

$214 B I-2 N D-E S C$.

$2614 \cdot 5$

0.3600

$208 T L$ 
WHITLEY CITY,KY

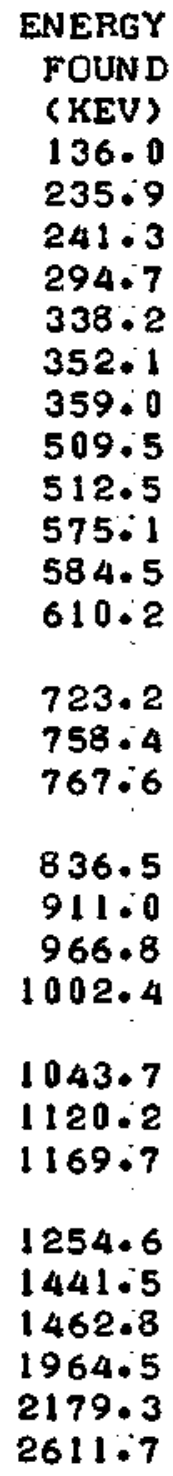

KNOWN

ENERGIES

W/IN $0.2 \%$

236.0

241.0

295.2

338. 0

352.0

609.3

609.4

768.0

$768: 7$

837.0

910.0

966.0

1001.0

1002.1

1043.0

1120.4

1168.5

1170.0

1253.5

1460.0

$1968: 0$

$2614 \cdot 5$
ABUN DANCE

0.0000

0.0370

0.1900

0.1500

0.3600

0.4700

0.1700

0.0080

0.0500

0.0080

0.0300

0.2000

0.0060

0.0036

0.7000

0.1700

0.0008

0.0020

0.1700

0.1100

0.0004

0.3600
SOURCE I SOTOPES

234PA-M

224RA*

$214 \mathrm{~PB}^{*}$

228AC*

$21 \triangle \mathrm{PB}^{*}$
$214 \mathrm{BI} *$
$214 \mathrm{BI} *-1 \mathrm{ST}-\mathrm{ESC}$.

$214 B I-2 N D-E S C$.

$214 B I *$

214BI

$210 T L$

228AC*

234PA-M

$212 B I *-15 T-E S C$.

$50 \mathrm{~V}-1$ ST-ESC.

214BI*

212BI-1 ST-ESC.

$214 \mathrm{BI}-1 \mathrm{ST}-\mathrm{ESC}$.

$214 B I *-1 S T-E S C$.

$40 \mathrm{~K}$

$214 \mathrm{BI}-2 \mathrm{ND}-\mathrm{ESC}$.

$208 \mathrm{TL}$ 
MANCHESTER, KY

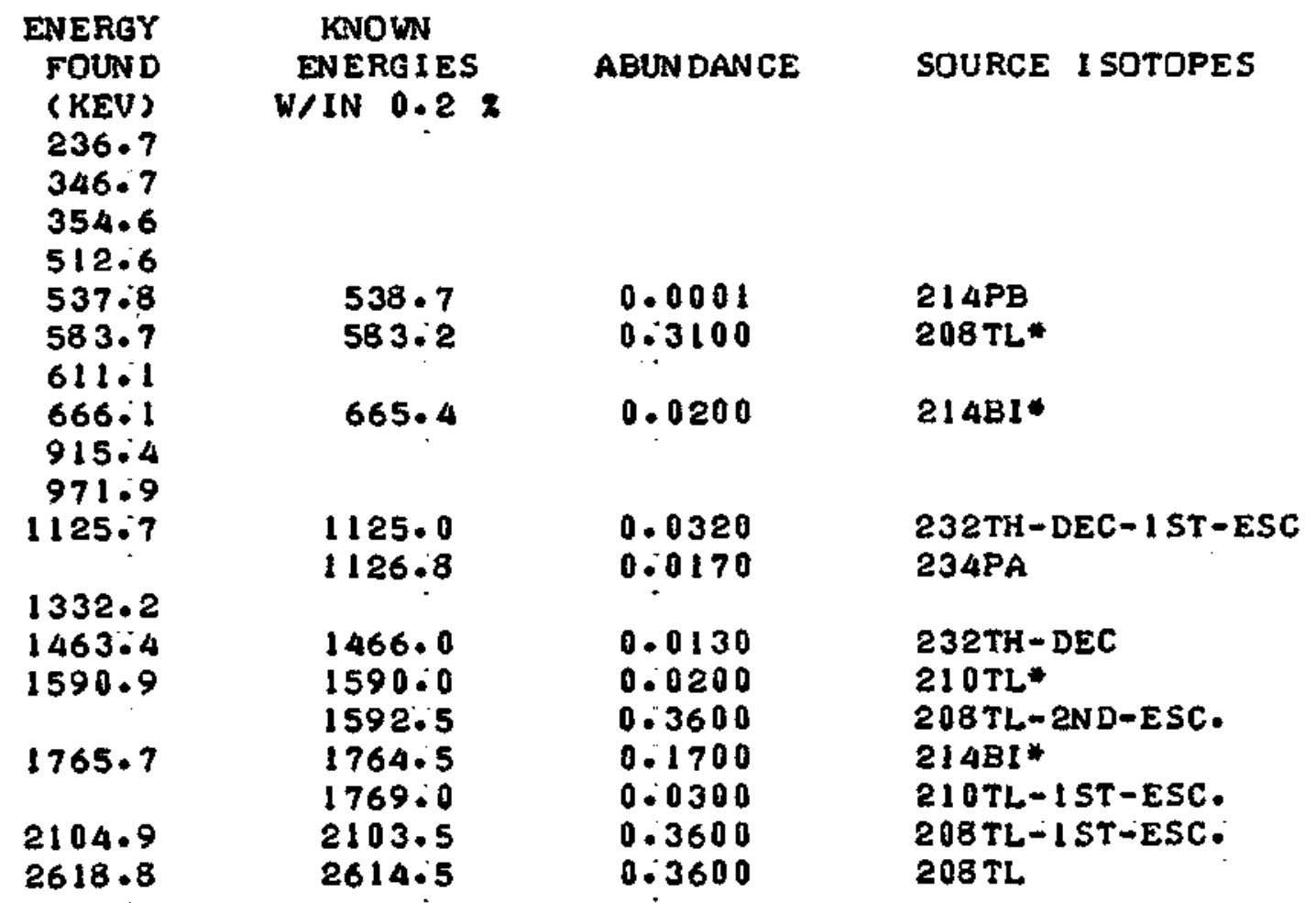


ATLANTIC BEACH, FLA

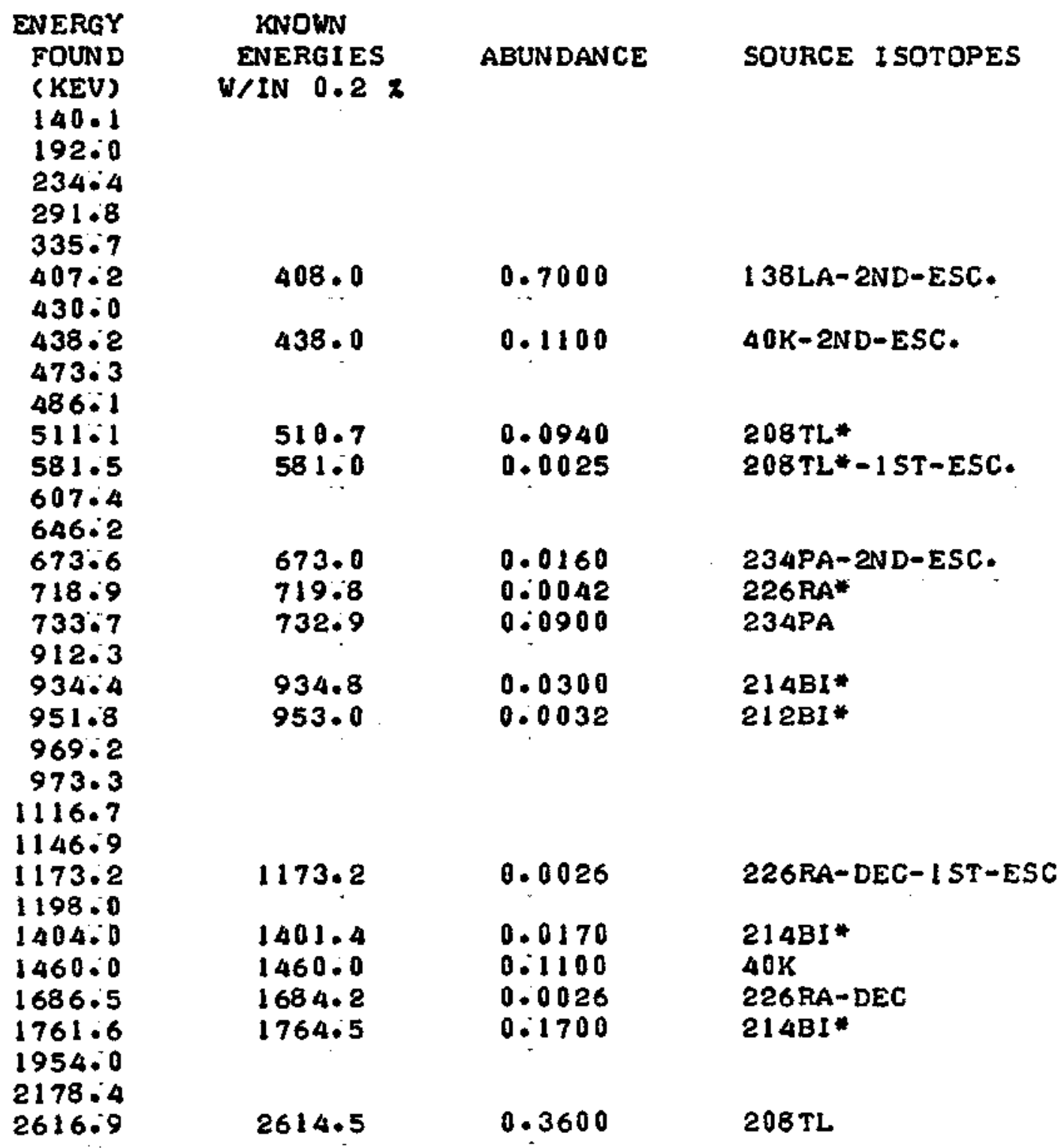


BARTOW,FLA FIRST RUN

\section{ENERGY \\ FOUND \\ (KEV) \\ 131.9 \\ 140.0 \\ 182.4 \\ $189: 8$ \\ 207.2 \\ 238.8 \\ 292.6 \\ 305.6 \\ 351.8 \\ 355.5 \\ 381.9 \\ $395: 3$ \\ 406.5 \\ 432.5 \\ $447: 0$ \\ 455.5 \\ 467.8 \\ 484.9 \\ $531: 3$ \\ 536.0 \\ 563.7 \\ 568.4}

579.5

$584: 9$

597.2

$608 \cdot 7$

612.7

$648: 2$

$664: 0$

682.9

698.6

704.4

$769: 3$

$778 \cdot 4$

787.5

$793: 8$

806.0

822.6
KNOWN

ENERG IES

W/IN $0.2 \%$

132.0

$238 \cdot 6$

305.4

306.0

352.0

355.6

395.0

405.9

454.8

$468: 0$

532.0

568.0

$568: 1$

569.5

$580: 3$

609.3

609.4

649.0

699.0

699:0

703.2

768.0

$768: 7$

770.3

779.0

787.1

792.8

795.0

806.3

$821: 0$
ABUN DANCE

0.0020

0.4700

0.0030

0.9500

0.3600

0.0500

0.0120

0.0017

0.0033

0.0200

0.7000

0.0200

0.0043

0.1300

0.0036

0.4700

0.1700

0.0150

0.0430

0.1700

0.0080

0.0080

0.0500

0.0170

0.0140

0.0120

0.0014

1.0000

0.0150

0.0016
SOURCE ISOTOPES

$228 \mathrm{TH} *$

$212 \mathrm{~PB}^{*}$

$214 \mathrm{~PB}$

$176 \mathrm{LU}$

214 PB*

$214 B I *-2 N D-E S C$.

$214 B I$

226RA*

226 PA*

$210 \mathrm{TL}-2 N D-E S C$.

$50 \mathrm{~V}-2 N D-E S C$

21 OTL* - 2ND-ESC. $212 B I *-1$ ST-ESC:

234PA

21 $4 \mathrm{Pg} *$

214BI*

$214 B I *-1 S T-E S C$.

234PA-2ND-ESC.

234PA

$210 \mathrm{TL}-1 \mathrm{ST}-\mathrm{ESC}$.

$214 \mathrm{BI}$

$214 \mathrm{BI}-2 \mathrm{ND}-\mathrm{E} 5 \mathrm{C}$.

$214 B I *$

$214 B I *-1 S T-E S C$.

228 AC*

$214 \mathrm{BI}$

226RA-DEC-1ST-ESC

$210 \mathrm{TL}$

214BI*

$214 \mathrm{BI}$ * 


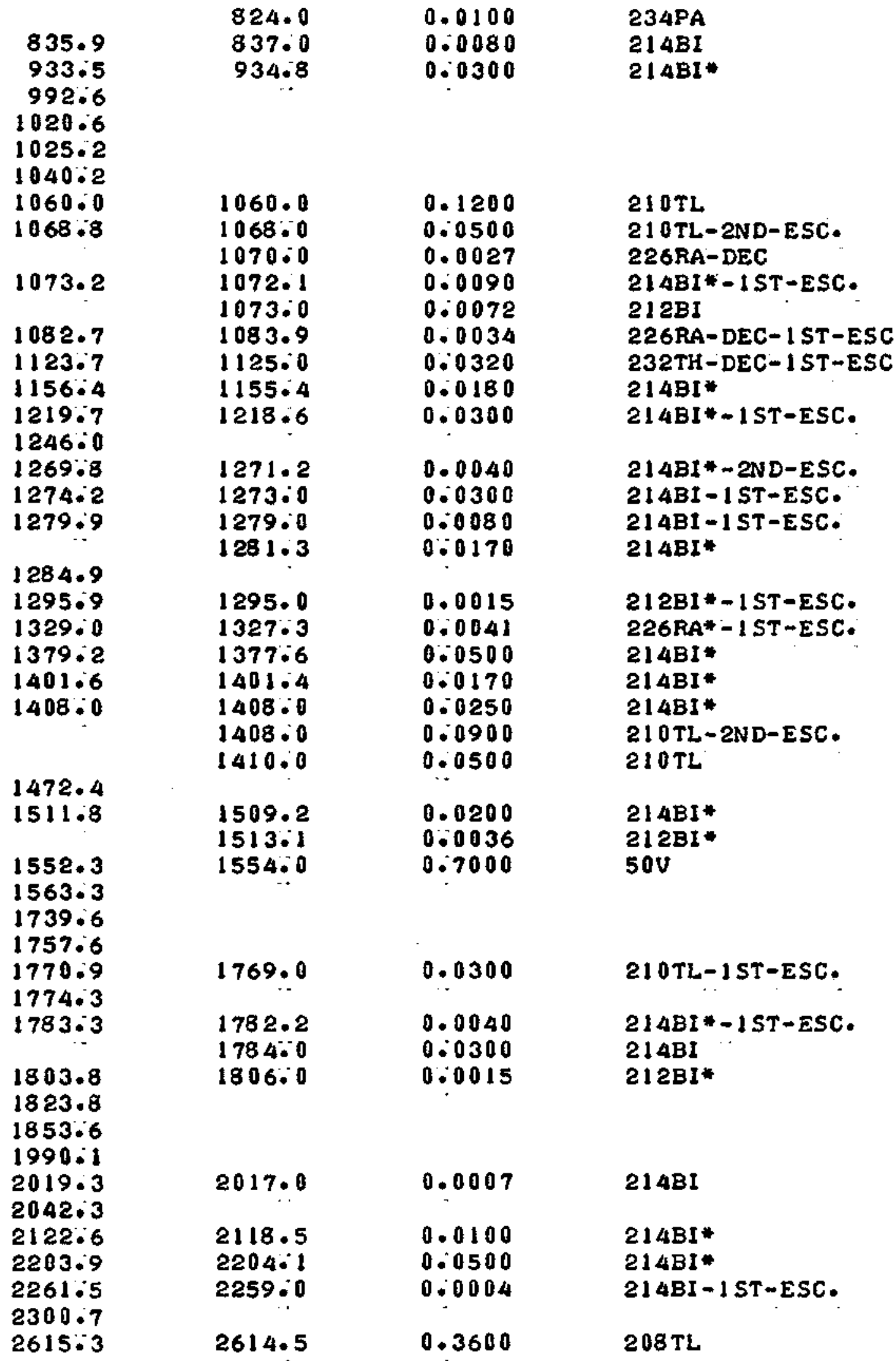


BARTOW,FLA SECOND RUN

ENERGY
FOUND
(KEV)
184.3
240.1
276.3
283.1
293.5
351.8
609.9
724.8
767.8
936.3
1124.7
1159.1
1240.0
$1381: 9$
1405.8
1411.8
1511.2
1664.2
1730.7
$1764: 4$
$1852: 5$
2124.7
$2208: 3$
2450.4
2616.7

KNOWN

ENERGI ES W/IN $0.2 \pi$ $184: 0$

$184: 0$

293.5

$352: 0$

609.3

609.4

$768 \cdot 0$

$768: 7$

934.8

1125.0

1126.8

1160.0

$1238: 3$

$1383 \% 0$

$1408: 0$

1408.6

$1410: 0$

$1509: 2$

1513.1

$1661 \% 2$

$1729: 6$

1764.5

$1849 \% 0$

2204.1

$2447: 6$

2614.5
ABUNDANCE

0.0001

0.0170

0.0420

0.3600

0.4700

0.1700

0.0080

0.0500

0.0300

0.0320

0.0170

0.0150

0.0600

0.0020

0.0250

0.0900

0.0500

0.0200

0.0036

0.0120

0.0300

0.1700

0.0500

0.0165

0.3600
0.0800
SOURCE ISOTOPES

$228 \mathrm{TH}$

228 AC*

234PA

21 4 PE*

$214 B I *$

$214 B I *-1 S T-E S C$.

$214 B I-2 N D-E S C$.

$214 B I *$

214BI*

232TH-DEC- $1 S T-E S C$

234PA

234PA- 1 ST-ESC.

$2148 I^{*}$

$214 B I-2 N D-E S C$.

214BI*

$210 \mathrm{TL}-2 \mathrm{ND}-\mathrm{ESC}$.

$210 \mathrm{TL}$

$2148 I^{*}$

$212 B 1 *$

214BI*

$214 \mathrm{BI} *$

$21481 *$

$210 T L-1 S T-E S C$.

$214 \mathrm{BI} *$

226RA

$208 \mathrm{TL}$ 
STONE MOUNTAIN, GA

\begin{tabular}{|c|c|c|c|}
\hline $\begin{array}{r}\text { ENERGY } \\
\text { FOUND }\end{array}$ & $\begin{array}{l}\text { KNOWN } \\
\text { ENERGIES }\end{array}$ & ABUN DAN CE & SOURCE I SOTOPES \\
\hline $\begin{array}{l}\text { (KEV) } \\
134 \cdot 5 \\
182.6\end{array}$ & $W / I N 0.2 \pi$ & HDDIV DAINCL & 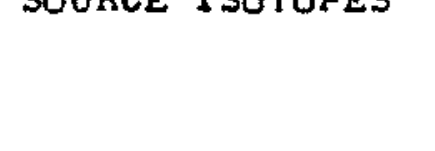 \\
\hline $\begin{array}{l}293.4 \\
352.8 \\
413.5\end{array}$ & $293 \cdot 5$ & 0.0420 & 234PA \\
\hline $\begin{array}{l}490: 9 \\
612: 1 \\
632: 3\end{array}$ & 491.1 & 0.0036 & $212 B I *-2 N D-E S C$. \\
\hline $\begin{array}{l}648: 5 \\
676.8 \\
682.7\end{array}$ & 649.0 & 0.0150 & $234 P A-2 N D-E S C$ \\
\hline $822: 4$ & $\begin{array}{l}821 \cdot 0 \\
824 \cdot 0\end{array}$ & $\begin{array}{l}0.0016 \\
0.0100\end{array}$ & $\begin{array}{l}214 \mathrm{BI} * \\
234 \mathrm{PA}\end{array}$ \\
\hline $\begin{array}{l}865 \cdot 4 \\
886: 6\end{array}$ & $866 \cdot 6$ & 0.0500 & $2\lfloor A B I *-1 S T-E S C$ \\
\hline 898.8 & $\begin{array}{l}899.0 \\
899: 3\end{array}$ & $\begin{array}{l}0.0500 \\
0.0410\end{array}$ & $\begin{array}{l}210 T L-1 S T-E S C \\
234 P A\end{array}$ \\
\hline $\begin{array}{r}936.7 \\
1081: 5 \\
1112.9\end{array}$ & & & \\
\hline $1125: 3$ & $\begin{array}{l}1125.0 \\
1126.8\end{array}$ & $\begin{array}{l}0.0320 \\
0.0170\end{array}$ & $\begin{array}{l}232 T H-D E C-1 S T-E S C \\
234 P A\end{array}$ \\
\hline $\begin{array}{l}1158 \cdot 1 \\
1368: 5 \\
1381: 4 \\
1428 \cdot 3\end{array}$ & $\begin{array}{l}1160: 0 \\
1366: 0 \\
1383: 0 \\
1425: 6 \\
1430: 0\end{array}$ & $\begin{array}{l}0.0150 \\
0: 0020 \\
0: 0020 \\
0: 0165 \\
0: 7000\end{array}$ & $\begin{array}{l}234 \mathrm{PA}-1 S T-E S C \\
214 B I-1 S T-E S C \\
214 B I-2 N D-E S C \\
226 R A-2 N D-E S C \\
138 L A\end{array}$ \\
\hline $\begin{array}{l}1463.4 \\
1510 \% 2\end{array}$ & $\begin{array}{l}1466: 0 \\
1509: 2 \\
1513.1\end{array}$ & $\begin{array}{l}0.0130 \\
0.0200 \\
0.0036\end{array}$ & $\begin{array}{l}232 \mathrm{TH}-\mathrm{DEC} \\
214 \mathrm{BI} * \\
212 \mathrm{*I} *\end{array}$ \\
\hline 1649.7 & $\begin{array}{l}1650: 0 \\
1651: 0\end{array}$ & $\begin{array}{l}0.0200 \\
0.0000\end{array}$ & $\begin{array}{l}210 \mathrm{TL} \\
214 \mathrm{BI}-1 \mathrm{ST}-\mathrm{ESC} \text {. }\end{array}$ \\
\hline 1680.6 & $\begin{array}{l}1678: 0 \\
1679: 5 \\
1681: 0\end{array}$ & $\begin{array}{l}0.0004 \\
0.0008 \\
0.0020\end{array}$ & $\begin{array}{l}214 B 1-2 N D-E S C \\
212 B I \\
214 B 1\end{array}$ \\
\hline $\begin{array}{l}1765.3 \\
1860.0\end{array}$ & 1764.5 & 0.1700 & $214 B I *$ \\
\hline $\begin{array}{l}1919: 3 \\
2108: 6 \\
2135: 2\end{array}$ & 1919.0 & 0.0900 & $210 \mathrm{TL}-1 \mathrm{ST}-\mathrm{ESC}$ \\
\hline $\begin{array}{l}2205: 3 \\
2612: 3\end{array}$ & $\begin{array}{l}2204 \cdot 1 \\
2614 \cdot 5\end{array}$ & $\begin{array}{l}0.0500 \\
0.3600\end{array}$ & $\begin{array}{l}214 \mathrm{BI} \\
208 \mathrm{TL}\end{array}$ \\
\hline
\end{tabular}




\section{BIBLIOGRAPHY}

Adams, J. A. S., and Fryer, G. E., 1964, "Portable Gamma-Ray Spectrometer for Field Determination of Thorium, Iranium, and Potassium," in The llatural Radiation Environment, eds. J. A. S. Adams and W. M. Lowder (Chicago: Tniversity of Chicago Press), p. 577.

Adams, J. A. S., and Lowder, H. M. (Eds.), 1964, in The Natural Radiation Environment (Chicago: University of Chicago Press).

Adams, J. A. S., and Lowder, W. M., (Eds.), 1973, in The Natural Radiation Environment (Chicago: University

AEC, 1970 , Atomic Energy Commission, Chart of the Nuclides, 10 th edn, (AEC Division of Isotopes Development, Modified by Rattelle-Northwest, Richland, Washington), (Washinaton, D. C.: U. S. Government Printing Office).

Anspaugh, L. R., Phelps, P. L., Huckabay, G. W., Gudiksen, P. H., and Lindeken, C. L., 197L, "Methods for the In situ lleasurements of Radionuclides in Soi1," Uत्CRL $\overline{74061 .}$

Archer, V. E., Brinton, H. P., and Wagoner, J. K., 1964a, Health Physics Journal $10,1183$.

Archer, V. E., Carroll, B. E., Brinton, H. P., and Saccomanno, G., 1964b, "Epidemiological Studies of Some Hon-

Fatal Effects of Uranium Mining," in Proceedings of the Symposium on Radiological Health and Safety in Mining and Mil Ting of Nuclear MateriaTs, Vot. I, IAEA, vienna, pp. $2 \overline{1-36 .}$

Archer, V. E., Magnuson, H. J., Holaday, D. A., and Lawrence, P. A., 1962, Journal of Dccupational Medicine 4,55 .

Bale, W. F., and Shapiro, J., 1955, "Radiation Dosage to Lung from Radon and its Daughter Products," presented at the IAEA Conference on Peaceful Uses of Atomic Energy, Geneva, Switzerland. 
Bale, W. F., and Shapiro, J., 1956, "Radiation Dosage to Lung from Radon and its Daughter Products," in Proceedings

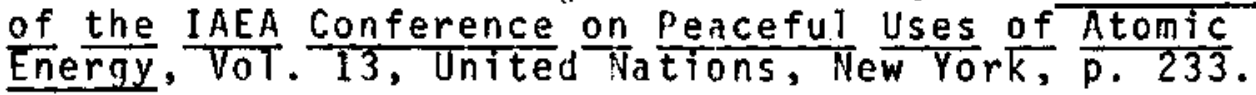

Baranov, V. I., and Novitskaya, A. P., 1960, Radiokhimiya 2 , 485 .

Beck, H. L., 1966, Health Phys. 12, 313.

Beck, H. L., Condon, W. J., and Lowder, H. M., 1964, "Spectrometric Techniques for Measuring Environmental Gamma Radiation," U. S. AEC, Health and Safety Laboratory, HASL -150 .

Rennett, B. G., 1970, Health Phys. 19, 757 .

Chamberlain, A. C., and Dyson, E. D., 1956, British Journal of Radioloay 29, 317 .

Cullen, T. L., 1967, "A Study of Natural Radioactivity in Brazil." Pontifical Catholic University, Rio de Janeiro, Brazil.

Gillman, L. T., 1969, MIRD Pamphlet 4, Journal of Nuclear Medicine 10, Supplement No. 2 .

Eisenbud, M., 1963 , Environmental Radioactivity (Hew York:

EPA, 1972, Report of Special Studies Group, "Estimates of Ionizing Radiation Doses in the United States, 1960-2000," ORP/CSD72-1 (Washington, D. C.: U. S. Government Printing office).

Evans, R. D., 1959, Health Phys. 17, 229.

FRC, 1963, Federal Radiation Council, "Estimates and Evaluation of Fallout in the United States from Nuclear Testing Conducted through 1962," FRC Report No. 4 (Washington, D. C.: U. S. Government Printing office).

FRC, 1965, Federal Radiation Council, "Background Material for the Development of Radiation Protection Standards Protective Action Guides for Strontium-39, Strontium-90 and Cesium-137," (Washington, D. C.: U. S. Government Printing office).

Fuchs, N. A., (Ed.), 1964, The Mechanics of Aerosols (0xford: Pergamon Press). 
fabrysh, A. F., and Davis, F. J., 1955, Nucleonics 13, No. 1, 50 .

George, A. C., Hinchliffe, L., Epps, R., and Shepich, T. J., 1970, "Respiratory Tract Disposition of Radon Daughters in Humans Exposed in a Uranium Mine, Phase II," U. S. $A E C$, Health and Safety Laboratory, HASL 70-7.

Hahn, n., 1936, Applied Radiochemistry (New York: Cornell University Press).

Hamilton, J. H., Manthuruthil, J. C., and Rasmussen, J. 0., 1972, Nuclear Instruments and Methods 103, 277.

Harley, Naomi H., 1971, Ph. D. Thesis, "Spatial Distribution of Alpha Dose Based on Experimental Energy

Absorption Measurements," New York University Medical Center, New York.

Holaday, D. A., Rushing, D. E., Coleman, R. D., Woolrich, P. F., Kusnetz, H. L., and Bale, H. F., 1957, "Control of Radon and Daughters in Uranium Mines and Calculations on Biologic Effects," U. S. Public Health Service Publication No. 494 (Washington, D. C.: U. S. Government Printing Office).

ICRU, 1957, "Report of Committee II on Permissible Dose for Internal Radiation," ICRU Publication 2 (New York: Pergamon Press).

ICRP, 1959, "Maximum Permissible Body Burdens and Maximum Permissible Concentrations of Radionuclides in Air and in Water for Occupational Exposure," ICRP

Publication ? (New York: Pergamon Press).

Jacobi, M., 1964, Health Phys. 10, 1163.

Jaffey, A. H., 1954, Review of Scientific Instruments $25,349$.

Johnson, W. H., Jr., 1952, Physical Review 88, 1213.

lohnson, H. H., Jr., and Heir, R. N., 1962, Nature 194, 265.

Jones, T. D., Auxier, J. A., Snyder, W. S., and Warner, G. G., 1973, Health Phys. 24, in press.

Kirikov, A. P., Bogoslovskaia, T., and Gorshkov, f., 1932, Bulletin of the United Geological and Prospecting Service (USSR) 41, 1293 (In Russian). 
Krugten, H. Van, and Nooyen, B. Van (Eds.), 1971, Angular Correlations in Nuclear Disintegration

(Netherlands: WoTters-Noordhoff).

Lederer, C. M., Hollander, J. M., and Perlman, I. (Eds.), 1967, Table of Isotopes, $6 \mathrm{th}$ edn. (New York: Wiley).

Libby, W. F., 1946, Phys. Rev. 69, 671.

Libby, W. F., 1955, Science $122,3158,57 \mathrm{ff}$.

Lowder, W. M., Beck, H. L., and Condon, W. J., 1964, Nature 202,745 .

Lowder, W. M., George, A. C., Gogolak, C. V., and Blay, A., 1971, "Indoor Radon Daughter and Radiation Measurements in East Tennessee and Central Florida," $U$. S. AEC, Health and Safety Laboratory. HASL - TM- $71-8$.

Lundin, F. E., Jr., Lloyd, J. W., Smith, E. M., Archer, V. E., and Holaday, D. A., 1969, Health Phys. 16, 571.

Marsden, E., 1959, Nature 183, 924.

Marsden, E., 1960, Nature 187, 192.

Martin, D., and Jacobi, M., 1972, Health Phys. 23, 23.

Martin, M. J., and Blichert-Toft, P. H., 1970, Nuclear Data Iables, U. S. A tomic Energy Commission, $\underline{\overline{A B}}, 1$.

Martz, D. E., Molleman, D. F., McCurdy, D. E., and Schiager, K. J., 1969, Health Phys. 17, 131.

May, K., 1945, Journal of Scientific Instruments 22, 187.

Mayneord, W. V., 1964, Advancement of Science 21 (London:

The British Association for the Advancement of

Science), pp. 127-131.

Morgan, K. Z., 1967, Maximum Permissible Exposure of Miners in the United States to Radon and Its Daughters," Hearings before the Joint Committee on Atomic Energy, Ninetieth Congress, First Session, Part 2 (Washington, D. C.: U. S. Government Printing office). 
Morgan, K. Z., 1971, in Proceedings of the Third Nationa Conference on Radiation ControTs, Scottsda

NCRP, 1959, National Council on Radiation Protection and Measurements, "Maximum Permissible Body Burdens and Maximum Permissible Concentrations in Air and in Water for Occupational Exposure," NCRP Report 22 (Washington, D. C.: NCRP

Publications, P. 0. Box 4867).

NCRP, 1971, National Council on Radiation Protection and Measurements, "Basic Radiation Protection Criteria Recommendations of the National Council on Radiation Protection and Measurements, "NCRP Report 39 (Washington, D. C.: NCRP Publications, P. 0. Box 4867).

Notea, A., 1971, Nuc1. Instr. Methods 91, 513.

Oakley, D. T., 1971, Doctor of Science Thesis, "Matural Radiation Exposure in the United States," Harvard School of Public Health, Boston.

Parker, H. M., 1969, Health Phys. $16,553$.

PHS, 1961, Public Health Service, Governor's Conference on Health Hazards in Uranium Mining, A Summary Report, PHS Publication No. 843 (Washington, D. C.: U. S. Government Printing office). Rankama, K., 1956, I sotope Geology (London: Pergamon

Roser, F. X., 1965, "A Study of Natural and Artificial Radioactive Contamination in Brazil," Pontifical Catholic University, Rio de Janeiro, Brazil.

Roser, F. X., and Cullen, T. L., 1962, "Environmental Radioactivity in High Backaround Areas of Brazil," Institute of Physics, Pontifical Catholic University, Rio de Janeiro, Brazil.

Poser, F. X., and Cullen, T. L., 1966, "A Study of Natural Radioactivity in Brazil," Pontifical Catholic University, Rio de Janeiro, Brazil.

Rutherford, E., 1904, Philosophical Transactions of the Royal Society, Series A, Vol. 204, 169. 


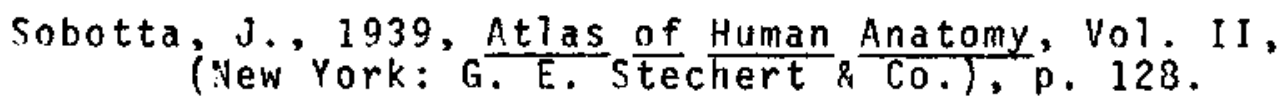

Shapiro, 1., 1954, "An Evaluation of the Pulmonary Radiation Dosage from Radon and Its Daughter Products," University of Rochester Report UR-298.

Shapiro, J., 1956, American Medical Association Archives of Industrial Health 14 , 169 .

Spiers, F. H., McHugh, M. J., and Appleby, O. B., 1964, "Experimental Gamma-Ray Dose to Populations;

Surveys Made with a Portable Meter," in The Hatural Radiation Environment, eds. J. A. S. Adams and U. M. Lowder (Chicago: University of Chicago Press), pp. $885 \mathrm{ff}$.

Starik, I. Y., and Melikova, 0. S., 1957, (English Version) U. S. Atomic Energy Commission Report AEC-TR-4498.

Storm, E., and Israel, H. I., 1970, Nucl. Data Tabies, U. S. At. Energy Comm., A7, 565 .

Tanner, A. R., 1964, "Radon Migration in the Ground," in The Natural Radiation Enviroment, eds. J.A. S. Adams and $M$. Lowder (Chicago: University of Chicago Press), p. $161 \mathrm{ff}$.

Thorpe, J. F., and Whiteley, M. A., 1946, Thorpe's Dictionary of Applied Chemistry, 4 th edn., Vol. Il CLondon: Longmans, Green \& Co.), p. 233 .

Toth, A., 197?, Health Phys. 23, 281.

Tsivoqlou, F. C., Ayer, H. E., and Holaday, D. A., 1953, Nucleonics 11 , No. 9,40 .

United Kinndom National Radiological Protection Board, 1972 , Statement on The Use of By-Product Gypsum in Building Materials, June 14.

UMSCEAR, 1958, United Nations Scientific Committee on the Effects of Atomic Radiation (UNSCEAR), 13th Session, Supplement 17 (New York: United Nations).

UNSCEAR, 1962, United Nations Scientific Committee on the Effects of Atomic Radiation (UNSCEAR), 17th Session, Supplement 16 (New York: United Nations). 
UNSCEAR, 1966, United Nations Scientific Committee on the Fffects of Atomic Radiation (UNSCEAR), $21 \mathrm{st}$

Session, Supplement 14 (New York: United Nations).

UNSCEAR, 1969 , United Nations Scientific Committee on the Effects of Atomic Radiation (UNSCEAR), 24 th

Session, Supplement 13 (New York, United Nations).

Wagner, E. B., and Hurst, G. S., 1961, Health Phys. $\underline{5}, 20$.

Waconer, J. K., Archer, V. E., Carroll, B. E., Holaday, D. A., and Lawrence, P. A., 1964 , Journal of the National Cancer Institute $\underline{32}, 787$.

Wanoner, J. K., Archer, V. E., Lundin, F. E., Holaday, D. A., and Lloyd, J. M., 1965, New England Journal of Medicine 273, 191 .

Hakat, M. A., 1971, Nucl. Nata Tables, U. S. At. Energy Comm., A9, 445 .

Wollenberg, H. A., and Smith, A. R., 1964, "Studies in Terrestrial famma-Radiation," in The Natural Radiation Environment, eds. J. A. S. Adams and W. M. Lowder (Chicago: University of Chicago Press), p. 513 . 


\section{BIBLIOGRAPHY \\ (Uncited)}

AEC, $1970 a$, "Precipitation Scavenging," in Proceedings of a Symposium, Richland, Washington, June 2-4,1970, CONF-700601 (Springfield, Virginia: National Technical Information Service).

AEC, $1970 \mathrm{~b}$, "Morphology of Experimental Respiratory rarcinogenesis," in Proceedings of a Symposium, Gatlinburq, Tennessee, May 13-16, 1970 , CONF-700501 (Springfield, Virginia: Hational Technical Information Service).

Altshuler, B., Melson, N., and Kuschner, M., 1964 , "Estimation of the Lung Tissue Dose from the Inhalation of Radon and Daughters, "Health Phys. 10,1137 .

Archer, V. E., and Lundin, F. E., 1967, "Radiogenic Lung Cancer in Man: Exposure-Effect Relationship," Environmental Research $1,370$.

Axelson, 0., 1971, "Lung Cancer Among Populations Having Lunn Irradiation," Lancet 1, 7740, pp. 46-47.

Basson, J. K., Wyndham, C. H., Heyns, A. J. A., Keeley, H. H., Rarnard, C. P. S., Munro, A. H., and Webster, 1., 1971, "A Biostatistical Investigation of Lung Cancer Incidence in South African fold/llranium Mines," Fourth International Conference on Peaceful Uses of Atomic Energy, fieneva, September 6-16, 1971.

Beck, H. L., Lowder, W. M., Bennett, B. G., and Condon, M. J., 1966, "Further Studies of External Environmental Radiation," Health and Safety Laboratory, II. S. AEC Report HASL -170 .

Black, S. C., Archer, V. E., Dixon, W. C., and Saccomanno, G., 1968, "Correlation of Radiation Exposure and Lead-210 in Uranium Miners," Health Phys. 14, 81.

Blanchard, R. L., Archer, V. E., and Saccomanno, G., 1969, "Blood and Skeletal Levels of Pb-210--Po-210 as a Measure of Exposure to Inhaled Radon Daughter Products," Heal th Phys. 16, 585. 
Blifford, I. H., Jr., Friedman, H., Lockhart, L. B., Jr., and Baus, R. A., 1956, "Geographical and Time Distribution of Radioactivity in the Air," Journal of Atmospheric and Terrestrial Physics 2,1 .

Bouville, A., Leroy, B., Guedalia, D., Delos, Y., and Fontan, 1., 1971, "Une Methode de Mesure du Desequilibre Radioactif dans 1 'Atmosphere entre le Radon et ses Descendants a Vie Courte," Aerosol Science 2, 381 .

Bradley, W. E., and Pearson, J. E., 1970, "Aircraft Measurements of the Vertical Distribution of Radon in the Lower Atmosphere," Journal of Geophysical Research 75 , No. 30,5890 .

Bushong, S. C., 1964, "The Composition and Spatial Distribution of Background Radiation," Health Phys. 10 , 731 .

Casarett, L. J., and Milley, P. S., 1964, "Alveolar Reactivity Followina Inhalation of Particles," Health Phys. 10 , 1003.

Chapuis, A., Lopez, A., Fontan, J., Billard, F., and Madelaine, G. J., 1970, "Spectre Granulometrique des Aerosols Radioactifs dans Une Mine d'Uranium," Aerosol Science 1,243 .

Clifton, P. J., Farrow, M., and Hamilton, E. I., 1971, "Measurements of Th-232 in Normal and Industrially Exposed Humans," Annals of Occupational Hygiene 14. 303.

Corn, M., 1971, "Dose to the Respiratory Tract from Personal, nccupational, and Community Air Pollutants,"

Environmental Letters 1 , No. 1, 29.

Craft, B. F., Oser, J. L., and Norris, F. W., 1966, "A Method for Determining Relative Amounts of Combined and Uncombined Radon Daughter Activity in Underground Uranium Mines," Journal of American Industrial Hygiene Association 27, 154.

Dautrebande, L., and Walkenhorst, W., 1964 , "Deposition of Microaerosols in Human Lung with Special Reference to Alveolar Spaces," Health Phys. 10, 981.

navies, C. N., 1964, "A Comparison between Inhaled Dust and Dust Recovered from Human Lungs," Health Phys. 10. 1029. 
Donaldson, A. W., 1969, "The Epidemiology of l.ung Cancer Among Uranium Miners," Health Phys. 16, 563.

Djuric, D., Kilibarda, M., Novak, L., Panov, D., and Vukotic, M., 1964, "Studies on Airhorne Radioactive Contamination of Miners in a Yugoslav Uranium Mine," Health Phys. 10, 1059.

Duggan, M. J., Howell, D. M., and Soilleux, P. 3., 1968, "Concentrations of Radon in Coal Mines in England and Scotland," Nature 219, 1149.

Eichholz, G. G., Hilborn, J. W., and McMahon, C., 1953, "The Determination of Uranium and Thorium in Ores," Canadian Journal of Physics 31, 4, 613.

Eisenbud, M., 1962, "Sources of Ionizing Exposure to the General Public," Bulletin of New York Academy of Medicine 38, No. 11, pp. 741-744.

Enge1, S., 1964, "Comparative Anatomy and Pulmonary Air Cleaning Mechanisms in Man and Certain Experimental Animals," Health Phys. 10, 967.

Eve, I. S., 1964, "Some Suggested Maximum Permissible Single Intakes of Uranium," Health Phys. 10, 773.

Flesch, J. P., Norris, C. H., and Nugent, A. F., Jr., 1967, "Calibrating Particulate Air Samplers with Monodisperse Aerosols: Application to the Andersen Cascade Impactor," Journal of American Industrial Hygiene Association 28, 507.

Federal Radiation Council, 1967, "Guidance for the Control of Radiation Hazards in Uranium Mining," Report No. 8 (Washington, D. C.: U. S. Government Printing office).

Fusamara, N., Kurosawa, R., and Misawa, H., 1964, "The Measurement of Radioactive Gas and Dust in Uranium Mines in Japan," Heal th Phys. 10, 909.

Garcia, L. F., 1952, Master's Thesis in Physics, "Variations in the Radium and Radon Contents of the Clinch River," Vanderbilt University. 
Garland, P. J., Lovett, M. B., and Wilson, R. B., 1971, "A Simple System for the Rapid Determination of Airborne Radioactivity," in Proceedings of International Symposium, 5-9 July 1971, Munich, Germany. Sponsored by IAEA and Federal Republic of Germany (IAEA).

feorge, A. C., and Breslin, A. J., 1967, "Deposition of Natural Radon Daughters in Human Subjects," Health Phys. $13,375$.

Gold, S., Borkhau, H. W., Shleien, B., and Kahn, B., 1964 , "Measurement of Naturally Occurring Radionuclides in Air," in The Natural Radiation Environment, eds. J. A. S. Adams andW. M. Lowder (Chicago: University of Chicago Press).

Gold, R., and Strosh, A. M., 1971, "Gamma-Ray Dosimetry for the llatural Radiation Environment,"

Transactions of the American Nuclear Society 14 , 502.

Gopal-Ayengar, A. R., Sundaram, K., Mistry, K. B., Sunta, C. M., Nambi, K. S. V., Kathuria, S. P., Basu, A. S., and David, M., 1971, "Evaluation of the Long-Term Effects of High Background Radiation on Selected Population Groups of the Kerala Coast," Fourth International Conference on Peaceful Uses of Nuclear Energy, Geneva, September 6-16, 1971 (United Nations).

Gormley, P. G., and Kennedy, M., 1949, "Diffusion from a Stream Flowing through a Cylindrical Tube," Royal Irish Academy Proceedings A52, 12, pp. 163-169.

Gross, P., 1964, "The Processes Involved in the Biologic Aspects of Pulmonary Deposition, Clearance, and Retention of Insoluble Aerosols," Health Phys. 10, 995.

Hamilton, E. I., 1970, "The Concentration and Distribution of Uranium in Human Skeletal Tissues," Calc. Tiss. Res. 7, 150 .

Hardin, J., Gold, S., Kahn, B., and Straub, C., 1964, Radionuclide Content of Airborne Particies, 1962-1963," Health Phys. 10, 923.

Hardy, E. P., and Chu, N., 1967, "The Ratio of Cs-137 to Sr-90 in Global Fallout," Health and Safety Laboratory, IJ. S. AEC Report HASL-I82. 
Havlovic, V., and Snihs, J. O., 1971, "Distribution of Natural Radioactivity on the Environmental Submicronic Aerosols," Tellus 23 (4-5), 441.

Heinrich, E. W., 1958, Mineralogy and Geology of Radioactive Raw Materials (New York: McGraw-Hill).

Helmer, R. G., Greenwood, R. C., and Gehrke, R. J., 19/1, "Precise Comparison and Measurement of Gamma-Ray Energies with a Ge(Li) Detector," iucl. Instr. Methods 96,173 .

Holaday, D. A., 1969, "History of the Exposure of Miners to Radon," Health Phys. 16, 547.

Hursh, J. B., Schraub, A., Sattler, E. L., and Hofman, H. P., 1969, "Fate of Pb-212 Inhaled by Human Subjects," Heal th Phys. $16,257$.

Ionescu, C., 1971, "Gamma Ray Spectrometry of Uranium Samples," Revue Roumaine de Physique 16, 643.

Kajland, A., Edfors, M. L., Friberg, L., and Holma, B., 1964, "Radioactive Monodisperse Test Aerosols and Lung Clearance Studies," Health Phys. 10, 941 .

Kartha, K. I. P., 1968, "Background Radiation in the Coastal (Monazite) Areas of Kerala (South India), "Health Phys, 15,368 .

Korff, S. A., 1964, "Production of Neutrons by Cosmic Radiation," in The Natural Radiation Environment, eds. J. A. S. Adams and W. M. Lowder (Chicago: University of Chicago Press).

Landah1, H. D., 1963, "Particle Removal by the Respiratory System, Note on the Removal of Airborne Particulates by the Human Respiratory Tract with Particular Reference to the Role of Diffusion," Bulletin of Mathematical Biophysics 25,29 .

Lockhart, L. B., Jr., 1964, "Radioactivity of the Radon-222 and Radon-220 Series in the Air at Ground Level," in The Natural Radiation Environment, eds. J. A. S. Adams and W. M. Lowder (Chicago: University of (hicago Press).

Lindeken, C. L., and Petrock, K. F., 1966, "Solid-State Pulse Spectroscopy of Airborne Alpha Radioactivity Samples," Health Phys. 12, 683. 
Lindel1, B., 1960, "An Approach to the question of Computing Doses and Effects from Fallout," Health Phys. $2,341$.

Lingeman, E. W. A., Konijn, J., Polak, P., and Wapstra, A. H., 1969, "The Decay of Pb-214 and 0 ther Ra-226 Daughters," Nuclear Physics A133, 630 .

Lonowell, C. R., Knopf, A., and Flint, R. F,, 1941, outlines of Physical Geology (New York: Wiley).

Lowder, W. M., Seqall, A., and Condon, W. J., 1964, "Environmental Radiation Survey in Northern New Enqland," in The Natural Radiation Environment, eds. J. A. S. Adams and W. M. Lowder (Chtcago: University of Chicago Press).

Lowder, W. M., and Condon, W. J., 1965, "Measurement of the Exposure of Human Populations to Environmental Radiation," Nature 206, 658 .

Lowder, W. M., and Beck, H. L., 1966, "Cosmic-Ray Ionization in the Lower Atmosphere," Journal of Geophysical Research 71, No. 19, 4661 .

McEachern, P., Myers, W. G., and White, F. A., 1971, "Uranium Concentrations in Surface Air at Rural and Urban Localities within New York State," Environmental Science and Technology 5 (3), 700.

Melandri, C., and Prodi, V., 1971, "Simulation of the Regional Deposition of Aerosols in the Respiratory Tract," Journal of the American Industrial Hygiene Association 32,52 .

Mercer, T. T., and Stowe, W. A., 1969, "Deposition of Unattached Radon Decay Products in an Impactor Stage," Health Phys. 17, 259.

Minato, S., and Kawano, M., 1970, "On the Constitution of Terrestrial Gamma Radiation," Journal of Geophysical Research 75, No. 29, 5325 .

Morgan, K. Z., 1971, "Health Physics and the Environment," in Proceedings of International Symposium on Rapid Methods for Measuring Radioactivity in the Environment, Sponsored by IAEA and Federat Republic of Germany, Munich, July 5-9, 1971, IAEA/SM/148. 
Muth, H., Rajewsky, B., Hantke, H. J., and Aurand, K., 1960, "The Normal Radium Content and the Ra-226/Ca Ratio of Various Foods, Drinking Water and Different Organs and Tissues of the Human Body," Health Phys, 2, 239.

O'Brien, K., 1971, "Cosmic Ray Propagation in the Atmosphere," Il Nuovo Cimento, Vol. 3A, No. 3, 521 .

O'Brien, K., and McLaughlin, J. E., 1970, "Calculation of Dose and Dose-Equivalent Rates to Man in the Atmosphere from Galactic Cosmic-Rays," Health and Safety Laboratory, U. S. AEC Report HASL-228.

Palmer, H. E., Perkins, R. W., and Stuart, B. 0., 1964, "The Distribution and Deposition of Radon Daughters Attached to Dust Particles in the Respiratory System of Humans Exposed to Uranium Mine Atmospheres," Health Phys. 10, 1129.

Patterson, H. W., Hess, W. H., Moyer, B. J., and Wallace, R.W., 1959, "The Flux and Spectrum of Cosmic Ray Produced Neutrons as a Function of Altitude," Health Phys. 2 , 69 .

Pelletier, C. A., Wegst, A. V., and Whipple, G. H., 1964, "Concentrations of Radioactive Particles in Surface Air, November 1962 through March 1963," Health Phys. 10, 917 .

Pensko, J., Jagielak, J., Biernacka, M, , and Zak, A, , 1971, "Ionizing Background Radiation in the Kowary Basin," Nukleonika 16 $(5-6), 293$.

Raabe, 0. G., 1969, "Concerning the Interactions that Occur Between Radon Decay Products and Aerosols, "Health Phys. 17, 177 .

Rolle, R., 1972, "Rapid Working Level Monitoring," Health Phys. 22, 233.

Saccomanno, G., Archer, V. E., Saunders, R. P., James, K. A., and Beckler, P. A., 1964, "Lung Cancer of Uranjum Miners on the Colorado Plateau," Health Phys. 10 . 1195 .

Shleien, B., 1969, "Evaluation of Radium-226 in Total Diet Samples, 1964 to June 1967," Radiological Health Data 10,12 . 
Si11, C. W., 1969, "An Integrating Sampler for Determination of Rn-222," Health Phys. 16, 371 .

Solon, L. R., Lowder, H. M., Shambon, A., and Blatz, H., 1959, "Further Investiqations of Natural Environmental Radiation," Health and Safety Laboratory, U. S. AEC Report HASL-73.

Somayaji, K. S., 1961, "Evaluation of the Ventilation Rate from the Decay of Filter-Paper Air Samples of Thoron or Radon Daughters," Health Phys, 6, 136.

Stephenson, J., Stevens, D. C., and Morton, D. S., 1971 , "Removal of Radon and Thoron Daughter Products from Glass Fibre Air Sample Filters," Annals of Occupational Hyqiene $\underline{14}, 309$.

Splichal, W. F., Jr., 1966, "Background Radiation Monitor," Health Phys. 12, 683.

Stewart, K., 1964, "The Modes of Formation and Properties of Aerosol Particles," Health Phys. 10, 389.

Storruste, A., Reistad, A., Rudjord, T., Dahler, A, and Liestol, I., 1965, "Measurements of Environmental Gamma Radiation in Norwegian Houses," Health Phys. 11, 261.

Strauss, W., 1966, Industrial Gas Cleaning (New York: Pergamon Press).

Styro, B. I., and Orlova, N. V., 1971, "The Determination of the Sizes of Aerosol Particles Generated in Dry, Dust-Free Ionized Air Upon Radon Decay," UDC 551.510.7:551.510.42. Translated from USSR Bulletin of Atmospheric and Oceanic Physics 7 , No. 8, pp. 916-917, 1961 .

Thompkins, R. W. 1970, "Radiation in Uranium Mines," Canadian Mining Journal 91, No. 10, 103.

Turner, R. C., Radley, J. M., and Mayneord, W. V., 1958, "The Naturally nccurring Alpha Ray Activity of Foods," Health Phys. 1, 268.

Walton, A., Kologrivov, R., and Kuip, J. L., 1959, "The Concentration and Distribution of Radium in the Normal Human Skeleton," Health Phys. $1,409$. 
Washington, R. A., Chi, W., and Regan, R, 1972, "The Use of Vermiculite to Control Dust and Radon Daughters in Underground Uranium Mine Air," 12 th Air Cleaning Conference, Oak Ridge, Tennessee, August 28-31; Canadian Department of Mines and Resources, Internal Report No. 72.

Wrenn, M. E., Eisenbud, M., Costa-Ribeiro, C. C., Hazle, A. J., and Siek, R. C., 1969, "Reduction of Radon Daughter Concentrations in Mines by Rapid Mixing without Makeup Air," Health Phys. 17, 405.

Yeates, D. B., foldin, A. S., and Moeller, D. W., 1972, "Natural Radiation in the Urban Environment," Nuclear Safety $\underline{13}, 275$.

Zhdanova, N. F., and Labushkin, V. G., 1971, "Comparison Measurements of the Concentration of Daughter Products of Emanations in Air," UDC 539.16.083:546.217 (Translated from Izmeritel'naya Tekhnika, No 8, pp. 73-75, August 1971; original article submitted August 1968). 


\section{VITA}

John Alden Auxier was born in Paintsville, Kentucky, in 1925. He received the B.S. degree in Physics from Berea College in 1951, the Master of Science degree in Physics from Vanderbilt University in 1952, and the Ph.D. degree in Huclear Engineering from Georgia Institute of Techrology in 1972.

After receiving his M.S. dagree in 1952, he became a member of the staff of the University of Texas Primate Laboratory where he coordinated and directed the Health Physics Program and worked on the joint Oak Ridge National Laboratory-Primate Laboratory Exposure Experiment.

In 1955 he joined the Oak Ridge National Laboratory staff. Since that time, he has held a number of positions in the Health Physics Division. He is presently the Director of the Health Physics Division which is comprised of about 200 people engaged in research, engineering, and applied problems of health physics.

He has published extensively in the fields of radiation dosimetry and radiation physics and presented numerous oral papers.

He was the recipient of one approved jatent along with two other Dak Ridge National Laboratory staff members. He also received the National Preparedness Award, Nationa? Institute for Disaster Mobilization, in 1962, and the Elda 
E. Anderson Award, Health Physics Society, in 1963 . He has been certified by the American Board of Health Physics.

Mr. Auxier has been one of the editors of the HEALT't PHYSICS JOURAAL since its inception.

He is a member of the Health Physics Society, American Association for the Advancement of Science, Southeastern Section of the American Physical Society, and the East Tennessee Chapter of the Heaith Prysics Society. He is a member and the first president of scientists and Engineers for Appalachia. He has been or is now a member of the National Academy of Sciences Advisory Comittee on Civil Defense and the subcommittee on Civil Defense and the Sutcomittee on Radiation Silelding, ICru Task Group on veutron Instrumentation, USASI Subcomittee N-13.8, RCRF Scientific Committee 25, IAEA Pariel on liuclear iccident Dosimetry Systems, AEC-DBER CF-252 Biomedical Advisory Panel, and the ICRP Task Group on Emergency and Accidental Exposures. 